\title{
The Dynamics of Return Migration, Human Capital Accumulation, and Wage Assimilation ${ }^{\mathrm{a}}$
}

\author{
Jérôme Adda ${ }^{\mathrm{b}}$, Christian Dustmann $^{\mathrm{c}}$ and Joseph-Simon Görlach ${ }^{\mathrm{d}}$
}

June 2020

\begin{abstract}
This paper develops and estimates a dynamic model where individuals differ in ability and location preference to evaluate the mechanisms that affect the evolution of immigrants' careers in conjunction with their re-migration plans. Our analysis highlights a novel form of selective return migration where those who plan to stay longer invest more into skill acquisition, with important implications for the assessment of immigrants' career paths and the estimation of their earnings profiles. Our study also explains the willingness of immigrants to accept jobs at wages that seem unacceptable to natives. Finally, our model provides important insight for the design of migration policies, showing that policies which initially restrict residence or condition residence on achievement shape not only immigrants' career profiles through their impact on human capital investment but also determine the selection of arrivals and leavers. [136 words]
\end{abstract}

JEL: F22, J24, J61

Keywords: International migration, human capital, expectations.

\footnotetext{
${ }^{a}$ We are grateful to Courtney Brell for constructive comments and suggestions. Dustmann acknowledges funding by the European Research Council (ERC) Advanced Grant No 323992.

b Adda: Bocconi University, BIDSA and IGIER, Via Roentgen 1, 20136 Milan, Italy (email: jerome.adda@unibocconi.it).

${ }^{\mathrm{c}}$ Dustmann: University College London and Centre for Research and Analysis of Migration, Gower St, London WC1E6BT, UK (email: c.dustmann@ucl.ac.uk).

d Görlach: Bocconi University, BIDSA, CReAM and IGIER, Via Roentgen 1, 20136 Milan, Italy (email: josephsimon.goerlach@unibocconi.it).
} 


\section{Introduction}

The dramatic increase in the movement of people over the past two decades has pushed immigration and its contribution to the economic well-being of destination countries to the forefront of political debate. A fundamental policy challenge for receiving countries is to ensure immigration's economic contribution, through policies that select those allowed to settle and work in one's country, and encourage arriving immigrants to maximize their economic output. To design such policies requires a full understanding of how immigrants' decisions are made and are affected by policy interventions. One important reason why this is far from straightforward is that immigrants have the option of returning home, which means that their decisions regarding labor supply, skill investment and consumption are taken in conjunction with decisions about the migration's length, and are conditioned on consumption possibilities and amenities in the home country. ${ }^{1}$ To model this added complexity requires a framework that accounts for not just the dynamic nature of immigrants' choices, but also for location preferences that affect both return migration and the initial migration decision itself.

To understand how choices of immigrants and their career profiles interact with re-migration decisions and respond to policy intervention, this paper develops and estimates a dynamic lifecycle model where individuals decide whether to migrate, and where those who migrate simultaneously choose investment in human capital, labor force participation and savings, anticipating their optimal migration duration. We estimate this model based on various data sources on Turkish immigration to Germany, using longitudinal survey- and micro-census data over several decades.

\footnotetext{
${ }^{1}$ In a comprehensive cross-country review, the OECD (2008) estimates that 20 to 50 percent of immigrants leave the host country within five years of arrival. Bandiera et al. (2013) document that between 60 and 75 percent of immigrants to the U.S. during the Age of Mass Migration eventually emigrated again. Return migration is also salient in the population we study in this paper, with close to half of migrants returning within 15 years after arrival.
} 
A first key feature of our model is that human capital is composed of two separate stocks: accumulated work experience and host country specific human capital. The latter describes skills such as language proficiency, knowledge about and acquired familiarity with the host country labor market and society, and social contacts. This form of human capital not only affects productivity but also determines immigrants' social assimilation and complements consumption. While being valuable in the host country, it is of reduced value back home. We identify the accumulation of host country specific human capital from a number of observed outcomes, such as language proficiency and immigrants' attachment to the host country.

A second important aspect of our model is that it recognizes that immigrants differ not only in their productivity, but also in their preferences for where to live. To see why this is important, consider immigrants Mehmet and Berk, who are identical except for their location preferences. Mehmet more strongly prefers to live in his origin country, and so would like to remain in the host country for 5 years only, while Berk intends to stay there permanently. The shorter pay-off period reduces Mehmet's incentive to invest in host country specific human capital (such as language proficiency), resulting in lower wage growth. Thus, the different location preferences will lead to different career profiles, and to correlation between earnings growth and the length of a migration.

Suppose now that after two years abroad, Berk experiences a persistent shock to his location preference, induced e.g. through an unobserved family event which renders the host country relatively less attractive, leading to a revision of his plans from remaining permanently in the host country to returning home after another three years abroad. This change in intended duration will alter incentives to invest in human capital specific to the host country, and thus affect wage growth. While in this example both Mehmet and Berk will return home after five years, their career profiles 
differ, as Berk's initial human capital investment was based on the plan to stay permanently before he was exposed to a persistent shock to his location preference.

This example shows that assuming shocks to location preferences as iid is not sufficient to capture the above dynamics, neither is information about the migration's final duration, as this does not allow distinguishing between Mehmet's and Berk's career profiles. One novelty of our paper is to model shocks as a stochastic but persistent process, identified from information about return plans of immigrants at repeated points over the migration cycle, which reflect underlying changes in persistent location preferences. We obtain such information from a panel survey over three decades that includes a unique measure of immigrants' planned migration durations. ${ }^{2} \mathrm{We}$ use this information to identify persistent shocks to individuals' locational preferences. Thus, our model allows us to reevaluate the different mechanisms that affect the evolution of immigrants' careers in conjunction with their re-migration plans, and to assess the consequences of this interplay for the estimation of immigrants' earnings profiles, the selectivity of outmigration, and the design of migration policies.

Our analysis makes several fundamental contributions to our understanding of immigrants' behavior. First, it provides a new perspective on the interpretation of selective outmigration, where those who plan to stay longer invest more into skills, and have thus steeper career paths. ${ }^{3}$ This "behavioral selection" affects the composition of the migrant population alongside selection based on unobserved productivity (“ability selection”), as analyzed in earlier work (see e.g., Borjas and

\footnotetext{
${ }^{2}$ See Van der Klaauw and Wolpin (2008) and Van der Klaauw (2012) for a discussion of the value of such information for identification, and Arcidiacono et al. (2017) for a more recent application.

${ }^{3}$ In contrast with a Ben Porath (1967) type model, or analyses that investigate the effect of life expectancy on human capital investment (as in Jayachandran and Lleras-Muney, 2009), the horizon over which investments pay off is in our case endogenous, and migrants adjust their return decision in response to economic shocks in the host country. This complicates the analysis and requires that return migration and human capital investment is modelled jointly.
} 
Bratsberg 1996; Hu 2000; Lubotsky 2007; Dostie et al. 2020), and may either re-enforce or counteract such selection on ability. ${ }^{4}$ Whereas behavioral selection creates a positive correlation between earnings growth and migration duration, we find that ability selection is non-monotonic over the migration cycle. These findings have important implications for selection biases in the estimation of immigrants' earnings profiles that are used to evaluate economic assimilation and the contribution of immigrants to the host country. ${ }^{5}$ It highlights a form of selection previously overlooked, where negative selection may result not from low-productivity immigrants leaving the country but from those who wish to stay longer investing more in human capital.

Second, our model explains the willingness of immigrants to accept jobs at wages that seem unacceptable to natives, such as low-paid employment in the agricultural sector and in parts of the service industry. We show that the preparedness of immigrants to accept such jobs is directly related to migrations being temporary, as consuming part of their earnings in countries with different price levels leads immigrants to be paid different "effective" real wages than natives. Further, variation in expected migration durations leads to heterogeneity in reservation wages among otherwise identical individuals. Our analysis therefore provides reasons why immigrants have lower reservation wages than natives, a key assumption in the analysis of Amior (2017) on how immigration affects native employment and welfare. ${ }^{6}$

Third, our model provides important insights for the design of migration policies. Policies that initially restrict residence or condition residence on achievement shape not only immigrants'

\footnotetext{
${ }^{4}$ See also the interdependence between location choice and wage progression in Llull and Miller's (2018) analyses of internal migration in Spain and the U.S., respectively.

${ }^{5}$ Starting with Chiswick (1978), a large and growing literature studies earnings profiles of immigrants (see, for example, Borjas 1985, Longva and Raaum 2003, Barth et al. 2004, Bratsberg et al. 2006, and Green and Worswick 2012). See Dustmann and Görlach (2015) for a review and assessment.

${ }^{6}$ See also related work by Albert and Monras (2018), who argue that spatial sorting of immigrants is related to reservation wage considerations.
} 
career profiles through their impact on human capital investment but also determine the selection of arrivals and leavers. ${ }^{7}$ Changes in the composition of new arrivals may in turn have important consequences for labor market prospects of native workers, as pointed out by Llull (2017, 2018). Based on our estimated model parameters, we simulate and compare the impact of different migration policies on immigrant behavior, selection and welfare consequences under three different schemes, relative to a baseline in which migrants can freely choose whether and when to return. Under each scheme, a decision for permanent settlement is made after five years. Scheme I conditions permanent settlement on employment and the attainment of an earnings threshold, similar to e.g. the Tier 2 visa scheme in the UK. Scheme II ties permanent residence to the integration level of immigrants, measured e.g. by language proficiency, akin to requirements in several European countries. Scheme III imposes no conditions, but introduces uncertainty about the possibility to stay, not dissimilar to the situation in which many refugee migrants find themselves. We illustrate that each policy impacts in different ways human capital investment choices, tax contributions, and welfare of immigrants, as well as return migration and the composition of the initial arrival cohorts. ${ }^{8}$

Our analysis also contributes to the small but growing literature on structural models that allow for temporary migrations. While Colussi (2003), Thom (2010), Lessem (2018) and Kovak and Lessem (2020) focus on the effect of border enforcement on Mexico-U.S. migration, Bellemare (2007) and Rendon and Cuecuecha (2010) investigate job search and outmigration

\footnotetext{
${ }^{7}$ Many immigration policies directly affect an immigrant's investment horizon. For instance, H1-B visas in the U.S. are valid for three years, extendable to six years. Similarly, guest worker programs and student visas in many countries restrict migration duration or tie residence permits to specific conditions like enrolment or job contracts.

${ }^{8}$ The fiscal contribution of immigration has been studied for instance by Auerbach and Oreopolus (1999) and Storesletten $(2000,2003)$, although these analyses do not account for the effects of human capital accumulation, selection and anticipated return migration.
} 
behavior of immigrants in Germany and the U.S., and Kırdar (2012) and Nakajima (2015) evaluate the social insurance and fiscal contributions of temporary migrants. ${ }^{9}$ The above three aspects that we consider - behavioral selection, the notion of effective wages for temporary migrants, and the implications for human capital investment of immigration policies that limit the duration of stay are all new to this literature. Moreover, a fundamental novelty is that we allow for persistent changes in optimal expected migration durations over the migration cycle, which in turn affect decisions such as human capital investment and savings, ${ }^{10}$ so that short-run shocks can have longterm consequences.

The structure of the paper is as follows: In the next section we provide some background about the migration situation we study and discuss the data and samples. Section 3 explains the model and discusses its identification. Section 4 presents the estimation results and policy simulations, and we conclude in Section 5.

\section{Background, Data, Sample, and Descriptives}

Our empirical analysis focusses on immigration of Turks to Germany, who constitute the main immigrant population at 14 percent of all immigrants in 2011 (OECD, 2013). This migration movement had its origins in the strong upward trajectory of the West-German economy after 1955, which led to an increase in the share of foreign-born workers from 0.6 percent in 1957 to 11.2 percent in 1973. Bilateral agreements between Turkey and Germany in 1961 and 1964 guaranteed

\footnotetext{
${ }^{9}$ See Dustmann and Görlach (2016) for a more detailed overview of this literature. Structural models have also been used to analyze internal location choices (see e.g. Kennan and Walker, 2011; Buchinsky et al., 2014; Piyapromdee, 2017; Morten 2019; and Oswald, 2019).

${ }^{10}$ Cortes (2004) provides empirical support for the expected migration duration affecting human capital investment. Bratsberg et al. (2002), Engdahl (2014), and Gathmann and Keller (2018) document that access to citizenship fosters economic assimilation in the U.S., Sweden, and Germany, respectively. They argue that citizenship increases investment incentives in human capital as it increases the expected time in the host country.
} 
equal treatment of Turkish and German workers in terms of social insurance and ensured that retirement benefits could be claimed even after workers returned to Turkey (Holzmann et al., 2005). Importantly, an earlier two-year restriction on work permits was repealed, thus making migration duration a matter of individual choice (see Hunn, 2005, for a detailed historical account). While the recruitment of Turkish workers under the guest-worker agreement ended in 1973, immigration for family reunification and refugee migration after the military coup in 1980 caused a continued increase in the Turkish immigrant population even after this date. Both refugee and family migrants were granted permanent residence, so that migration durations have been chosen by migrants themselves (Martin and Miller, 1980; Martin 2002).

Hence, the immigrant population we study here comes from a source country with a different cultural background and language to the host country. In addition, the economies of the two countries were very different, with Turkey being a mainly agricultural economy during the period we analyze, and Germany highly industrialized. Moreover, there were no legal restrictions on migration durations, and migrants had equal rights to natives in the labor market as well as transferable retirement claims. These aspects, in combination with unique features of the data available to us and which we describe next, and the long horizon over which we can observe individuals, make it an ideal immigrant population to study dynamic aspects of migrants' labor market and migration choices.

\subsection{Data and Sample}

We restrict our study to males without tertiary education who were born in Turkey, were aged 16 or older at immigration, and who arrived in West Germany after $1961 .{ }^{11}$ Our analysis is based on

\footnotetext{
${ }^{11}$ Of those individuals in our data who satisfy the other criteria, only 5.4 percent have a tertiary education.
} 
several data sources, most notably the German micro-census (GMC) ${ }^{12}$ and the German Socioeconomic Panel (SOEP). ${ }^{13}$ The GMC is a 1 percent repeated cross-section sample of households that provides individual level information on employment status and earnings. We use a total of 22 waves covering the period $1976-2007,{ }^{14}$ including a total of 48,908 Turkish immigrants in Germany that fit our sample selection criteria. The SOEP, a household-based panel survey initiated in 1984, oversampled the then resident immigrant population. It interviewed in its first wave about 1,500 households with a foreign-born household head, who were subsequently re-interviewed each year. Refresher samples were added in 1995, 1998, 2000 and 2006. The questionnaires used for these interviews are available in the home country language.

The SOEP data are unique not only in that they provide repeated information on a large sample of immigrants over a long period, but also that each year they record the updated return plans of immigrants. Such information is rarely available, particularly in longitudinal format. Specifically, individuals were asked whether they wished to remain in Germany permanently, and if not, for how many more years they intended to stay. In addition to the planned length of stay, the survey records a large array of information on personal and household characteristics, including employment histories in both the country of origin and in Germany, income, and in some waves, household assets and annual savings and remittances. The survey also contains measures of spoken and written proficiency in the German language and measures of integration.

For our analysis, we combine an unbalanced panel of 4,481 unique observations during the years 1984-2011 with the 48,908 individuals from the GMC described above. To identify wages

\footnotetext{
${ }^{12}$ doi: $10.21242 / 12211.1976 .00 .00 .1 .1 .0$ to $10.21242 / 12211.2007 .00 .00 .1 .1 .0$.

${ }^{13}$ doi: $10.5684 /$ soep.v28.

${ }^{14}$ Waves of the GMC prior to 1976 do not report the year of immigration. For immigrants arriving prior to 1976, we use our model to address selection resulting from early returns.
} 
for returning migrants after they have left Germany, we rely on a unique survey by the German Institute for Employment Research (IAB) among Turkish migrants who returned to their home country in 1984 (see Hönekopp, 1987, and Dustmann and Kirchkamp, 2002, for details). We estimate the evolution of earnings in Turkey relative to German earnings levels by combining these data with time series information on nominal compensation per employee provided by the European Commission (2015) and gross national income from the World Development Indicators (World Bank, 2014). ${ }^{15}$ All monetary variables are deflated to 2005 euros using consumer price indices and exchange rates from the Bundesbank (2013) and the OECD (2013). ${ }^{16} \mathrm{We}$ obtain unemployment rates and unemployment durations in Turkey from Tansel and Taşçı (2010).

\subsection{Descriptive Evidence}

Return Migration.-We display in Figure 1 the outmigration rate of immigrants as a function of years since their arrival, distinguishing between two broad arrival cohorts (1970-1989 and 19902007). ${ }^{17}$ The graph shows that within the first five years after arrival, between 10 and 20 percent of each arrival cohort leaves the country, with higher out-migration rates for the earlier cohorts.

\footnotetext{
${ }^{15}$ The European Commission's (2015) AMECO database provides average nominal compensation per employee back to 1960 for West Germany and to 1988 for Turkey. To extrapolate to earlier earnings levels in Turkey, we use gross national income from the World Bank's (2014) World Development Indicators.

${ }^{16}$ See the Appendix B.1 for details.

${ }^{17}$ We use the representativeness of each cross-section of the GMC together with information on the year in which immigrants arrived in Germany to construct synthetic immigrant cohorts from which we can compute the rate of return migration, following Dustmann and Weiss (2007). Similar patterns have recently also been documented across different admission categories by Bratsberg et al. (2017).
} 
After 15 years, between 40 and 50 percent of each cohort has left. ${ }^{18}$ Thus, return migration in the context we study is substantial, in line with the findings of other studies (see e.g. OECD, 2008). ${ }^{19}$

To assess how actual return migration relates to migrants' return intentions, we examine information from the SOEP, which in addition to the planned length of stay records realized returns, based on follow up interviews with family or friends of respondents. ${ }^{20}$ Figure 2, which shows the distribution of the deviation of intended and actual return age for those individuals that left the country during the period of observation, suggests a strong link between reported intentions and actual migration durations (about 50 percent return within two years around their anticipated time of return). However, while the mode of this distribution is centered at zero and the distribution is roughly symmetric, there is also substantial dispersion around the mode, due to many migrants over- or under-estimating the length of their stay. Such differences between intentions and final realizations should induce corrections in incentives to invest in host country specific human capital and in savings over the migration cycle, a dynamic that ought to be captured by our model.

Immigrant Characteristics. - The differences between those with permanent and temporary intentions are underscored in Table 1a. Those who intend to remain permanently arrive at a younger age than those who intend to return, suggesting a stronger attachment to the country of origin when the migration takes place later. Employment probabilities and transition rates into

\footnotetext{
${ }^{18}$ The slightly higher outmigration rate of the earlier cohorts could be due to various factors that we explore below, including differences in preference composition and different macroeconomic conditions at emigration. For instance, earnings in Turkey have risen strongly relative to those in Germany: between 1970 and 2010, median real net earnings of workers in Turkey with no tertiary education have increased from $6.6 \%$ to $31.8 \%$ of the corresponding level in Germany.

${ }^{19}$ Those who leave the country could in principle move on to other host countries (cf. Damas de Matos and Parent, 2019). This is however unlikely the case for the migrations we study here. In fact, 97.8 percent of the immigrants in our SOEP sample report that they would return to their origin country if leaving Germany.

${ }^{20}$ The average yearly outmigration rate in the GMC is $5.7 \%$, slightly lower than the $7.4 \%$ rate in the SOEP among individuals for whom a reason why they leave the panel is recorded. In our main estimation, we use outmigration rates from the GMC rather than the information on actual returns from the SOEP.
} 
work are also higher for those who consider themselves as temporary, in line with intertemporal substitution of leisure leading immigrants with temporary intentions to have lower reservation wages and accepting more job offers. The table entries on earnings, savings, and language proficiency reflect those illustrated in Figure 3, with immigrants who plan to stay permanently saving less (in both absolute and relative terms) and having on average higher gross earnings than those who intend to return. Providing more detail on the return intentions of immigrants, the last two rows of Table 1a show that those who plan to return wish to stay on average for about 7 additional years and that return intentions vary over time, with only $75 \%$ of those who indicated they wanted to stay permanently in year $t$ stating the same in the next year.

Finally, in Table $1 \mathrm{~b}$ we provide summary statistics from the GMC, which show that means of those variables that we observe in both data sets are reassuringly similar. The population in the SOEP is slightly older and has been in the host country for longer, which is related to the stock sampled character of that data set; we address this in the estimation below by explicitly modeling return migration. Lower log real earnings in the GMC are due to these differences in age and arrival time, and to earnings being measured on monthly (rather than annual) level and reported after taxes (rather than as gross earnings in the SOEP).

Assimilation, Earning and Saving Profiles.-To illustrate that planed migration durations determine choices and outcomes, we display in Figure 3a immigrants' log earnings and consumption profiles, separately for those who intend to return before retirement age, and who intend to remain permanently. ${ }^{21}$ Although purely descriptive, these patterns indicate two facts. First, the earnings profile of those stating their intention to stay in the host country permanently is

\footnotetext{
${ }^{21}$ We distinguish between individuals that, at interview, intended to stay permanently and temporarily, respectively. That is, Figure 3 a treats the data as repeated cross-sections.
} 
steeper than the profile of those planning to return. This could either be driven by compositional differences and selection, or by a stronger incentive to invest in host country specific skills among immigrants expecting to stay in the country for a longer time, as they face a longer pay off period for their investment. Second, the graph shows a larger difference between earnings and consumption for those with the intention to return. Since both earnings and consumption are displayed in logs, the vertical difference between the curves approximately corresponds to the savings rate. The higher saving rate for migrants who plan to return suggests an interaction between consumption and individuals' preferences towards the host country, or alternatively a response to lower earnings and prices for consumption at home (in line with intertemporal substitution of consumption), aspects that our model is able to capture.

A similar divergence between those with permanent and temporary migration intentions is illustrated in Figure 3b, where we plot the principal component from a number of outcomes that reflect host country specific investments, such as proficiency in speaking and writing the host country language, the tendency to read German newspapers, and the sense of "feeling German" against the years spent in Germany. Again, the figure illustrates large differences, with those with permanent migration intentions exhibiting steeper and more sustained growth of this measure.

Persistent Preference Shocks.-We next examine whether shocks to location preferences (induced by e.g. the death of a relative, meeting new friends, etc.) generate adjustments to return intentions that are simply iid, or contain a permanent component. A significant permanent component is likely to reflect changes in the life of the individual and affect investment incentives.

We consider a simple linear dynamic model of immigrant $i$ 's planned length of stay in period $t, \varsigma_{i t}:$

$$
\varsigma_{i t}=\mu_{i}-t+p_{i t}+q_{i t} \text {, with } p_{i t}=p_{i t-1}+v_{i t},
$$


where $\mu_{i}$ is an individual fixed effect, $q_{i t}$ captures transitory shocks to migration plans that are independent across time, and $p_{i t}$ is a persistent shock that follows a random walk with innovation $v_{i t}{ }^{22}$ Eliminating $\mu_{i}$ by differencing equation (1) allows us to estimate the variances $\sigma_{q}^{2}$ of $q_{i t}$ and $\sigma_{v}^{2}$ of $v_{i t}$, and thus to assess the relative importance of persistent and transitory innovations from the covariance structure of changes in intentions over time. ${ }^{23} \mathrm{GMM}$ estimates of the variances in Table 2 suggest both transitory and persistent shocks to stated return intentions, over and above individual fixed heterogeneity, with more than one third of each period's innovation having a persistent effect on future return plans. Interestingly, the estimates are barely affected when conditioning on year fixed effects, pointing to idiosyncratic shocks as the drivers of revisions in intended durations, rather than business cycles or macro shocks. This finding has important implications for our modelling strategy and our understanding of the dynamics of return migration.

The evidence presented above illustrates several important features of the data that we incorporate in our model. First, return migration is substantial. Second, individuals' intended migration durations are indeed informative about their eventually realized return migrations, though these plans are subject to large and persistent shocks. Third, there is evidence that the behavior of immigrants who wish to return is different from that of those who wish to stay permanently, including their labor market choices, savings choices and investment in host country specific human capital.

\footnotetext{
${ }^{22}$ Based on our data, we cannot reject the null hypothesis that the more general first order auto-regressive process is a random walk.

${ }^{23}$ Specifically, $\operatorname{var}\left(\Delta \varsigma_{i t}\right)=\sigma_{v}^{2}+2 \sigma_{q}^{2}$ and $\operatorname{cov}\left(\Delta \varsigma_{i t}, \Delta S_{i t-1}\right)=-\sigma_{q}^{2}$ provide a system of equations that identifies the variances of $q_{i t}$ and $v_{i t}$, denoted $\sigma_{q}^{2}$ and $\sigma_{v}^{2}$ respectively.
} 


\section{Model, Identification and Estimation Method}

We model individuals' outcomes and choices from the beginning of working life. Our analysis focuses on workers born in a specific emigration country, which we label $E$, and who have the initial choice to remain there, migrate to a particular immigration country $I$, or migrate elsewhere (the rest of the world $R O W$ ). Our analysis focuses on those who migrate to $I$, and we consider the migration decision to $R O W$ as an outside option with a payoff that we estimate. If they migrate to $I$, individuals make decisions about their labor market status, savings rates, whether or not to return to their home country, ${ }^{24}$ and their investment in human capital. We follow individuals on an annual basis, from the migration decision until retirement, distinguishing between different migration cohorts. We start by presenting the setup of the model after emigration to $I$. We then describe the initial migration decision.

\subsection{The Model}

Unobserved heterogeneity.-We allow for fixed and time-varying unobserved heterogeneity along two dimensions. First, individuals differ ex ante in their labor market productivity (or ability), denoted by $\alpha_{i}$. Second, preferences across individuals for a particular location $I$ or $E$ vary and consist of a transitory shock $\eta_{i t}^{j}, j=I, E$, and a persistent shock $\Psi_{i t}$, which represents the preference for the host country versus the home country (we normalize $\Psi_{i t}$ to one in the home country). This persistent shock follows a first order Markov process, with a symmetric transition

\footnotetext{
${ }^{24}$ We use emigration country and home country, as well as immigration country and host country, interchangeably. The vast majority $(97.8 \%)$ of immigrants in our sample report that they would return to their country of origin if leaving Germany rather than moving to a third country.
} 
matrix: $:^{25}$

$$
P\left(\Psi_{i t}=\psi_{k^{\prime}} \mid \Psi_{i t-1}=\psi_{k}\right)=\pi_{k^{\prime} k}, \text { with } \pi_{k^{\prime} k}=\pi_{k k^{\prime}}
$$

These persistent and transitory shocks capture aspects that are important to individuals when making their return decisions, but that we do not otherwise model explicitly, such as family events, finding/leaving a partner or the death of a parent.

We model the joint distribution of ability $\alpha_{i}$ and the initial location preference $\Psi_{i 0}$ in terms of discrete mass points and allow for a correlation between the two. Endogenous immigration further implies that this distribution can differ across arrival cohorts $g_{i}$, thus accounting for unobserved changes in the composition of immigrants over time. Allowing individuals to differ along two different types of unobserved traits will be important for characterizing selection that potentially biases the estimation of wage profiles and the effect of return decisions. It is also important for the policy analysis we perform in Section 4.4, as immigrants may respond differently to policies that emphasize either productivity or assimilation.

Human Capital.-Workers may acquire two distinct types of human capital in our model: work experience $X_{i t}$, and host country specific human capital $H_{i t} \cdot{ }^{26}$ Work experience is acquired through learning-by-doing (as in e.g. Eckstein and Wolpin, 1989), is partially portable across countries, and increases by one unit in each period the individual works:

$$
X_{i t+1}=X_{i t}+\mathbb{I}_{i t}^{\text {work }} \text {, }
$$

\footnotetext{
${ }^{25}$ This stochastic structure is in line with the estimation results for equation (1) in the previous section, which show that persistent shocks are important to describe the return behavior of migrants, over and above a fixed effect. Symmetry is assumed, since trends in $\Psi_{i t}$ are difficult to distinguish from unobserved human capital accumulation described below.

${ }^{26}$ Multiple dimensions of human capital are considered by, for instance, Gathmann and Schönberg (2010), Hu and Taber (2011), and Gayle et al. (2012, 2015); see Sanders and Taber (2012) for a survey of that literature.
} 
where $\mathbb{I}_{i t}^{\text {work }}$ takes the value one if individual $i$ works in period $t$ and zero otherwise. Given that the model allows for a choice to work, the accumulation of work experience is endogenous. Work experience accumulated in the home country prior to emigration may not be fully portable to the host country. For an individual arriving in period $t$, we thus represent the value of effective experience at immigration as $X_{i t}=\xi X_{i t}^{E}$, where $\xi$ denotes the discount factor on experience accumulated in the emigration country, $X_{i t}^{E} \cdot{ }^{27}$

Host country specific human capital is acquired through active investment (as in Ben-Porath, 1967), and evolves after migration as

$$
H_{i t+1}=H_{i t}+d_{H} \mathbb{I}_{i t}^{H},
$$

with $\mathbb{I}_{i t}^{H}$ being an indicator variable that equals one if the immigrant chooses to invest in $H_{i t}$. In this case the stock is increased by an amount $d_{H} \cdot{ }^{28}$ We capture investment costs as a disutility, as explained below. We treat $H_{i t}$ as a unidimensional latent variable in the model but link it to several observed measures in our data that include skills such as language proficiency, knowledge of the host country, social contact with the majority population, and communication skills. Denote those variables $\iota_{i t}^{k}, k=1, \ldots, K$, which we observe in the data. We specify the following factor model:

$$
\iota_{i t}^{k}=\Phi\left(\gamma_{0}^{k}+\gamma_{1}^{k} H_{i t}+\omega_{i t}^{k}\right), k=1, \ldots, K,
$$

where the $\gamma_{1}^{k}$ 's are factor loadings and $\Phi(\cdot)$ denotes the standard normal cumulative distribution function. In our setting, individuals derive utility directly from the common factor $H_{i t}$ rather than

\footnotetext{
${ }^{27}$ To ease computational burden, we do not keep track of home country experience as a separate state variable while individuals are in the immigration country.

${ }^{28}$ For computational simplicity, we treat $d_{H}$ as a fixed parameter that we estimate. The individual is choosing whether to invest or not in each period.
} 
$\iota_{i t}^{k}$, which considerably reduces the dimensionality of the model and allows us to solve and estimate it. We assume that the shocks $\omega_{i t}^{k}$ are normally distributed and iid.

Host country specific human capital $H_{i t}$ affects labor market productivity by complementing work experience $X_{i t}$, but it also helps the immigrant to locate job offers. Given the cost associated with the accumulation of $H_{i t}$ and its specificity to the host country, migrants have a dynamic tradeoff, in which those with a low preference for the host country may not judge it worthwhile to invest much because of the expected short duration of their migration spell.

As with unobserved preference and productivity, selective immigration may cause the initial stock $H_{i 0}$ to vary across arrival cohorts $g_{i}$ (following Borjas, 1985). We normalize it to zero for the first arrival cohort, while for the later one, we estimate it together with the other parameters of the model.

Earnings and Unemployment Benefits.-Log gross annual earnings in the immigration country are

$$
\log y_{i t}=\alpha_{0}^{I}+\alpha_{i}+f_{y}^{I}\left(X_{i t}\right)+\alpha_{H} H_{i t}+\varepsilon_{i t}^{I}
$$

where $\alpha_{0}^{I}$ is an intercept, $\alpha_{i}$ is individual specific productivity, and $f_{y}^{I}(\cdot)$ is a piecewise linear function of work experience with nodes at 2, 5, 10, and 20 years. Host country specific human capital $H_{i t}$ affects $\log$ wages in the immigration country linearly with return $\alpha_{H}$. As $H_{i t}$ accumulates endogenously, depending on a migrant's return migration plans, this component of the earnings equation leads to behavioral selection, distinct from the selection on unobserved ability $\alpha_{i}$. The error term $\varepsilon_{i t}^{I}$ is iid normal across time and individuals, with mean zero and variance $\sigma_{\varepsilon}^{2}$ 
For those who return (or decide not to migrate in the first place), real wages in the home country are modelled as:

$$
\log y_{i t}=\alpha_{0 t}^{E}+\rho_{\alpha} \alpha_{i}+f_{y}^{E}\left(X_{i t}^{p}\right)+\rho_{H} \alpha_{H} H_{i t}+\varepsilon_{i t}^{E}
$$

The first term is a wage intercept, such that $\alpha_{0 t}^{E}<\alpha_{0}^{I}$, as wages in the home country are lower than in the host country. It is also indexed by time, as home country wages tend to catch up with those in the host country over the period we consider. The second term is again an ability fixed effect, which we assume to be proportional to the one affecting wages in the host country in equation (6a). The third term is a nonlinear function of potential experience $X_{i t}^{p}{ }^{29}$ Finally, to reflect that host country specific human capital $H_{i t}$ has a lower return in the home country, we impose $\rho_{H}<1$

Budget Constraint.-We assume a standard intertemporal budget constraint under which asset holdings $A_{i t}$ depend on past assets, net income (or unemployment benefits $b_{i t}^{j}$ if the individual is not working), and consumption $c_{i t}$ in location $j=I, E$,

$$
\begin{gathered}
A_{i t+1}=\left(1+r_{t}^{j}\right) A_{i t}+\mathbb{I}_{i t}^{\text {work }} n e t\left(y_{i t} ; j\right)+\left(1-\mathbb{I}_{i t}^{\text {work }}\right) b_{i t}^{j}-c_{i t} \\
A_{i 0}=0, A_{i t} \geq 0
\end{gathered}
$$

Here $\operatorname{net}(\cdot ; j)$ is a function that relates gross earnings $y_{i t}$ to net earnings and models the tax schedule in each country. To approximate the unemployment compensation scheme in place over the period of study, we specify unemployment benefits $b_{i t}^{j}$ as a function of predicted earnings had the individual been working. ${ }^{30}$ Once migrants return, their assets are converted by a factor $x_{t}$ to

\footnotetext{
${ }^{29}$ We do not observe work experience in Turkish data but can calculate the potential experience of returning migrants.

${ }^{30}$ The German benefit rate is a function of past earnings, which we model using data from the SOEP (see Appendix

B.1 for details). There was no unemployment benefit in Turkey during most of our period of analysis; these were
} 
account for the purchasing power of the host country currency in the home country. ${ }^{31}$ This implies that the price of consumption differs across locations. Hence, as in Thom (2010), migrants who plan to return soon will have stronger incentives to accumulate savings, as consumption is relatively cheaper in their home country.

Labor Market Transitions. - In each period, employed workers are laid off with probability $\delta^{j}, j=I, E$, while individuals who are unemployed receive a job offer with probability $\lambda^{j}$ and decide whether to accept the job or remain unemployed. For the host country, the rates at which jobs are lost and new job offers arrive are functions of age $a g e_{i t}$ and host country specific human capital $H_{i t}$, since better knowledge of the host country may improve job finding and job retention:

$$
\delta^{I}=\Phi\left(\delta_{0}+\delta_{H} H_{i t}+f_{\delta}^{I}\left(a g e_{i t}\right)\right)
$$

and

$$
\lambda^{I}=\Phi\left(\lambda_{0}+\lambda_{H} H_{i t}+f_{\lambda}^{I}\left(a g e_{i t}\right)\right)
$$

where $f_{\delta}^{I}\left(a g e_{i t}\right)$ and $f_{\lambda}^{I}\left(a g e_{i t}\right)$ are piecewise linear functions of age, and $\Phi(\cdot)$ denotes the standard normal distribution function. For the home country, we define $\delta^{E}=f_{\delta}^{E}\left(a g e_{i t}\right)$ and $\lambda^{E}=$ $f_{\lambda}^{E}\left(a g e_{i t}\right)$, implying age-specific job loss and job finding probabilities. ${ }^{32}$

\footnotetext{
introduced only in 2002, but at a replacement ratio of only $9 \%$. We therefore set $b_{i t}=0$ for individuals who have returned home.

${ }^{31}$ In the period $t$ before a return, the budget constraint thus becomes $A_{i t+1} x_{t+1}=\left(1+r_{t}^{j}\right) A_{i t}+\mathbb{I}_{i t}^{\text {work }}$ net $\left(y_{i t}\right)+$ $\left(1-\mathbb{I}_{i t}^{\text {work }}\right) b_{i t}-c_{i t}$. See Appendix B.1 for details on interest, tax and exchange rates.

${ }^{32}$ We derive these from unemployment rates and unemployment durations as estimated by Tansel and Taşçı (2010).
} 
Preferences.-An individual's utility function is defined over consumption $c_{i t}$, leisure $(1-$ $\left.h_{i t}\right)$, host country specific human capital $H_{i t}$, and investment in it, $\mathbb{I}_{i t}^{H}$ :

$$
\begin{aligned}
u_{i t}=\underbrace{c_{i t} \phi_{c}\left(1-h_{i t}\right)}_{A} \underbrace{\left(\Psi_{i t}\left(H_{i t}+1\right)^{\phi_{H}}\right)^{I}}_{B} & \\
& -\underbrace{e\left(a g e_{i t}\right) \mathbb{I}_{i t}^{H}}_{C}+\underbrace{\eta_{i t}^{I} \mathbb{I}_{i t}^{I}+\eta_{i t}^{E}\left(1-\mathbb{I}_{i t}^{I}\right)}_{D} .
\end{aligned}
$$

Term (A) describes utility from consumption and leisure, where $h_{i t}$ takes an estimated value $h$ if the individual works and equals zero if not. Term (B) switches on in the host country and consists of the relative preference for location $I, \Psi_{i t}$, and host country specific human capital $H_{i t}$. It enhances utility of consumption, reflecting that those with a high relative preference for the host country enjoy consumption more than those with a low preference, as motivated by the empirical patterns shown in Figure 3a. Moreover, it allows utility from consumption in the host country to be positively affected by host country specific human capital $H_{i t}$, by e.g. enhancing information about consumption possibilities and creating connections to natives through language and knowledge of culture. As returns from consumption and leisure in the host country can be affected by the level of $H_{i t}$, endogenous accumulation of $H_{i t}$ may lead to past and potentially short-term events having permanent effects on immigrants' future choices.

Term (C) reflects the effort cost of investment in host country specific human capital $H_{i t}$. It is age dependent, to capture that older individuals may find it more difficult to acquire new language skills or to form social contacts. ${ }^{33}$ Finally, term (D) measures iid preference shocks in the emigration and immigration countries, $\eta_{i t}^{E}$ and $\eta_{i t}^{I}$, which we assume to follow an extreme value type I distribution.

\footnotetext{
${ }^{33}$ We specify the effort function to be linear in age: $e\left(a g e_{i t}\right)=e_{0}+e_{1} a g e_{i t}$.
} 
Dynamic Specification of the Model.-In each period, individuals choose their consumption, labor supply, and, if located in the host country, whether to invest in host country specific human capital or not and whether to return to the home country or not, conditional on the state vector ${ }^{34}$

$$
\Omega_{i t}=\left\{\text { age }_{i t}, \text { year }_{t}, X_{i t}, H_{i t}, A_{i t}, \mathbb{I}_{i t-1}^{\text {work }}, \mathbb{I}_{i t-1}^{I}, \alpha_{i}, \Psi_{i t}, \eta_{i t}^{E}, \quad \eta_{i t}^{I}, \varepsilon_{i t}\right\}
$$

The value function is then defined by the following Bellman equation, which describes how these choices affect contemporaneous and future utility:

$$
V\left(\Omega_{i t}\right)=\max _{c_{i t}, \mathbb{I}_{i t}^{\mathrm{H}} \mathbb{I}_{i t}^{\text {work }}, \mathbb{I}_{i t}^{I}} u\left(c_{i t}, \mathbb{I}_{i t}^{\mathrm{H}}, \mathbb{I}_{i t}^{I}, \mathbb{I}_{i t}^{\text {work }} ; \Omega_{i t}\right)+\beta E_{t} V\left(\Omega_{i t+1}\right),
$$

where $\beta$ is a discount factor and $E_{t}$ is the expectation operator conditional on information in period $t .{ }^{35}$ Expectations are taken over the vector of future shocks to preferences for location, income shocks, and labor market (firing and hiring) shocks. We assume that exchange rates and mean country of origin wages follow deterministic paths based on observed macroeconomic time trends (see Appendix B). The choices of consumption, investment in host country specific human capital, labor supply and location are made subject to the constraints explained above.

We assume that the decision to return to the home country is final - an assumption that characterizes well the population we consider. ${ }^{36}$ Once migrants have returned, they only choose their consumption and labor supply. ${ }^{37}$ We further assume that individuals who quit work do so

\footnotetext{
${ }^{34}$ Calendar time $\left(\right.$ year $\left._{t}\right)$ enters the state space as we account for changes in the macroeconomic environment different cohorts experience.

${ }^{35}$ We set $\beta=0.95$

${ }^{36}$ In several waves, the SOEP has inquired as to where individuals would want to migrate if leaving Germany. In our sample, 97.8 percent of Turkish immigrants state that they would leave for Turkey. In contrast to other migrations, such as Mexico-U.S. migrations where many migrants are seasonal workers in agriculture or construction, and migration is often circular, the assumption that return is final is realistic in our context. If individuals migrated repeatedly, we should observe individuals at older ages who arrived recently. Contrasting this, in the SOEP sample only $1.4 \%$ among those stating that they arrived during the past five years are aged 40 or older.

${ }^{37}$ In our sample, $91 \%$ of those planning to return intended to so before age 65 . Evidence from our Turkish return migrant sample suggests that $75 \%$ of returnees in our context do not immediately retire after returning to the home
} 
involuntarily. However, when out-of-work, individuals choose whether to work or not if they receive an offer, making labor supply and work experience endogenous. Finally, we set the retirement age at 65 , from which point individuals receive retirement benefits $y_{R}^{j}, j=I, E$, and only make consumption decisions, until age 80 (end of life in our model). To compute retirement benefits, we fix the state variables $X_{i t}, H_{i t}$, and $\Psi_{i t}$ at their values at age 64 (see Appendix B.2 for more details on the model's dynamic specification and how we solve it). ${ }^{38}$

Initial conditions. - Initially, individuals are located in their home country and make a onetime decision of whether to migrate or not, by comparing the welfare achieved in either location:

$$
\max \left\{V^{E}\left(\Omega_{i 0}\right)+\eta_{i 0}^{E} ; V^{I}\left(\Omega_{i 0}\right)+\eta_{i 0}^{I}-C_{t} ; V^{R O W}+\eta_{i 0}^{R O W}-C_{t}\right\}
$$

where $V^{E}\left(\Omega_{i 0}\right)$ and $V^{I}\left(\Omega_{i 0}\right)$ are the values individuals attribute to being in the emigration country and the immigration country respectively, and $V^{R O W}\left(\Omega_{i 0}\right)$ captures the option of migrating elsewhere ("rest of the world"). Preference shocks associated with either choice are denoted by $\eta_{i 0}^{E}, \eta_{i 0}^{I}$ and $\eta_{i 0}^{R O W}$, which are drawn independently from an extreme value distribution with spread parameter $\tau$, and $C_{t}$ is the utility cost arising from migration. This cost is indexed by time, as we allow it to take different values prior to 1973, between 1976-1980 and after 1980. Before 1973, Germany operated a guest-worker recruitment scheme, when the cost of migration was presumably lower. The period 1976-1980 corresponds to the political unrest that led to the 1980 coup in Turkey.

\footnotetext{
country.

${ }^{38} \mathrm{We}$ specify a wage replacement rate of 0.5 , in line with the average ratio between retirement benefits observed in our SOEP sample and earnings of the same individuals at ages 60-64. See also OECD (2011) for a detailed and comparable account of retirement schemes in Germany and Turkey.
} 


\subsection{Estimation and Identification}

We estimate our model using an indirect inference estimator that minimizes the distance between moments from the data and the equivalent moments simulated using the model (see Gourieroux et al., 1993). ${ }^{39}$ The data moments are computed from the GMC and SOEP, as well as data collected in Turkey on returned migrants (see Section 2.1), which is used to approximate the earnings migrants can expect after a return. Identification relies on static, conditional, and dynamic moments obtained from the data, usually through auxiliary regressions. We match moments that relate to the evolution of earnings, transitions between work and non-work, the evolution of savings and social integration, and actual and intended returns. As some of the outcomes we use are collected only in a sub-set of years, and are partly taken from different data sources, we target moments from multiple separate auxiliary regressions. We provide further details, including an analysis of the mapping of parameters into moments, in Appendix C.

Our model has two unusual features compared to previous structural models. First, the model contains a latent state variable (host country specific human capital $H_{i t}$ ) which contributes to wage growth. Second, the model includes an autocorrelated stochastic preference shock $\Psi_{i t}$. Both these features present a challenge for identification that we address below.

Identifying persistent preference shocks.-Typical dynamic discrete choice models such as Keane and Wolpin (1997) contain only iid shocks, and their identification using observed decisions is well understood. In our case however, there are both iid and persistent shocks to preferences and we use data on repeated measures of intended migration durations to identify the dynamics of the

\footnotetext{
${ }^{39}$ The minimized criterion is the squared difference between observed and simulated moments, weighted by their inverse (observed) standard deviation (as for instance in Haan and Prowse, 2017, who also apply this estimator to data from the German Socio-economic Panel). We report asymptotic standard errors.
} 
persistent preference shocks that we anticipated in Section 2.2. ${ }^{40}$ To construct the model counterpart of migration intentions, we draw, for each simulated individual, a number of future paths for shocks to earnings, employment and preferences. Each of these paths implies a sequence of choices as well as an optimal duration of stay in the host country, which we combine to construct the density of future return dates. We then take the median of these return dates as our model's equivalent to the intention stated by an individual at a given point in their migration history, as observed by us in the data. We use the median because it produces a more robust measure of intentions than does the mean, which is sensitive to outliers. ${ }^{41}$

Identification of host country specific human capital. — We identify the accumulation of latent host country specific human capital $H_{i t}$ through a factor model of several observed measures of host country specific skills and knowledge (see equation 5). To account for selective return migration, this factor model is estimated jointly with other model parameters. The simulation distinguishes two immigrant cohorts, one that arrives in 1970 at the height of the guest worker program, and one that arrives in 1990. The initial level $H_{i 0}$ varies across immigrant cohorts. Since $H_{i t}$ is unobserved, we need to normalize its initial level for one cohort and identify the variation across years of arrival through level differences in the observed measures across cohorts.

Identification of the initial decision. - The initial decision depends on the relative sum of

\footnotetext{
${ }^{40}$ Without data on intended migration durations, the model is in principle identified as changes in the location preference will affect investment in human capital. However, in practice, we only observe the stock of human capital (e.g. the level of language skills), and changes in this stock as a response to a preference shock are very difficult to detect. Moreover, variables such as language capital are measured with error, so that changes in the stock have a non-zero autocovariance structure that confounds the effect of preference shocks. Finally, there is no disinvestment in skills in case of a negative shock to location preference, so that data on human capital can only be informative on increases in the location preference for the host country. In contrast, intended migration durations respond to both positive and negative shocks to preferences.

${ }^{41}$ See Van der Klaauw and Wolpin (2008) for a related estimation strategy, in which they build a model of labor supply and retirement using data on life expectancy and the likelihood of work at older ages, and also use stated intentions for identification. What distinguishes our approach from theirs is that we use repeated intentions for each individual, which allows for revised intentions as individuals age and experience new shocks.
} 
discounted flows of utility in each location, the one-time cost of migration and the realization of the transitory preference shocks $\eta$. The discounted flows of utility in the emigration and immigration countries are identified from the observation of wages, assets and labor market choices in either location. The value of moving elsewhere (ROW) is summarized by the value $V^{R O W}$, which we assume is constant and that we identify from the observed number of Turkish emigrants in all OECD countries (except Germany), taken from Docquier et al. (2009). The cost and the variance of preference shocks are identified from the fluctuations in the emigration rate over time, from the early seventies to the nineties. We provide further details on identification in Appendix D.

Identification of the remaining parameters.-The wage equation for migrants who have returned to their home country is estimated from the IAB survey of returning migrants. ${ }^{42}$ To identify the other parts of the model, we match conditional moments from the data with those produced by the model. ${ }^{43} \mathrm{We}$ refer the reader to Appendix $\mathrm{C}$ for further details.

\subsection{Model Fit}

The top panel of Figure 4 shows the log of annual earnings against host country experience as observed in the SOEP sample (grey line) together with the profile predicted by the model (black

\footnotetext{
${ }^{42}$ Since these data are not linked to individual level outcomes in Germany, we need to make assumptions about the unobserved components of the equations. We thus specify that individuals with a high and low productivity $\left(\alpha_{i}\right)$ in Germany correspond to individuals with above and below median schooling level in the Turkish sample respectively, and that the returns to host country specific human capital $H_{i t}$ is zero after a return to Turkey. The latter is supported by the fact that return migrants in our context rarely continue working in the same sector. According to the survey of returning migrants, the most common industries in Germany prior to return are steel furnace $(29 \%)$, coal mining $(20 \%)$ and ship building (5\%), whereas after return the most frequent industries in Turkey are agriculture $(31 \%)$, department stores $(21 \%)$ and transportation (11\%). Returns to foreign experience, as discussed by Reinhold and Thom (2013) for Mexican returnees from the U.S. are thus likely less relevant in our case.

${ }^{43}$ Many of the observed moments are subject to selection bias due to migrants returning to their home country. The predicted moments are constructed taking into account selective return, relying on the modeling of return decisions. The correction is similar to a Heckman selection model. A similar estimation strategy can be found in Magnac et al. (1995).
} 
line). The specification chosen for the earnings function, with a linear spline over five experience intervals, fits the empirical earnings profile very well. The second panel shows the distribution of planned migration durations for newly arriving immigrants. Rather than the full distribution, we only target the mean and standard deviation of this distribution, as well as correlations with other observed outcomes. Nevertheless, our model replicates this distribution well.

Our model also matches well measures of host country specific human capital $H_{i t}$ such as oral and written language proficiency, the tendency to read German newspapers, and the degree to which immigrants feel German. The fit of these outcomes by time spent in the host country is shown in Figure 5. In Appendix C, we provide further evidence of the model's fit for employment transitions, as well as the full set of moments used in the estimation. In the same appendix, we further present evidence of the model's external validity (similar to the analysis of Todd and Wolpin, 2006). Since the relative price level in Turkey determines the purchasing power of assets accumulated in Germany once back in Turkey, it is an important determinant of economic migrants' choices. We show that the model is able to predict well the effect of relative prices on savings decisions, an aspect that we do not explicitly use in the estimation of our parameters. In Appendix D, we show the fit of the model regarding migrant inflows over time and how they respond to exogenous macroeconomic determinants. 


\section{Results}

\section{1. Estimated Parameters}

The model has 43 parameters that we estimate. We now discuss a subset of these parameters, with a focus on those that characterize the effect of host country human capital $H_{i t}$ on individuals' earnings profiles, their employment transitions, and utility.

Earnings.-The estimates in Table 3 show that a one standard deviation increase in host country human capital $H_{i t}$ raises earnings by about 9.5 percent. For a cohort of immigrants who all arrive at age 25 , we find a 1.1 standard deviation difference in the accumulation of $H_{i t}$ between those who have a low or high preference for the host country upon arrival, which contributes to an earnings gap between the two groups of $0.11 \log$ points after 10 years in the host country.

The accumulation of host country labor market experience increases wages annually by about $0.2 \log$ points over the first two years, which quickly decreases to $0.07 \log$ points in years $3-5$, and returns drop off even further in later years. This reduction in the marginal effect of experience in a host country has also been documented for the U.S. (Borjas, 1985; Lubotsky, 2007). Moreover, home country experience is only partially transferable: the estimate of 0.32 for the parameter $\xi$ suggests that on average, individuals lose about two thirds of general human capital acquired through working when emigrating from Turkey to Germany (cf. Friedberg, 2000). Finally, we allow for unobserved productivity differences, and the estimates in Table 3 show that these account for a difference in earnings between low and high productivity individuals of about 0.3 log points.

Employment Transitions.- - Host country specific human capital $H_{i t}$ not only affects earnings, but also employment transitions over the life-cycle. We find that a one standard deviation increase in $H_{i t}$ raises the job finding probability by 4.1 percentage points, while it lowers the risk of job 
loss by 1.3 percentage points (see Table 4). Both job offer and job loss functions vary with age, with a decrease in job offer rates and an increase in job loss rates at older ages. For instance, for individuals aged 60, the risk of losing a job increases by 1.9 percentage points per year.

Utility.-Term (A) of equation (10) captures the utility from consumption and leisure. The coefficient estimate of $\phi_{c}$ of 0.26 (see Table 5) implies a relative risk aversion of 0.74 , which is in line with estimates found in other studies. ${ }^{44}$ Further, disutility from working reduces the utility flow from consumption by a factor $(1-h)=0.84$ (or by $16 \%$ ) if an individual works.

Term (B) in equation (10) scales utility from consumption and leisure in the host country through the persistent shock to relative preferences for the host country $\Psi_{i t}$, and accumulated host country specific human capital $H_{i t}$. Considering first $H_{i t}$, the estimated parameter $\phi_{H}$ of 0.48 implies that for an immigrant who arrives at age 25 , the host country specific human capital accumulated on average during the first ten years in the host country raises utility from consumption by 37.8 percent relative to the utility from consumption derived at arrival. This means that temporary shocks to employment and earnings, through their effects on planned migration duration and thus on the accumulation of $H_{i t}$, can have long-lasting effects on later behavior. For instance, immigrants losing a job plan to return approximately 4.9 years earlier and are 42.5 percent less likely to invest in $H_{i t}$. As a consequence, this channel will lead to migration policies that affect the accumulation of $H_{i t}$ having long-term effects on immigrants' behavior and welfare, something we discuss in the context of our policy simulations in Section 4.4. Similarly, immigrants' preference for the host country upon arrival, $\Psi_{i 0}$, and the evolution of this preference over time, also affect the utility of consumption and leisure. The process for $\Psi_{i t}$ is highly persistent, with an

\footnotetext{
${ }^{44}$ Our estimate is comparable to Rendon and Cuecuecha (2010) and Imai and Keane (2004), who find relative risk aversion to be 0.56 and 0.74 , respectively. Allowing for heterogeneous risk preferences, Belzil et al. (2017) report a mean value for relative risk aversion of 0.73 .
} 
estimate for the annual probability of no change in preferences $\left(\pi_{k k}\right.$, see equation (2)) of 0.95 . This implies that an immigrant's initial preference towards the host country governs many of his decisions during the first few years after arrival. Unobserved productivity $\alpha_{i}$ and location preference $\Psi_{i 0}$ at arrival are negatively correlated, so that low ability individuals tend to stay longer.

As we discuss in Section 3.1, we allow different immigrant arrival cohorts to face different macroeconomic conditions. We also allow for different initial preferences for the host country and different levels of host country human capital at arrival. We model the difference in preferences by allowing for different probability distributions for the preference parameter $\Psi_{i 0}$ at arrival. The estimates in Table 5 show that the probability that an immigrant draws a high value of $\Psi_{i 0}$ at arrival is 0.9 percent higher for later arrival cohorts. Similarly, our estimate for host country human capital at arrival indicates a 0.7 standard deviations higher level for the later arrival cohort, meaning that everything else equal, later arrivals have a $0.095 \cdot 0.7=6.6$ percent higher earnings potential at arrival. Thus, the later cohort has not only a higher relative preference for the host country, but also arrives with skills more valuable in the host country's labor market.

Term $\mathrm{C}$ of the utility function includes an effort cost of investment in host country human capital, which can vary with age (with intercept $e_{0}$ and slope $e_{1}$ ). Our estimates of these parameters show that a 20 -year-old immigrant faces a 33 percent lower cost of investing in host country specific human capital $H_{i t}$ than an immigrant aged 30. Thus, our model implies not only that those who arrive at a later age invest less in $H_{i t}$ due to a shorter pay-off period, but also that investments into $H_{i t}$ require more effort for older individuals, and thus become more costly. This is in line with early findings of the role of age at arrival in a reduced form context by Friedberg (1992) and Eckstein and Weiss (2004). 


\subsection{Immigrants' Career Profiles}

We now analyze two key features of immigrants' careers: the selection of returning migrants and the role of the interplay between human capital accumulation and return plans for the evolution of wages. We do this by simulating the life cycle career paths of different arrival cohorts, based on our estimated parameters, distinguishing between four groups: immigrants who arrive with a high and a low initial preference for the host country $\left(\Psi_{i 0}\right)$, and, within each preference type, high and low productivity individuals, based on the realization of ability $\alpha_{i}{ }^{45} \mathrm{We}$ then track these four groups over their life cycle.

Length of Stay, Integration, and Migrant Selection.-We first investigate what determines selective out-migration. In contrast to the standard Roy type model, where selection is driven by unobserved ability only (see e.g. Borjas 1987, Borjas and Bratsberg 1996), in our model selection is also affected by preferences for the host country, both directly and indirectly through effects on behaviors. This is shown by the survival rates of immigrants in Figure 6, where solid and dashed lines represent low and high productivity individuals, and grey and black lines low and high preference individuals, respectively. ${ }^{46}$ The figure shows that those with an initially high preference for the host country remain longer on average than those with a low preference. Within each of the two preference groups, two counteracting mechanisms determine selection. First, among migrants with both a strong attachment to the home country $\left(\Psi_{i t}<1\right)$ and with a high productivity, an income effect raises the demand for time spent in the home country, creating a negative selection of those who stay longer. Second, for high productivity individuals, a substitution effect implies

\footnotetext{
${ }^{45}$ The shock to the location preference $\Psi_{i t}$ is stochastic and persistent, so that, as time passes, individuals gradually experience new taste shocks and adjust behavior and intentions accordingly (see equation 2).

${ }^{46}$ Since Figure 6 distinguishes unobserved types, we cannot construct a direct counterpart in the data. However, we show in Appendix Figure A5 that the model matches the aggregate survival profile well.
} 
larger opportunity cost of a return, which creates a positive selection of stayers. For the estimated parameter values we obtain, we find that the first effect dominates. For migrants with a preference for the host country $\left(\Psi_{i t}>1\right)$, both effects act in the same direction, and we find positive selection of stayers.

To understand better the composition of returning immigrants with respect to ability, Figure 7 plots the average wage fixed effects of returning migrants as a function of time. The figure illustrates how selection on ability varies over the cohort's migration cycle. Those who leave first are more likely to come from the group with low preference for the host country but high productivity (thus having a low incentive to invest in host country specific human capital but a high relative taste to consume in the home country), leading to positive selection on productivity. Over time, this group becomes smaller, and the flow of return migrants is increasingly dominated by low preference-low productivity individuals. As time passes, more high preference but low productivity individuals return home. ${ }^{47}$

Estimation of Earnings Profiles.- The selection of immigrants through return migration along these two dimensions affects wages in two ways. First, immigrants select according to fixed productivity differences. Second, heterogeneity in preferences leads to behavioral selection, where immigrants accumulate host country specific human capital to different degrees, with those who

\footnotetext{
${ }^{47}$ Contrast this to the standard one-factor Roy model used in the migration literature (see, e.g., Borjas and Bratsberg 1996), which provides unambiguous predictions about the sorting of individuals into non-migrants, temporary migrants and permanent migrants along the ability distribution. The standard Roy model assumes migration choices based only on income maximization, while migrants in our framework maximize utility, which is a function of both income and location. Hence, in addition to the substitution effect, which unambiguously makes a stay in the host country more attractive for high ability migrants, in our model selection of return migrants is also determined by an income effect that leads migrants with a preference for the home country to demand more time at home the higher their income.
} 
have steeper earnings profiles because they invest more in host country human capital (due to longer migration expectations), also staying longer on average.

To investigate the implications of our model for the estimation of immigrants' earnings profiles, consider a simplified (relative to our model) earnings equation

$$
y_{i t}=\alpha_{i}+\beta x_{i t}+\alpha_{H} H_{i t}+\varepsilon_{i t}
$$

where $(\log )$ earnings $y_{i t}$ are a linear function of unobserved productivity $\alpha_{i}$, observed experience $x_{i t}$, host country human capital $H_{i t}$ which is typically unobserved, and an unobserved transitory component $\varepsilon_{i t}$, independent of $\alpha_{i}, x_{i t}$, and $H_{i t}$. In this illustration, we focus on continuously employed individuals, so that $x_{i t}$ also reflects the total time an immigrant has spent in the country. Taking expectations conditional on observed experience and location $L_{i t}=I$ yields

$$
E\left[y_{i t} \mid x_{i t}, L_{i t}=I\right]=\beta x_{i t}+E\left[\alpha_{i} \mid x_{i t}, L_{i t}=I\right]+E\left[\alpha_{H} H_{i t} \mid x_{i t}, L_{i t}=I\right]
$$

Equation (13) reveals the two potential sources of bias. First, out-migration depends on unobserved productivity $\alpha_{i}$, with selection being positive or negative depending on whether the income or substitution effects dominate (see above), which induces a negative or positive bias in OLS estimates of the returns to experience $\beta$, respectively. Second, those who wish to stay longer accumulate higher levels of host country human capital $H_{i t}$, which induces an upward bias in OLS estimates. See Appendix E for further illustration of these biases.

If unobserved productivity was the only source of selection, simple difference estimation would eliminate the first type of bias. ${ }^{48}$ However, the second source of bias persists and will typically be positive as $E\left[\alpha_{H} \Delta H_{i t} \mid x_{i t}, L_{i t}=I\right]>0$. Eliminating this second bias requires additional information, which in our framework is achieved by explicitly modelling host country

\footnotetext{
48 The approaches by Lubotsky (2007) and $\mathrm{Hu}(2000)$ rely on that assumption.
} 
specific human capital and using repeated information on return intentions. In Appendix E, we quantify the bias affecting returns to host country experience. We show that an OLS estimator leads to a downward bias of up to 30 percent, while a first-difference estimator overestimates the returns by about 10 percent.

\subsection{Reservation and effective wages}

A lower price level in the country of origin implies a higher valuation of accumulated savings by immigrants with a positive probability to return than by natives, who with probability one will consume all their wealth in the host country. Accordingly, as each unit of host country currency buys more units of consumption goods at home than in the host country, spending a higher fraction of earnings at home leads to a higher "effective" real wage in the host country (in terms of average lifetime consumption). As a result, real effective earnings of the population of immigrants, and in particular of those planning to return, are higher than their observed earnings, leading to lower nominal reservation wages. ${ }^{49}$ This effect is reinforced if immigrants have a higher savings rate as a consequence of a preference for consumption in their home country, due to complementarity between consumption and origin country amenities.

We illustrate the heterogeneity in effective earnings of immigrants by simulating and plotting their distributions, separately for the 1970 and 1990 arrival cohorts (Figure 8). ${ }^{50}$ These distributions are truncated at one (corresponding to a permanent migrant, whose effective real wage is equal to his real wage), with means at 1.61 and 1.22 , respectively. One important implication of this is that the temporariness of migrations can lead immigrants to accept wages that are lower

\footnotetext{
${ }^{49}$ In our model, the implicit reservation wage can be backed out as the wage offer that makes an unemployed individual indifferent between accepting a job or remaining unemployed (see equation A3 in the appendix).

${ }^{50} \mathrm{We}$ obtain this distribution by scaling earnings by the fraction of (discounted) lifetime income spent in the home country and by the difference in purchasing power at the time of return.
} 
than those of natives, which may partly explain why immigrants are often seen to work in jobs below their qualification level. ${ }^{51}$

\subsection{Immigration Policies}

The observation that immigrants' economic choices depend on anticipated migration durations has important implications for immigration policies, many of which restrict the period of stay. ${ }^{52}$ The decision of the government about whether to allow a migrant permanent status is often delayed until several years after immigration and made conditional on employment, earnings thresholds, or the attainment of integration targets, such as language proficiency. These schemes not only affect the emigration decision and thus number and types of immigrants, but also their career profiles and longer-term contributions, as they affect human capital investment and return migration choices.

To better understand the implications of such policies, we simulate three policy environments in which immigrants are granted permanent residence only after five years, under different sets of conditions (schemes I-III). We then use our model to understand the effects on immigrants' welfare and their fiscal contribution of each of these policy regimes, accounting for selection of who immigrates and who returns to the home country. ${ }^{53}$

\footnotetext{
${ }^{51}$ Reservation wages will also be lower if immigrants have lower disutility of work. Our model features this mechanism in that migrants with a low preference for the host country also have a lower disutility from working in the host country than in their home country.

${ }^{52}$ These policies include schemes like the U.S. H1-B visa. Similar programs are in place in Canada and other traditional immigration countries like Australia, with its subclass 482 work visa. For details on these and temporary worker schemes in more recent migrant destinations like the Gulf Cooperation Council countries, see Martin (2015). ${ }^{53}$ Policies similar to those we investigate here are in place in various countries. Immigrants to the UK, for instance, can apply for a permanent residence card after five years (https://www.gov.uk/apply-for-a-uk-residence-card/). Similar possibilities exist for non-EU immigrants to Germany (http://www.bamf.de/EN/DasBAMF/Aufgaben/Daueraufenthalt/daueraufenthalt-node.html) and EU15 and EFTA immigrants to Switzerland (http://www.swissinfo.ch/eng/work-permits/29191706).
} 
Under scheme I, a permanent residence permit is awarded only if by year five the immigrant is in work and has attained an earnings threshold. Such a condition applies for instance to Tier 2 visa holders in the UK. ${ }^{54} \mathrm{We}$ assume that the right to stay beyond five years is granted if at that point an individual is in work and achieves earnings of at least $€ 20,000$. Under scheme II, permanent residency is granted only if certain skill requirements, such as language proficiency, are met, a policy that resembles those in place in various countries. ${ }^{55} \mathrm{We}$ assume that immigrants are required to achieve at least the $30^{\text {th }}$ percentile of their cohort's host country human capital distribution. Under scheme III, permanent residency is granted after five years with no additional requirements, but only to a fraction of each arrival cohort. This reflects the uncertainty faced by immigrants where the hosting country does not commit ex ante to allowing permanent residence, as is often the case for refugees. In our simulation below we assume that a permanent residence permit is issued with a 30 percent probability and does not depend on individual characteristics and choices. We consider the impacts of these policies relative to a baseline where immigrants are given indefinite right to work and remain upon entering the country.

Each of these policies affects immigrants' earnings, welfare, and fiscal contributions, both through selection, and via changes in behavior. All three schemes reduce the expected length of stay, which affects the accumulation of host country human capital negatively. However, by tying permanent residency to individual achievement in schemes I and II, this is counteracted by incentives to invest into human capital for those who expect this to be sufficient to be granted

\footnotetext{
${ }^{54}$ See https://www.gov.uk/settle-in-the-uk/y/you-have-a-work-visa/tier-2-general-visa for details on the requirements for settlement in the UK under this route.

${ }^{55}$ For instance, immigrants applying for settlement in the UK need to pass the so-called "Living in the UK" test, as well as meet English language requirements (https://www.gov.uk/settle-in-the-uk/y/you-have-a-work-visa/tier-2general-visa). Similarly, the German Residence Act of 2004 states that "A foreigner shall be granted the permanent settlement permit provided that [...] he or she has a sufficient command of the German language, ..." (Bundesministerium der Justiz und für Verbraucherschutz, 2017).
} 
permanent status. One major difference between scheme II, which conditions residence on sufficient investment in host country human capital, and scheme I, which grants permanence to immigrants who pass an earnings threshold, is that the former favors immigrants with a high preference for the host country and strong investment in host country human capital, while the latter favors high productivity immigrants. These groups differ in their economic behavior even after permanent residence has been granted. Moreover, such policies also affect the expected returns to emigrating in the first place for different groups of individuals, and thus immigrant selection. Subtle differences in immigration policies will therefore have lasting impacts on the composition and behavior of immigrant populations. ${ }^{56}$

Comparing Policy Schemes. - To illustrate and compare the impact different policy schemes have on behavior and selection, we consider here a cohort of individuals who at age 25 choose to migrate to Germany during the period of the guest-worker program, and whose right to stay permanently is determined five years after arrival.

The first column in panel (a) of Table 6 shows mean annual earnings (in Euros) during all years a migrant is in the host country, taxes paid, and annual consumption expenditure for the baseline scenario with no restrictions imposed. Under scheme I (second column), immigrants who do not pass the earnings threshold are forced to leave the country after 5 years. This policy selects high productivity migrants, resulting in average annual earnings gains among the resident migrant population of $€ 1,964$ if benchmarked against the baseline scenario, and an increase in tax payments of $€ 642$ ( $€ 515$ in income taxes and $€ 127$ in VAT).${ }^{57}$ However, the policy also affects return

\footnotetext{
${ }^{56}$ For an analysis of integration policies aimed at eliminating barriers to occupational entry for permanent migrants, see the recent paper by Lessem and Sanders (2020).

${ }^{57}$ Our approximation of the earnings tax schedule is described in Appendix B.1. For VAT we use the standard rate of $11 \%$ that was in place in 1970 , when immigrants in this simulation exercise arrive.
} 
migration, with a higher fraction of migrants leaving within five years (either voluntarily in anticipation that a permanent stay is unlikely, or involuntarily, see panel b), so that the changes in column 2 are driven both by composition effects and behavioral adjustment. Moreover, since the restriction imposed by this policy induces voluntary returns and leads to temporarily unemployed individuals leaving, overall tax contributions per capita of the initial immigrant cohort are reduced by $€ 1,460$ per annum. ${ }^{58}$

Next, consider scheme II, which grants a permanent residence conditional on meeting a host country human capital requirement. Since immigration generally is biased towards individuals with a high preference towards the host country, who after migration are more willing to invest in host country human capital, such a policy deters only a small proportion of individuals from migrating. This policy further increases the investment incentive for immigrants who in the absence of the policy would have chosen to stay beyond five years, but would have invested less than the required threshold, thus generating a positive effect on earnings, consumption, and taxes paid per capita, with an average annual tax gain of $€ 789$ (see column 3 ). This policy leads to a tax loss of $€ 651$ per capita (across all arriving immigrants) due to individuals leaving the host country earlier than under the baseline scenario.

The last column of Table 6 shows the effect of Scheme III, introducing uncertainty about being granted permanence at a future date, where we assume that individuals are randomly declined permanence with a $30 \%$ probability after five years. As the possibility of having to leave after five years reduces the expected return to investments in host country specific human capital, this decreases average annual earnings over the life cycle by $€ 1,941$, leading to lower consumption expenditures, as well as to a reduction in fiscal contributions, with an average annual decline in

\footnotetext{
${ }^{58}$ Whether this leads to an overall fiscal gain or loss depends on transfers and welfare payments to immigrants.
} 
taxes of $€ 633$ per immigrant. Accounting for those who are induced to out-migrate due to uncertainty or forced to leave in year five, this increases to $€ 1,921$.

Panel $b$ shows that each of these schemes has a strong effect on migration durations, with between $21 \%$ and $34 \%$ of immigrants leaving voluntarily within the first five years, in anticipation of potentially being forced to leave. Moreover, these policies also influence the composition and number of newly arriving immigrants. Whereas scheme II - which favors immigrants with a strong preference for the destination - only has a small effect on total immigration, schemes I and III reduce immigration by about 25 percent (see row "Reduction in Immigration"). In addition, policies such as the ones studied here will affect not only the overall inflow, but also the composition of those who emigrate in terms of unobserved preferences and productivity. This can be seen by comparing the effects on welfare of different types of immigrants contrasted to the baseline scenario (last four rows of panel (b)). For instance, lifetime welfare for high preference immigrants is substantially reduced under schemes I and III, while scheme II is relatively more attractive for this type.

\section{Conclusion}

An immigrant's decision to leave the host country before the end of one's productive life is an aspect of migration as fundamental as the initial migration decision itself. Yet although the decision to emigrate has been studied extensively, far less is known about immigrants' decisions to return migrate, and how this affects other aspects of behavior well before the return date.

In this paper, we develop a framework that models this decision in a context of uncertainty, and where individuals can revise their migration plans over the migration cycle. We show that return plans are an important source of heterogeneity in immigrants' earnings and career profiles, 
and an essential driver for a type of selective outmigration that is unrelated to unobserved ability, with important implications, among others for the estimation of immigrants' earnings equations. Return plans also affect immigrants' reservation wages, thereby explaining why many immigrants are willing to take jobs for wages unacceptable to natives. Moreover, the relation between immigrants' career paths and the expected migration duration implies that migration policies that introduce restrictive conditions for permanent residency not only affect immigrants' careers and contribution to the host country, but also selection of those who out-migrate, and the composition of new arrivals.

By emphasizing the interplay between immigrants' return plans and their decisions and choices over the migration cycle, this paper highlights novel aspects for the evaluation of immigrant selection, the determinants of their earnings paths, and the way policies impact on immigrant welfare and on host country populations. The issues we raise in this paper have important implications for the evaluation of welfare effects of immigration, and for the design of migration policies.

\section{References}

Albert, Christoph, and Joan Monras. 2018. "Immigration and Spatial Equilibrium: The Role of Expenditures in the Country of Origin." CEPR Discussion Paper 14842.

Amior, Michael. 2017. "The Impact of Migration in a Monopsonistic Labor Market: Theoretical Insights." Unpublished Manuscript.

Arcidiacono, Peter, V. Joseph Hotz, Arnaud Maurel, and Teresa Romano. 2017. "Ex Ante Returns to Occupational Choice." Unpublished Manuscript.

Auerbach, Alan J., and Philip Oreopoulos. 1999. "Analyzing the Fiscal Impact of U.S. Immigration." American Economic Review 89.2: 176-180.

Bandiera, Oriana, Imran Rasul, and Martina Viarengo. 2013. "The making of modern America: migratory flows in the age of mass migration." Journal of Development Economics 102: 23-47. 
Barth, Erling, Bernt Bratsberg, and Oddbjørn Raaum. 2004. "Identifying Earnings Assimilation of Immigrants under Changing Macroeconomic Conditions." Scandinavian Journal of Economics, 106(1): 1-22.

Bellemare, Charles. 2007. "A Life-Cycle Model of Outmigration and Economic Assimilation of Immigrants in Germany." European Economic Review, 51(3): 553-76.

Belzil, Christian, Arnaud Maurel, and Modibo Sidibé. 2017. "Estimating the Value of Higher Education Financial Aid: Evidence from a Field Experiment." Unpublished Manuscript.

Ben-Porath, Yoram. 1967. "The Production of Human Capital and the Life Cycle of Earnings." Journal of Political Economy, 75(4): 352-65.

Borjas, George J. 1985. "Assimilation, Changes in Cohort Quality, and the Earnings of Immigrants." Journal of Labor Economics, 3(4): 463-89.

Borjas, George J. 1987. "Self-selection and the Earnings of Immigrants." American Economic Review, 77(4): 531-553.

Borjas, George J., and Bernt Bratsberg 1996. "Who Leaves? The Emigration of the ForeignBorn." Review of Economics and Statistics, 78(1): 165-67.

Bratsberg, Bernt, Erling Barth, and Oddbjørn Raaum. 2006. "Local Unemployment and the Relative Wages of Immigrants: Evidence from the Current Population Surveys." Review of Economics and Statistics, 88(2): 243-63.

Bratsberg, Bernt, Oddbjørn Raaum, and Knut Røed. 2017. "Immigrant labour market integration across admission classes." Nordic Economic Policy Review, 17-54.

Bratsberg, Bernt, James F. Ragan, and Zafar M. Nasir. 2002. "The Effect of Naturalization on Wage Growth: A Panel Study of Young Male Immigrants." Journal of Labor Economics, 20(3): 568-597.

Buchinsky, Moshe, Chemi Gotlibovski, and Osnat Lifshitz. 2014. "Residential Location, Work Location, and Labor Market Outcomes of Immigrants in Israel." Econometrica, 82(3): 9951054.

Bundesbank. 2013. "Time series BBDP1.A.DE.N.VPI.C.A00000.I10.L: Consumer Price Index - Germany". Available at http://www.bundesbank.de/.

Bundesministerium der Justiz und für Verbraucherschutz. 2017. "Aufenthaltsgesetz in der Fassung der Bekanntmachung vom 25. Februar 2008 (BGB1. I S. 162), das zuletzt durch Artikel 10 Absatz 4 des Gesetzes vom 30. Oktober 2017 (BGBl. I S. 3618) geändert worden ist". Available at www.gesetze-im-internet.de/aufenthg_2004/index.html.

Chiswick, Barry. 1978. "The Effect of Americanization on the Earnings of Foreign-Born Men.” Journal of Political Economy, 86(5): 897-921.

Colussi, Aldo. 2003. "Migrants' Networks: An Estimable Model of Illegal Mexican Migration." University of Pennsylvania Job Market Paper, Philadelphia, PA.

Cortes, Kalena E. 2004. "Are Refugees Different from Economic Immigrants? Some Empirical Evidence on the Heterogeneity of Immigrant Groups in the United States." Review of Economics and Statistics, 86(2): 465-80. 
Damas de Matos, Ana, and Daniel Parent. 2019. "Canada and High-Skill Emigration to the United States: Way Station or Farm System?” Journal of Labor Economics, 37(S2): S491-S532.

Docquier, Frédéric, B. Lindsay Lowell, and Abdeslam Marfouk. 2009. "A Gendered Assessment of Highly Skilled Emigration." Population and Development Review, 35(2): 297321.

Dostie, Benoit, Jiang Li, David Card, and Daniel Parent. 2020. "Employer Policies and the Immigrant-Native Earnings Gap" National Bureau of Economic Research Working Paper No. 27096.

Dustmann, Christian, and Joseph-Simon Görlach. 2015. "Selective Out-Migration and the Estimation of Immigrants' Earnings Profiles." In The Handbook of the Economics of International Migration, Vol. 1A, ed. Barry R. Chiswick and Paul W. Miller, 489-533. Amsterdam: North Holland.

Dustmann, Christian, and Joseph-Simon Görlach. 2016. "The Economics of Temporary Migrations." Journal of Economic Literature, 54(1): 98-136.

Dustmann, Christian, and Oliver Kirchkamp. 2002. "The optimal migration duration and activity choice after re-migration." Journal of Development Economics, 67(2): 351-372.

Dustmann, Christian, and Yoram Weiss. 2007. "Return Migration: Theory and Empirical Evidence from the UK." British Journal of Industrial Relations, 45(2): 236-256.

Eckstein, Zvi, and Yoram Weiss. 2004. "On the Wage Growth of Immigrants: Israel, 19902000." Journal of the European Economic Association, 2(4): 665-95.

Eckstein, Zvi, and Kenneth I. Wolpin. 1989. "Dynamic Labour Force Participation of Married Women and Endogenous Work Experience." Review of Economic Studies, 56(3): 375-390.

Engdahl, Mattias. 2014. "Naturalizations and the economic and social integration of immigrants." IFAU Working Paper 2014:11.

European Commission. 2015. "Economic and Financial Affairs: AMECO Database". Available at http://ec.europa.eu/economy_finance/ameco/user/serie/ResultSerie.cfm

Friedberg, Rachel M. 1992. "The Labor Market Assimilation of Immigrants in the United States: The Role of Age at Arrival." Brown University Working Paper, Providence, RI.

Friedberg, Rachel M. 2000. "You Can't Take It with You? Immigrant Assimilation and the Portability of Human Capital.” Journal of Labor Economics, 18(2): 221-251.

Gathmann, Christina, and Nicolas Keller. 2018. "Access to Citizenship and the Economic Assimilation of Immigrants.” Economic Journal, 128(616), 3141-3181.

Gathmann, Christina, and Uta Schönberg. 2010. "How General is Human Capital? A TaskBased Approach.” Journal of Labor Econonomics, 28(1), 1-50.

Gayle, George-Levi, Limor Golan, and Robert A. Miller. 2012. "Gender Differences in Executive Compensation and Job Mobility." Journal of Labor Economics, 30(4), 829-872.

Gayle, George-Levi, Limor Golan, and Robert A. Miller. 2015. "Promotion, Turnover, and Compensation in the Executive Labor Market." Econometrica, 83(6), 2293-2369. 
Gourieroux, Christian, Alain Monfort, and Eric Renault. 1993. "Indirect Inference." Journal of Applied Econometrics, 8 (Supplement: Special Issue on Econometric Inference Using Simulation Techniques): S85-S118.

Green, David A., and Christopher Worswick. 2012. "Immigrant earnings profiles in the presence of human capital investment: Measuring cohort and macro effects." Labour Economics, 19(2): 241-259.

Haan, Peter, and Victoria Prowse. 2017. "Optimal Social Assistance and Unemployment Insurance in a Life-Cycle Model of Family Labor Supply and Savings." Unpublished Manuscript.

Hönekopp, Elmar. 1987. "Rückkehrförderung und Rückkehr ausländischer Arbeitnehmer." Beiträge zur Arbeitsmarkt- und Berufsforschung 114: 287-366.

Holzmann, Robert, Johannes Koettl, and Taras Chernetsky. 2005. "Portability Regimes of Pension and Health Care Benefits for International Migrants: An Analysis of Issues and Good Practices." The World Bank Social Protection Discussion Paper Series No. 0519.

$\mathrm{Hu}$, Luojia, and Christopher Taber. 2011. "Displacement, Asymmetric Information, and Heterogeneous Human Capital.” Journal of Labor Economics, 29(1), 113-152.

Hu, Wei-Yin. 2000. "Immigrant Earnings Assimilation: Estimates from Longitudinal Data." American Economic Review, 90(2): 368-72.

Hunn, Katrin. 2005. Nächstes Jahr kehren wir zurück: die Geschichte der türkischen 'Gastarbeiter'in der Bundesrepublik. Göttingen: Wallstein Verlag.

Imai, Susumu, and Michael P. Keane. 2004. "Intertemporal Labor Supply and Human Capital Accumulation." International Economic Review, 45(2): 601-41.

Infratest Sozialforschung. 2011. "SOEP 1984 - Erhebungsinstrumente 1984 (Welle 1) des Sozio-oekonomischen Panels. SOEP Survey Paper 8: Series A. Berlin DIW/SOEP.

Jayachandran, Seema, and Adriana Lleras-Muney. 2009. "Life Expectancy and Human Capital Investments: Evidence from Maternal Mortality Declines." Quarterly Journal of Economics, 124(1): 349-397.

Keane, Michael P., and Kenneth I. Wolpin. 1997. "The Career Decisions of Young Men." Journal of Political Economy, 105(3), 473-522.

Kennan, John, and James Walker. 2011. "The Effect of Expected Income on Individual Migration Decisions.” Econometrica, 79(1): 211-251.

Kirdar, Murat G. 2012. "Estimating the Impact of Immigrants on the Host Country Social System when Return Migration Is an Endogenous Choice." International Economic Review, 53(2): 453-86.

Kovak, Brian and Rebecca Lessem, 2020. "How do U.S. visa policies affect unauthorized immigration?" Journal of Monetary Economics, forthcoming.

Lessem, Rebecca. 2018. "Mexico-U.S. Immigration: Effects of Wages and Border Enforcement." Review of Economic Studies, 85(4): 2353-2388.

Lessem, Rebecca, and Carl Sanders. 2020. "Immigrant Wage Growth in the United States: The Role of Occupational Upgrading.” International Economic Review, 61: 941-972. 
Longva, Pål, and Oddbjørn Raaum. 2003. "Earnings assimilation of immigrants in Norway A reappraisal." Journal of Population Economics, 16(1): 177-193.

Llull, Joan. 2017. "Immigration, Wages, and Education: A Labour Market Equilibrium Structural Model”, The Review of Economic Studies, 85(3): 1852-1896.

Llull, Joan. 2018. "Selective Immigration Policies and the U.S. Labor Market." Unpublished Manuscript.

Llull, Joan, and Robert A. Miller. 2018. "Internal Migration and Work Experience in Dual Labor Markets." Unpublished Manuscript.

Lubotsky, Darren. 2007. "Chutes or Ladders? A Longitudinal Analysis of Immigrant Earnings." Journal of Political Economy, 115(5): 820-67.

Magnac, Thierry, Jean-Marc Robin, and Michael Visser. 1995. "Analyzing Incomplete Individual Employment Histories using Indirect Inference." Journal of Applied Econometrics, 10, S153-S169.

Martin, Philip L., and Mark J. Miller. 1980. "Guestworkers: Lessons from Western Europe.” Industrial and Labor Relations Review 33(3): 315-330.

Martin, Philip. 2002. "Germany: Managing Migration in the $21^{\text {st }}$ Century." Comparative Immigration and Integration Program Working Paper.

Martin, Philip. 2015. "Guest or Temporary Foreign Worker Programs." In The Handbook of the Economics of International Migration, Vol. 1A, ed. Barry R. Chiswick and Paul W. Miller, 717-773. Amsterdam: North Holland.

Morten, Melanie. 2019. "Temporary Migration and Endogenous Risk Sharing in Village India." Journal of Political Economy, 127(1), 1-46.

Nakajima, Kayuna. 2015. "The Fiscal Impact of Border Tightening." University of WisconsinMadison Job Market Paper, Madison, WI.

Organisation for Economic Cooperation and Development (OECD). 2008. International Migration Outlook 2008. Paris: OECD Publishing.

Organisation for Economic Cooperation and Development (OECD). 2011. Pensions at a Glance. Paris: OECD Publishing.

Organisation for Economic Cooperation and Development (OECD). 2013. OECD.Stat Web Browser. http://stats.oecd.org/

Oswald, Florian. 2019. "The Effect of Homeownership on the Option Value of Regional Migration." Quantitative Economics, 10(4): 1453-1493.

Piyapromdee, Suphanit. 2017. "The Impact of Immigration on Wages, Internal Migration and Welfare." PIER Discussion Paper No. 69.

Reinhold, Steffen, and Kevin Thom. 2013. "Migration Experience and Earnings in the Mexican Labor Market.” Journal of Human Resources, 48(3): 768-820.

Rendon, Silvio, and Alfredo Cuecuecha. 2010. "International Job Search: Mexicans In and Out of the U.S." Review of Economics of the Household, 8(1): 53-82. 
Sanders, Carl, and Christopher Taber. 2012. "Life-Cycle Wage Growth and Heterogeneous Human Capital." Annual Review of Economics, 4(1), 399-425.

Storesletten, Kjetil. 2000. "Sustaining Fiscal Policy Through Immigration." Journal of Political Economy 108.2: 300-323.

Storesletten, Kjetil. 2003. "Fiscal implications of immigration-A net present value calculation." Scandinavian Journal of Economics, 105(3): 487-506.

Tansel, Aysit, and H. Mehmet Taşçı. 2010. "Hazard Analysis of Unemployment Duration by Gender in a Developing Country: The Case of Turkey." Labour, 24(4): 501-30.

Thom, Kevin. 2010. "Repeated Circular Migration: Theory and Evidence from Undocumented Migrants." Mimeo, New York University.

Todd, Petra E., and Kenneth I. Wolpin. 2006. "Assessing the Impact of a School Subsidy Program in Mexico: Using a Social Experiment to Validate a Dynamic Behavioral Model of Child Schooling and Fertility." American Economic Review, 96(5): 1384-1417.

TurkStat. 2006. "Structure of Earnings Survey". Available at http://www.turkstat.gov.tr/PreTablo.do?alt_id=1008

Van der Klaauw, Wilbert. 2012. "On the Use of Expectations Data in Estimating Structural Dynamic Choice Models." Journal of Labor Economics, 30(3): 521-54.

Van der Klaauw, Wilbert, and Kenneth I. Wolpin. 2008. "Social Security and the Retirement and Savings Behavior of Low-Income Households." Journal of Econometrics, 145(1): 21-42.

World Bank. 2014. World Development Indicators, Washington, D.C. 


\section{Appendix (For Online Publication)}

\section{A. Data Description}

The estimates of our model parameters are based on sample moments from several data sources, most notably from the German micro-census (GMC) and from the German Socio-Economic Panel (SOEP). We reduce heterogeneity along dimensions not modeled by restricting the sample to males without tertiary education, who were born in Turkey and aged 16 or older at immigration, and who arrived in Germany after 1961. The GMC provides information on employment and earnings, ${ }^{59}$ and the representativeness of its samples allows a construction of synthetic cohorts that are informative about the rate of out-migration (see Dustmann and Weiss, 2007). The SOEP provides longitudinal data on accumulated work experience, separately prior and post immigration, as well as savings and integration outcomes (spoken and written language knowledge, the tendency to read German language newspapers, and attachment to the host country). Importantly, the SOEP asks for migration plans, i.e. whether an individual plans to stay or (and when) to return. The exact wording (in respondents' preferred language) of the question is as follows: "How long do you want to live in Germany? [1] I want to return within the next 12 months [2] I want to stay several more years in Germany number of years

[3] I want to remain in Germany permanently "(Infratest Sozialforschung, 2011).

To identify latent host country specific human capital in our model, we use the evolution of a number of observed outcomes reported in the SOEP that reflect the level of host country specific human capital an individual has accumulated. These include spoken and written language knowledge, the tendency to read host country newspapers, and respondents' sense of belonging to the host country. Figure A1 illustrates how these indicators increase with time spent in the host country.

We augment these individual level data sources with macroeconomic information and data that describe the conditions individuals face in Turkey if they choose to return. In particular, we use individual level data from a survey conducted by the German Institute for Employment

\footnotetext{
${ }^{59}$ In the GMC, earnings are reported in brackets, and we assign individuals an earnings level equal to the mid-point of their respective bracket. This is not a problem for our estimation, as we categorize simulated earnings into exactly the same brackets and construct the same earnings measure for the simulated moments (see the description of our estimation strategy below). The GMC reports net earnings. To account for this, we apply the tax schedule described in Appendix B.1 to the simulated sample.
} 
Research (IAB) in Turkey among former migrants to Germany to identify individuals' earnings function after a return to Turkey (see Hönekopp, 1987). To capture the evolution of earnings in Turkey relative to German earnings levels, we use time series on nominal compensation per employee in the two countries, provided by the European Commission (2015), and gross national income from the World Development Indicators (World Bank, 2014). ${ }^{60}$ To obtain a better measure of earnings for the particular group of non-tertiary educated male workers to which we restrict our micro-samples, we scale the macro time series using median gross labor income for male workers without a tertiary education in Turkey, information that is provided by the Turkish statistical office (TurkStat 2006) for 2006.

All monetary variables are adjusted to 2005 euros using consumer price indices from the Bundesbank (2013). The relative price levels individuals face in Turkey and thus the rate at which accumulated assets are converted are taken from the OECD (2013). ${ }^{61} \mathrm{We}$ allow for different interest rates in Germany and Turkey. Real interest rates are computed using nominal interest and inflation rate series, taken from the OECD (2013) and the World Bank's (2014) World Development Indicators. ${ }^{62}$ Finally, we obtain unemployment rates and unemployment durations in Turkey from Tansel and Taşçı (2010).

\section{B Model Description}

\section{B.1 Specification Details}

Earnings conversion factor, interest rates and relative price levels. To account for the diverging macro trends between Germany and Turkey that affect immigrants' return decisions, we model behavior of immigrants who arrive at different points in time. To account for this in the estimation, we simulate choices and outcomes of immigrants arriving in 1970 and 1990 . These individuals face different macroeconomic conditions that we obtain directly from the data. In the model, all macroeconomic variables (relative earnings in Turkey, relative price levels and interest rates in the

\footnotetext{
${ }^{60}$ The European Commission's AMECO database provides series of average nominal compensation per employee for both Germany and Turkey back to 1988. To extrapolate to earlier relative earnings levels in Turkey, we use gross national income from the World Bank's (2014) World Development Indicators.

${ }^{61}$ Relative price levels are based on the ratio of purchasing power parities for actual individual consumption and nominal exchange rates, each taken from the OECD's statistical database at http://stats.oecd.org/.

${ }^{62} \mathrm{We}$ use short-term annual interest rates from the OECD's statistical data base (http://stats.oecd.org/) for Germany. Since the same measure is not available for Turkey, we use the deposit rate series from the World Bank's (2014) World Development Indicators.
} 
two locations) are based on the series described in the previous sub-section, and are predicted using second order polynomials of time, as we detail below.

Earnings in Turkey are based on the IAB's Return Migrant Survey, and in the model simulation predicted as $\log y_{i t}=\rho_{t}+7.64+1.82 \alpha_{i}+0.0279 X_{i t}^{p}-0.475 \cdot 10^{-3}\left(X^{p}\right)_{i t}^{2}$, where the conversion factor $\rho_{t}$ accounts for macroeconomic convergence between the origin and destination countries. This factor varies over time as predicted by a second order polynomial of years $t$ since $1970\left(\rho_{t}=0.034+7.267 \cdot 10^{-3} t-3.054 \cdot 10^{-5} t^{2}\right)$. Relative price levels and thus the rate $x_{t}$ at which assets are converted if an individual returns to Turkey are predicted as $x_{t}=$ $0.328-3.759 \cdot 10^{-3} t+2.732 \cdot 10^{-4} t^{2}$, where again $t$ measures the years since 1970 and the coefficients are estimated using the time series described in the previous sub-section. Similarly, using the series of nominal interest and inflation rates from the World Bank's (2014) World Development Indicators and the OECD previously described, we approximate the real interest rates in Germany and Turkey, respectively, as $r_{t}^{I}=-9.826 \cdot 10^{-3}+6.885 \cdot 10^{-6} t-1.019$. $10^{-7} t^{2}$ and $r_{t}^{E}=1.178 \cdot 10^{-3}-3.820 \cdot 10^{-5} t+7.247 \cdot 10^{-6} t^{2}$.

Benefits and earnings tax schedules. In the model, unemployment benefits in Germany are defined as a proportion of predicted earnings had the individual been working. ${ }^{63}$ The prediction is based on earnings equation (6a) and the individual's current state variables (excluding the transitory shock $\varepsilon_{i t}^{I}$ ). To account for the non-linearity of benefit schedules, the benefit ratio (denoted $b r$ below) is itself a function of earnings. To calibrate this function, we first compute the ratio of mean benefits and mean earnings for each individual with at least one benefit and one employment spell in the SOEP. We then fit a third order polynomial in log earnings to these benefit ratios, converted by the standard normal cdf (denoted $\Phi(\cdot)$ ). The latter ensures that predicted benefit ratios are bounded between zero and one. This yields the benefit ratio $\operatorname{br}\left(y_{i t}\right)=\Phi\left(1.801 \cdot 10^{3}-0.538\right.$. $\left.10^{3} \log y_{i t}+53.659\left(\log y_{i t}\right)^{2}-1.783\left(\log y_{i t}\right)^{3}\right)$. In Turkey, during most of the period of our analysis, no unemployment insurance was in place, so we set $\operatorname{br}\left(y_{i t}\right)=0 .{ }^{64}$

\footnotetext{
${ }^{63}$ Previous earnings, on which unemployment benefits are based in practice, are not a state variable in our model. We thus use earnings predicted by an individual's current state variables as the closest approximation.

${ }^{64}$ It was introduced only in 2002 , but at a fairly low replacement ratio of $9 \%$.
} 
To calibrate the function net $(\cdot)$ for Germany, we assume that the individual is married. ${ }^{65}$ The tax schedule also depends on the number of children, although the differences in taxation with respect to this variable are small. Fitting a third order polynomial in $\log y_{i t}$ to the tax schedule that we bound by the standard normal cdf yields net earnings equal to net $\left(y_{i t}\right)=y_{i t}(1-$ $\left.\Phi\left(-544.388+149.517 \log y_{i t}-13.741\left(\log y_{i t}\right)^{2}+0.422\left(\log y_{i t}\right)^{3}\right)\right) .^{66}$

In our model, an individual receives retirement benefits from age 65 until the end of life, which are a function of earnings levels in the two locations and the experience the individual has accumulated. Because in the model we keep track only of effective experience (a composite of the years individuals have been working in the emigration and immigration countries), we need to approximate the fraction of experience that has been accumulated in the two locations. To compute pension entitlements in the immigration country, we assume that an individual has worked for a total of 40 years by the time of retirement. Hence, denoting experience accumulated in the emigration and the immigration country by $X^{E}$ and $X^{I}$, respectively, and dropping subscripts for ease of notation, we have $X=\xi X^{E}+X^{I}$ and $X^{E}+X^{I}=40$. Together, these imply that the fraction of experience accumulated in the emigration country amounts to $\frac{X^{E}}{40}=1-\frac{\frac{X}{40}-\xi}{1-\xi}$, while that in the immigration country equals $\frac{X^{I}}{40}=\frac{\frac{X}{40}-\xi}{1-\xi}$. We assume a replacement ratio of 0.5 that is applied to the weighted average of an individual's earnings potential in the two locations at age $64,{ }^{67}$ where the weights are given by the fraction of experience accumulated in either location. This yields retirement benefits in Germany equal to $y_{R}^{I}=0.5\left[\left(\frac{\frac{X}{40}-\xi}{1-\xi}\right) y_{64}^{I}+\left(1-\left(\frac{\frac{X}{40}-\xi}{1-\xi}\right)\right) y_{64}^{E}\right]$, where we denote the earnings potentials ${ }^{68}$ in the immigration country and the emigration country at age 64 by $y_{64}^{I}$ and $y_{64}^{E}$, respectively. Bilateral agreements between Germany and Turkey ensure that returning migrants can repatriate pension entitlements (Holzmann et al., 2005). Retirement benefits individuals receive from the Turkish pension system after a return to Turkey depend on

\footnotetext{
${ }^{65}$ In our SOEP sample, 83.2 percent of respondents are married.

66 The authors' own calculations based on the German tax schedule in 1999 (earliest year available on http://www.parmentier.de/steuer/incometax.htm), differences to other years are small.

${ }^{67}$ In our SOEP sample, the average ratio of retirement benefits to earnings at ages 60-64 is 0.51.

${ }^{68}$ As with unemployment benefits, retirement benefits are based on previous earnings. Since these are not a state variable in our model, we use earnings predicted by an individual's current state variables as the closest approximation.
} 
the time spent abroad. Since total duration in the host country is not a state variable in the model that we keep track of once an individual returns, we need a similar approximation to compute retirement benefits in the home country. We do this by computing the average fraction of working life spent in the host country by arrival cohort and age at immigration, both of which are ex-ante determined, constant state variables in our model and observed in the SOEP. We then assign individuals retiring in Turkey a weighted average of benefits in Germany and benefits in Turkey, with the weights given by the fraction of their working life spent in Germany.

\section{B.2 Dynamic Specification of the Model}

We now describe in more detail the dynamic choices of individual immigrants, explained in the main text in Section 3.1 (equation 11) in terms of the generic Bellman equation:

$$
V\left(\Omega_{i t}\right)=\max _{c_{i t}, \mathbb{M}_{i t}^{H}, \mathbb{I}_{i t}^{\text {work }, \mathbb{I}_{i t}^{I}}} u\left(c_{i t}, \mathbb{I}_{i t}^{\mathrm{H}}, \mathbb{I}_{i t}^{I}, \mathbb{I}_{i t}^{\text {work }} ; \Omega_{i t}\right)+\beta E_{t} V\left(\Omega_{i t+1}\right)
$$

This Bellman equation can be decomposed into a sequence of choices involving conditional value functions conditioned on employment status and the decision of whether or not to return to the home country. We make the distinction between being in work and being unemployed because individuals face different choice sets. Individuals who are unemployed can accept a job if they are offered one. Individuals who are working may be fired but cannot choose to be unemployed. Similarly, the return to the home country is an absorbing state in that we do not allow (nor observe) individuals to come back to Germany. Hence, these conditional value functions explicitly model constraints that are only implicit in (A1).

We begin with the value functions for those who have decided to stay in the immigration country. The value of working is expressed as

$$
\begin{aligned}
V_{W}^{I}\left(\Omega_{i t}\right)= & \max _{c_{i t}, \mathbb{I}_{i t}^{H}} u\left(c_{i t}, \mathbb{I}_{i t}^{\mathrm{H}}, \mathbb{I}_{i t}^{I}=1, \mathbb{I}_{i t}^{\text {work }}=1 ; \Omega_{i t}\right) \\
& +\beta E_{t}\left[\left(1-\delta^{I}\left(\Omega_{i t+1}\right)\right) \tilde{V}_{W}^{I}\left(\Omega_{i t+1}\right)+\delta^{I}\left(\Omega_{i t+1}\right) \tilde{V}_{U}^{I}\left(\Omega_{i t+1}\right)\right],
\end{aligned}
$$

where $\tilde{V}_{W}^{I}\left(\Omega_{i t}\right)$ and $\tilde{V}_{U}^{I}\left(\Omega_{i t}\right)$ denote the value functions of working and unemployment prior to deciding where to locate (defined below). The individual faces a probability $\delta^{I}\left(\Omega_{i t+1}\right)$ of being fired, in which case he starts the next period as unemployed. Individuals who are currently unemployed make choices according to the following Bellman equation: 


$$
\begin{aligned}
V_{U}^{I}\left(\Omega_{i t}\right)= & \max _{c_{i t}, \mathbb{I}_{i t}^{H}} u\left(c_{i t}, \mathbb{I}_{i t}^{H}, \mathbb{I}_{i t}^{I}=1, \mathbb{I}_{i t}^{\text {work }}=0 ; \Omega_{i t}\right) \\
& +\beta E_{t}\left[\begin{array}{c}
\lambda^{I}\left(\Omega_{i t+1}\right) \max \left\{\tilde{V}_{U}\left(\Omega_{i t+1}\right), \tilde{V}_{W}\left(\Omega_{i t+1}\right)\right\} \\
+\left(1-\lambda^{I}\left(\Omega_{i t+1}\right)\right) \tilde{V}_{U}\left(\Omega_{i t+1}\right)
\end{array}\right],
\end{aligned}
$$

where $\lambda^{I}\left(\Omega_{i t+1}\right)$ is the probability of a job offer. When offered a job, individuals decide whether or not to accept it, depending in particular on the realization of the income shock $\varepsilon_{i t+1}$ (see equation 6a).

For those who decide to return to the home country and who work at home, the consumption decision is

$$
\begin{aligned}
V_{W}^{E}\left(\Omega_{i t}\right)= & \max _{c_{i t}} u\left(c_{i t}, \mathbb{I}_{i t}^{H}=0, \mathbb{I}_{i t}^{I}=0, \mathbb{I}_{i t}^{w o r k}=1 ; \Omega_{i t}\right) \\
& +\beta E_{t}\left[\left(1-\delta^{E}\left(\Omega_{i t+1}\right)\right) V_{W}^{E}\left(\Omega_{i t+1}\right)+\delta^{E}\left(\Omega_{i t+1}\right) V_{U}^{E}\left(\Omega_{i t+1}\right)\right] .
\end{aligned}
$$

For those who do not work at home, the respective Bellman equation is:

$$
\begin{gathered}
V_{U}^{E}\left(\Omega_{i t}\right)=\max _{c_{i t}} u\left(c_{i t}, \mathbb{I}_{i t}^{H}=0, \mathbb{I}_{i t}^{I}=0, \mathbb{I}_{i t}^{w o r k}=0 ; \Omega_{i t}\right) \\
+\beta E_{t}\left[\begin{array}{c}
\lambda^{E}\left(\Omega_{i t+1}\right) \max \left\{V_{U}^{E}\left(\Omega_{i t+1}\right), V_{W}^{E}\left(\Omega_{i t+1}\right)\right\} \\
+\left(1-\lambda^{E}\left(\Omega_{i t+1}\right)\right) V_{U}^{E}\left(\Omega_{i t+1}\right)
\end{array}\right] .
\end{gathered}
$$

Finally, individuals in the immigration country make every period a location decision by comparing the value of staying an additional year abroad, defined in (A2) and (A3), with the value of returning to the home country, defined in (A4) and (A5):

$$
\tilde{V}_{l}^{I}\left(\Omega_{i t}\right)=\max \left\{V_{l}^{I}\left(\Omega_{i t}\right), V_{U}^{E}\left(\Omega_{i t}\right)\right\}, \quad l=U, W .
$$

\section{B.3 Simulating Planned Migration Durations}

The estimation relies on matching moments predicted by the model to moments observed in the data. To use moments involving intended durations, we need to construct the model counterpart of this observed outcome. The basic idea is as follows. In our model, the probability of returning in a given period has a closed form solution, which given the assumed extreme value distribution of preference shocks $\eta$ takes a logistic form involving the value functions defined in (11). To determine the conditional probabilities of returning in all future periods, we simulate $S$ future paths 
for shocks to earnings, employment, and preferences, and determine the optimal consumption, labor supply, and investment in host country specific human capital for each individual and each of the $S$ paths in the simulated sample. Each of these paths for every individual determines a future probability of returning to the home country, conditional on the current state vector, and allow us to construct the density of future return dates. This density is again conditional on the simulated individual's current state vector. We then define the median of the distribution of return dates as equivalent to the intention stated by an individual at a given time and observed by us in the data. We opt for the median because it produces a more robust measure of intentions than does the mean, which is sensitive to outliers. If individuals' intended age at return exceeds age 64, we assume they intend to stay forever.

More formally, the intended length of stay $\varsigma$ given the state $\Omega_{i t}$ at time $t$ is $\varsigma\left(\Omega_{i t}\right)=m_{i t}$ such that $\sum_{s=1}^{S} \mathbf{1}\left[\sum_{j=0}^{65-a g e_{i t}} j \mathbb{I}_{S}\left[\right.\right.$ return at $\left.\left.t+j \mid \Omega_{i t}\right] \leq m_{i t}\right] \in\left[\frac{S}{2}, \frac{s+1}{2}\right]$, where at time $t$, $\mathbb{I}_{S}\left[\right.$ return at $\left.t+j \mid \Omega_{i t}\right]$ indicates whether simulation $s$ predicts that the migrant will return at time $t+j$ given current state variables, and at the end of working life $\mathbb{I}_{S}\left[\right.$ return at $\left.65 \mid \Omega_{i t}\right]=1$ regardless whether the individual returns. This formula allows us to have a theoretical counterpart to the stated return intentions that we observe for each individual in our data. ${ }^{69}$

\section{Model Simulation, Choice of Moments and Model Fit}

Estimation requires that the outcomes predicted by the model are simulated under rules following as closely as possible the ones under which the samples observed in our datasets are generated. In our context, the following issues need to be accounted for: (1) Immigrants in our samples have arrived at different points in time, thus facing different macroeconomic conditions. (2) Immigrants arrive at different ages. ${ }^{70}$ (3) Some individuals have accumulated work experience in the origin country prior to migration. (4) A small fraction of immigrants in our sample who migrated between the ages 16 and 18 also have accumulated some work experience in the destination country. (5)

\footnotetext{
${ }^{69}$ We simulate $S=25$ paths of future shocks per individual. Because the simulation of intentions is computationally intensive, we do it only for individuals aged 25 and 35 rather than simulating intentions at every point in time. We choose these relatively young ages because it is at this life stage that most host country specific human capital investment takes place and many immigrants in our sample arrive. Considering intentions at two points in time is sufficient to allow us to construct dynamic moments involving intentions.

${ }^{70}$ As explained in Section 2.1, we restrict the empirical samples to immigrants who have arrived at ages 16 or older.
} 
Individuals enter the survey populations at different stages of their life-cycle (conditional on being in Germany). (6) Panel data typically exhibit some degree of attrition. While in our context an important source of attrition is return migration, which we model explicitly, we cannot exclude that there is attrition for other reasons.

To deal with these points, we use the joint empirical distribution of individuals' arrival cohort, age at immigration, home country experience, host country experience accumulated between ages 16 and 18, the age individuals are first surveyed and the age when they are last surveyed in the SOEP. We then draw an initial value for arrival cohort, age at immigration, home and host country experience from this distribution, and use the model to simulate outcomes in later periods. Finally, we draw from the above joint distribution the ages at which individuals are observed. We then construct the simulated moments used in the estimation based on simulated observation points corresponding to these ages. This ensures the selection in the simulated sample closely follows that in the data. In Table A1, we provide a complete description of the moments used to estimate the model. As a weighting matrix, we use the inverse of the diagonal matrix of the standard deviations of the moments. This matrix puts more weight on moments that are measured more precisely in the data, such as labor market outcomes.

To analyze the mapping of parameters into the moments used in the estimation, we numerically compute the gradient matrix of the moment vector with respect to the parameter vector. A necessary condition for identification is that for each parameter there are one or more moments with a non-zero gradient, and that there is no collinearity between gradient vectors for different parameters. Figure A2 illustrates this gradient matrix graphically. Darker shades indicate a larger response of a predicted moment to a change in a particular parameter. As there are no rows that are white throughout, there exists at least one identifying moment for each parameter, and in fact all parameters are identified by more than one moment.

Consider for instance the topmost parameter, which is the intercept $\lambda_{0}$ of the linear index determining the rate at which job offers arrive. This parameter most directly relates to the intercept in the auxiliary regression of transitions into employment on a spline in age. This moment is displayed as the sixth column in the graph, corresponding to the first column of the second set of moments, which contains the coefficients from precisely this auxiliary regression. However, all other moments are indirectly affected by the probability of finding a job too, most strongly 
moments relating to agents' outmigration (moment set $\mathrm{H}$ ) and saving choices (moment set J). Other parameters are identified from only specific subsets of the moment vector. In particular, the parameters of the factor model for observed integration measures (detailed in Section 3.1) only determine how latent host country specific human capital maps into observed integration outcomes, but these parameters do not determine agents' behavior. Hence, only moments that directly involve integration information are sensitive to those parameters. Figure A2 shows this, as only moment sets $\mathrm{D}, \mathrm{G}$ and $\mathrm{K}$ are affected by changes in parameters from the factor model (second to last set of parameters on the vertical axis). The effort cost of investing in host country specific human capital is parameterized by an intercept (row 29) and a slope coefficient on age (row 30). As the intercept is low relative to the age dependent part of the effort cost (see the estimates for $e_{0}$ and $e_{1}$ in Table 5), moments are more sensitive to the latter. Hence, whereas the slope coefficient has an effect on all moments, the intercept affects only a relative small set of moments related to savings decisions. Note, however, that this is sufficient for identification of both parameters.

In what follows, we describe the sources of identification for the model's parameters.

Earnings. Information contained in regressions of earnings on a set of explanatory variables contributes to the identification of the parameters in equation (6a). Specifically, we regress earnings observed in the SOEP and earnings simulated by the model on the same sets of observed and simulated variables, including work experiences in the host- and home country (prior to emigration) and integration measures (oral and written skills in German, feeling German, reading of German newspapers). These moments inform on the model parameters in equation (6a) and in $f_{y}\left(X_{i t}\right)$, the return to experience accumulated in the origin country prior to immigration $\xi$, and the coefficient on host country specific human capital $\alpha_{H}$.

Employment Transitions. We identify parameters governing employment transitions $\delta^{I}$ and $\lambda^{I}$ in equations (8) and (9) by using as moments coefficients from auxiliary regressions of observed transition in and out of work on a spline in age, actual work experience and the same integration measures as in the earnings equation discussed above. The latter allows the identification of the effect of latent host country specific human capital on employment transitions.

Utility. Preference parameters $\phi_{\mathrm{c}}$ and $\phi_{H}$ are identified from observed choices. In particular, the exponent on consumption $\phi_{\mathrm{c}}$ is identified from the observed level of annual saving by individuals 
with different earnings and employment status. The exponent on host country specific human capital $\phi_{H}$ determines how savings choices differ for individuals with different levels of $H_{i t}$, and is identified by linking saving choices to return intentions. The age specific effort cost $e\left(a g e_{i t}\right)$ of investing in $H_{i t}$ is identified from the age profiles of integration measures, conditional on age at migration. As previously discussed, persistence in the relative preference for the host country, $\Psi_{i t}$, is identified from autocorrelation in individuals' planned migration durations. The level of $\Psi_{i t}$, on the other hand, is identified from the distribution of migration durations.

We list the full set of moments used for identifying the parameters of our model in Table A1. Some parameters have to be normalized because they are only identified up to scale and location. We normalize the initial level of the host country specific human capital to zero for the 1970 arrival cohort and set the effect of $H_{i t}$ on oral language knowledge in the factor model to one.

Tables A2-A10 show the goodness of fit with respect to the full set of moments used in the estimation, whereas Figure A3 summarizes this fit graphically.

As an additional test for the model's validity, we investigate whether the model is able to predict the effect of changes in relative price levels on savings, a moment that is not targeted in our estimation. The effect of relative price levels on savings is relevant in our context: The relative price level in Turkey determines the purchasing power of assets accumulated in Germany but spent in Turkey, and thus is an important determinant of economic migrants' choices. Table A10 compares the coefficient from a regression of annual savings on relative price levels observed in the data to that predicted by the model. The model's prediction is well within the confidence intervals of the data moments. ${ }^{71}$

\section{Simulation of Counterfactual Migration Policies}

In considering counterfactual migration policies, the policy environment not only affects selective return migration and other migrant behaviors, but also which migrants immigrate in the first place. We now explain how we take account of selection of who immigrates in the simulation of these policies.

${ }^{71}$ This is similar to the approach by Todd and Wolpin (2006). 
The model in Section 3 predicts - conditional on productivity, location preferences and other state variables - the values individuals attribute to being respectively in the emigration country and the immigration country, $V^{E}\left(\Omega_{i t}\right)$ and $V^{I}\left(\Omega_{i t}\right)$. We subsume the value individuals derive from moving to an alternative destination in the rest of the world by $V^{R O W}$, and assume that individuals face a utility cost $C$ of emigrating from $E$. We first describe identification of a constant cost of migration, before describing how we let this cost vary across emigrant cohorts.

In an initial period $t=0$, an agent's problem in the emigration country is

$$
\max \left\{V^{E}\left(\Omega_{i 0}\right)+\eta_{i 0}^{E} ; V^{I}\left(\Omega_{i 0}\right)+\eta_{i 0}^{I}-C, V^{R O W}+\eta_{i 0}^{R O W}-C\right\} .
$$

The model predicts for each unobserved individual type an emigration rate conditional on $C$, $V^{R O W}$ and the variance of the preference shocks $\eta$, which is governed by a spread parameter $\tau$. Under the assumption that the preference shocks $\eta_{i 0}^{E}, \eta_{i 0}^{I}$ and $\eta_{i 0}^{R O W}$ are type I extreme value distributed, this probability takes the logistic form

$$
\operatorname{Prob}(\text { migrate to } I)=\frac{\exp \left(\frac{V^{I}\left(\Omega_{i 0}\right)-C}{\tau}\right)}{\exp \left(\frac{V^{E}\left(\Omega_{i 0}\right)}{\tau}\right)+\exp \left(\frac{V^{I}\left(\Omega_{i 0}\right)-C}{\tau}\right)+\exp \left(\frac{V^{R O W}-C}{\tau}\right)}, \text { (A7) }
$$

where $\Omega_{i 0}$ includes individual $i$ 's unobserved type (productivity $\alpha_{i}$ and initial location preference $\Psi_{i 0}$ ), as well as observed state variables. Focusing on migrants to location $I$ and of a given type, we can also write this probability as:

$$
\operatorname{Prob}(\text { migrate to } I \mid C, \text { type })=\frac{M_{\text {type }}(C)}{T_{\text {type }}},
$$

where $M_{\text {type }}$ denotes the number of migrants to $I$ of a given type, whereas $T_{\text {type }}$ is the total number of individuals of that type in the emigration country population.

While the share $\omega_{\text {type }}^{T} \equiv \frac{T_{\text {type }}}{T}$ of each unobserved type in the emigration country's population $T \equiv \sum_{\text {type }} T_{\text {type }}$ is not readily observed, data on aggregate migration rates $\frac{M}{T}$ to $I$ allow identification of these shares under the model, as well as identification of the implied migration 
$\operatorname{cost} C$, as we explain below. The distribution of unobserved types in the migrant population is implied by our estimates. ${ }^{72}$ Denote the share for each type by $\omega_{\text {type }}^{M} \equiv \frac{M_{\text {type }}}{M}$.

Then the total Turkish population can be written as

$$
T \equiv \sum_{\text {type }} T_{\text {type }}=\sum_{\text {type }} \frac{M_{\text {type }}}{\operatorname{Prob}(\text { migrate to } I \mid C, \text { type })}=\sum_{\text {type }} \frac{M \omega_{\text {type }}^{M}}{\operatorname{Prob}(\text { migrate to } I \mid C, \text { type })} \text {. }
$$

Since the migration rate in (A7) is a monotonically decreasing function of $C$ for each type, aggregate migration is too. As such, any observed emigration level thus implies a particular value of $C$, with higher migration rates corresponding to lower migration costs. Hence, the observed aggregate migration rate,

$$
\frac{M}{T}=\left(\sum_{\text {type }} \frac{\omega_{\text {type }}^{M}}{\text { Prob }(\text { migrate to } I \mid C, \text { type })}\right)^{-1},
$$

identifies the cost $\hat{C}$ of migrating based on the value function as described above.

This cost implies a fraction of movers $\hat{p}_{\text {type }}=\operatorname{Prob}($ migrate to $I \mid \hat{C}$, type $)$ to $I$ within each type, which in turn allows us to determine the distribution of types in the emigration country's population, since $\frac{\hat{T}_{\text {type }}}{T}=\frac{M \omega_{\text {type }}^{M}}{T \hat{p}_{\text {type }}}$.

The above argument took as given the value $V^{R O W}$ of migrating to an alternative destination, as well as the variance of preference shocks $\eta$, and it assumed a constant $\operatorname{cost} C$ of migration, for which we show identification through the observed migration rate $\frac{M}{T}$ at one point in time. With repeatedly observed migration rates and given that we distinguish in our model different cohorts of migrants, we can estimate the cost of migration and who is selected into migration at different points in time, and hence for different cohorts of immigrants. Year-to-year fluctuations during the two decades 1970-1990 furthermore identify the spread parameter $\tau$ of the distribution from which transitory shocks $\eta$ are drawn. We compute annual emigration rates for this period from German

\footnotetext{
${ }^{72}$ For the immigrant population, we estimate the points of support for unobserved productivity $\alpha_{i}$ and location preference $\Psi_{i t}$ (see Tables 3 and 5).
} 
National Statistical Office immigration flow data for Turkish males, and the male population in Turkey from Eurostat.

In practice, we allow for different levels of $C_{t}$ during years in which the guest worker agreement was in place (until 1973) and later years. Besides the sharp drop in emigration after 1973, Turkey has also seen a steep increase in emigration during the political unrest in 1976-1980 that led to the 1980 coup. To match this, we allow for different costs during each of these volatile years. Finally, the value $V^{R O W}$ of migrating elsewhere is identified by matching the observed share for Germany among non-tertiary educated male Turkish emigrants in all OECD countries, with data taken from Docquier et al.(2009). Table A12 lists the calibrated parameters determining the initial immigration decision, with costs denoted in utility. In Figure A6, we show the observed and simulated time series of emigration rates.

Our model also accounts for the effect of changes in macroeconomic conditions on individual migrants' choices. Specifically, variation in earnings and prices in the country of origin relative to the destination country affect the benefits of migration. Figure A7 shows that we are able to match well the relation between relative earnings and price levels in the country of origin on the one hand, and emigration rates on the other, supporting our model's validity for the context considered.

\section{E. Behavioral Selection vs Selection on Ability}

We now quantify the size of the bias arising when estimating log wage equations, resulting from neglecting behavioral selection. Displaying earnings profiles for four types (i.e., high/low productivity, high/low preference at arrival), Figure A8 illustrates the two separate sources of bias, where the vertical axis shows the log wage, and the horizontal axis time since arrival. Each earnings graph is plotted up to the median time of return within each group. Within the groups of immigrants with a low preference for the host country (the two grey lines), the negative ability selection of those who stay longer is reflected by the difference in length and level of the lines. This difference biases OLS estimates of the returns to experience downward in that those who stay longer have a lower earnings profile. Moreover, within ability groups, the difference in earnings growth between high- and low preference individuals (the difference in length and slope between the grey and black profiles) generates an upward bias. This "behavioral" bias is the result of differential investment into host country specific human capital, where those with high preferences 
for the host country invest more in host country human capital leading to steeper earnings profiles, and also stay longer. It is present even when there is no heterogeneity in unobserved productivity between the two groups of individuals. Thus, whereas the bias arising from selection on productivity can be eliminated using a first-differences estimator, the behavioral bias cannot.

We quantify the two types of bias by simulating a sample of immigrants who differ in both ability and preference from our model and applying different estimators. To isolate the ability selection bias, we control in an OLS estimation for latent host country specific human capital, thus conditioning on behavioral selection. Column 1 in Table A13 shows that return migrants selfselecting on ability induces a downward bias in estimated returns to experience of up to 30 percent. Column 2, in turn, displays the upward bias from behavioral selection, which is isolated by eliminating the ability selection bias through estimation in first differences. Immigrants arrive at different ages, implying different costs and incentives to invest in host country specific human capital, as well as different levels of initial experience. To show that this does not drive the results, columns 3 and 4 restrict the estimation to immigrants all arriving at age 25 . We find little impact on the magnitude of estimates, with the behavioral bias still amounting to about 10 percent. 


\section{Figures and Tables}

Figure 1: Outmigration

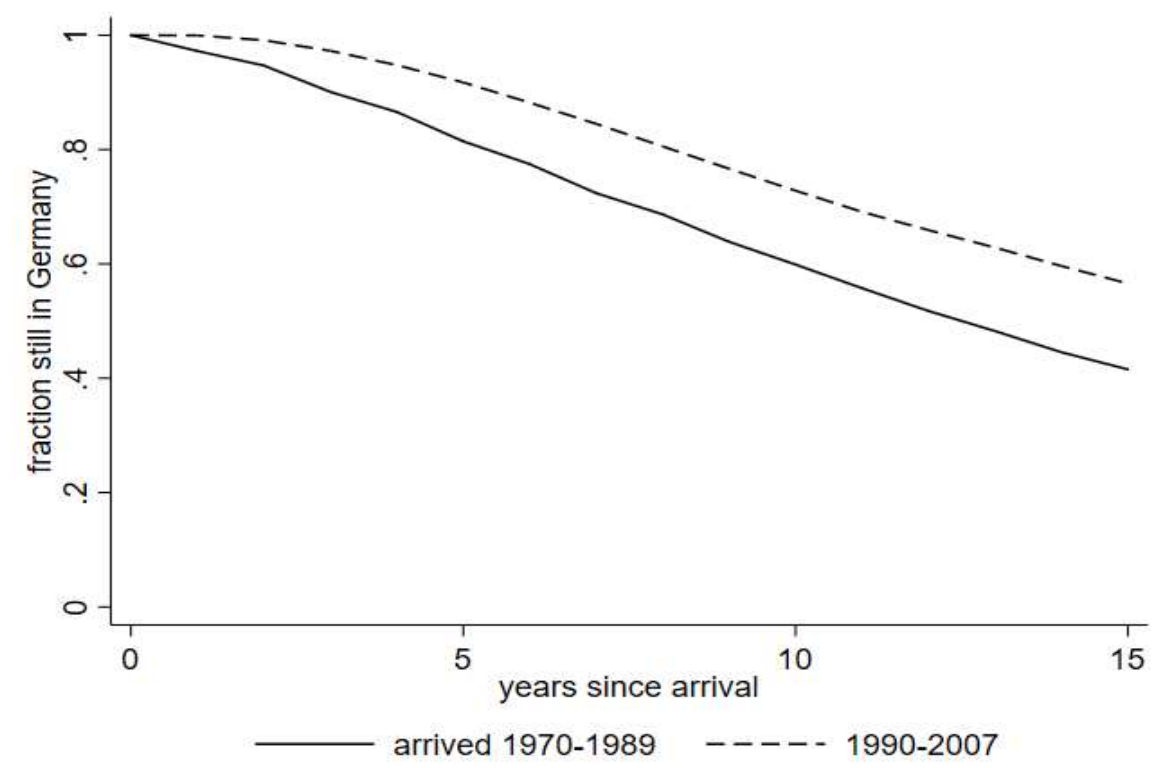

Source: German micro-census 1976-2007.

Note: The graph shows the fraction of initial arrival cohorts still residing in Germany by years since arrival. Synthetic cohorts have been constructed exploiting the representativeness of the micro-census samples and information on the year of arrival. The sample is restricted to non-tertiary educated male immigrants from Turkey who arrive to Germany after 1961 at the age of at least 16 years. 
Figure 2: Perceived and actual migration durations.

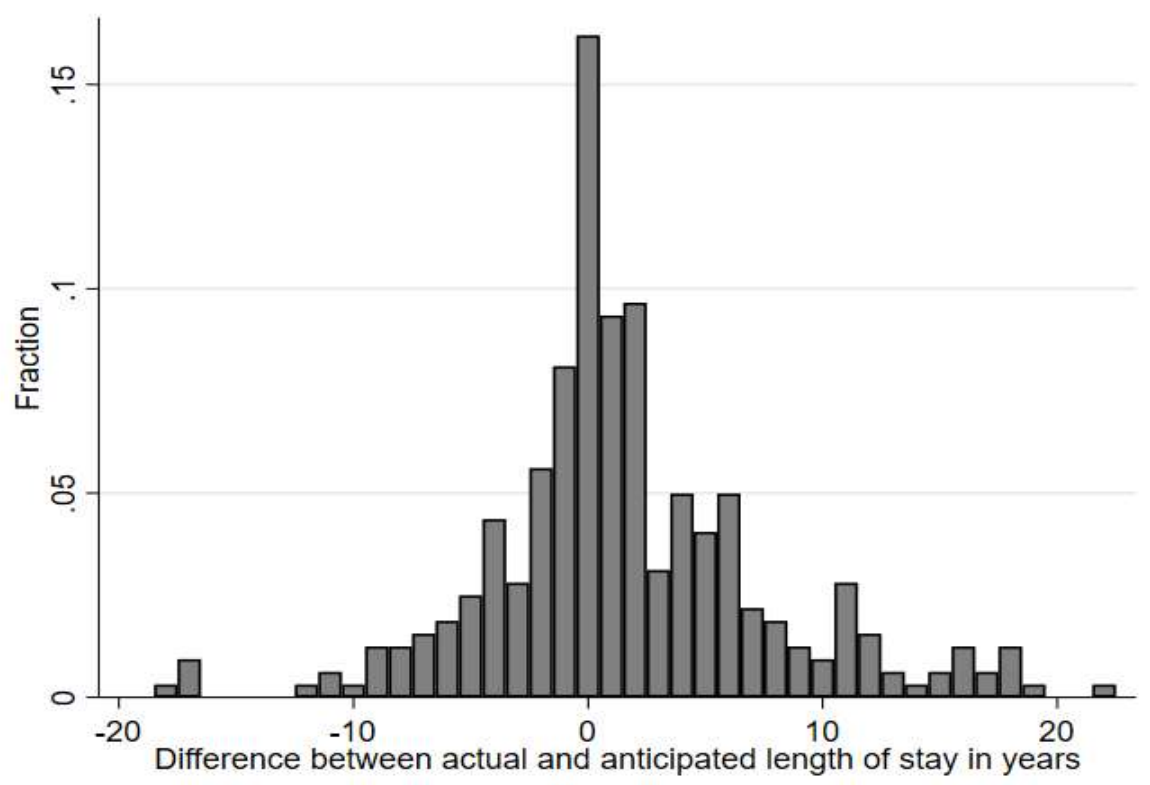

Source: SOEP 1984-2011.

Note: The figure shows the distribution of deviations of actual from anticipated migration durations for immigrants planning to return and who are observed to actually return during the panel period. The sample is further restricted to nontertiary educated male immigrants from Turkey who arrive to Germany after 1961 at the age of at least 16 years. 
Figure 3: Outcomes by intention to stay

\section{(a) Earning and saving profiles}

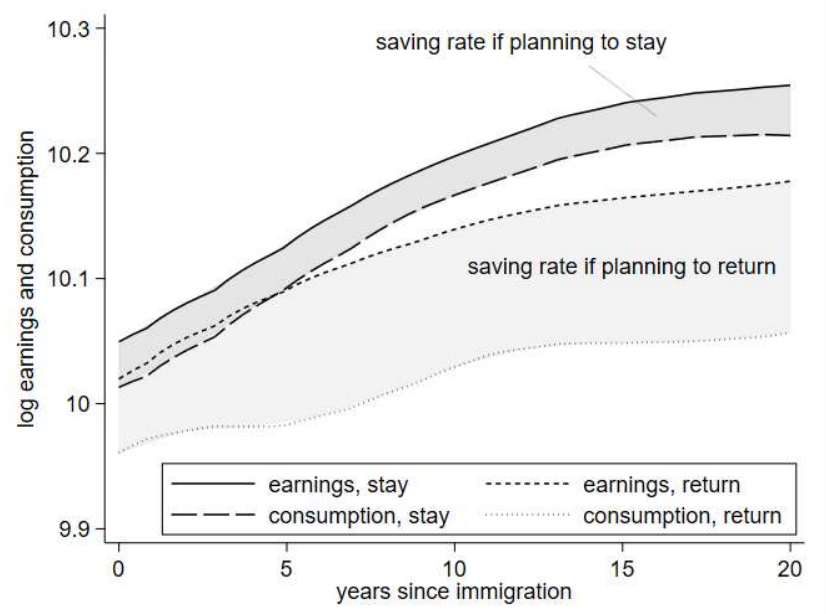

(b) Specific investments

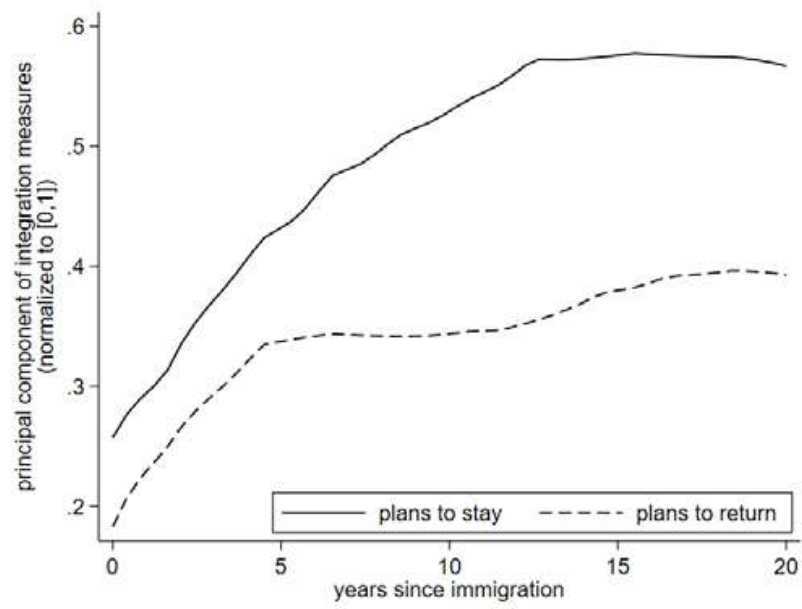

Source: German Socio-economic Panel 1984-2011.

Note: Panel (a) shows log annual earning and consumption profiles by stated return intention. "Stay" indicates observations where individuals report an intention to stay until at least age 65; "return" intentions to return earlier. As the difference between log earnings and log consumption, the shaded areas indicate the approximate saving rates. Panel (b) show the principal component of observed integration measures (spoken and written knowledge of host country language, tendency to read German newspapers, sense of feeling German) by stated return intentions. We first eliminate cohort effects from these outcomes. As information on the various assimilation measures is collected in different waves of the SOEP, we collapse the data by years since immigration and return intention before extracting the principal component. The latter is then normalized to lie between 0 and 1 . The sample is restricted to non-tertiary educated male immigrants from Turkey who arrive to Germany after 1961 at the age of at least 16 years. 
Figure 4: Model fit - Earnings profile
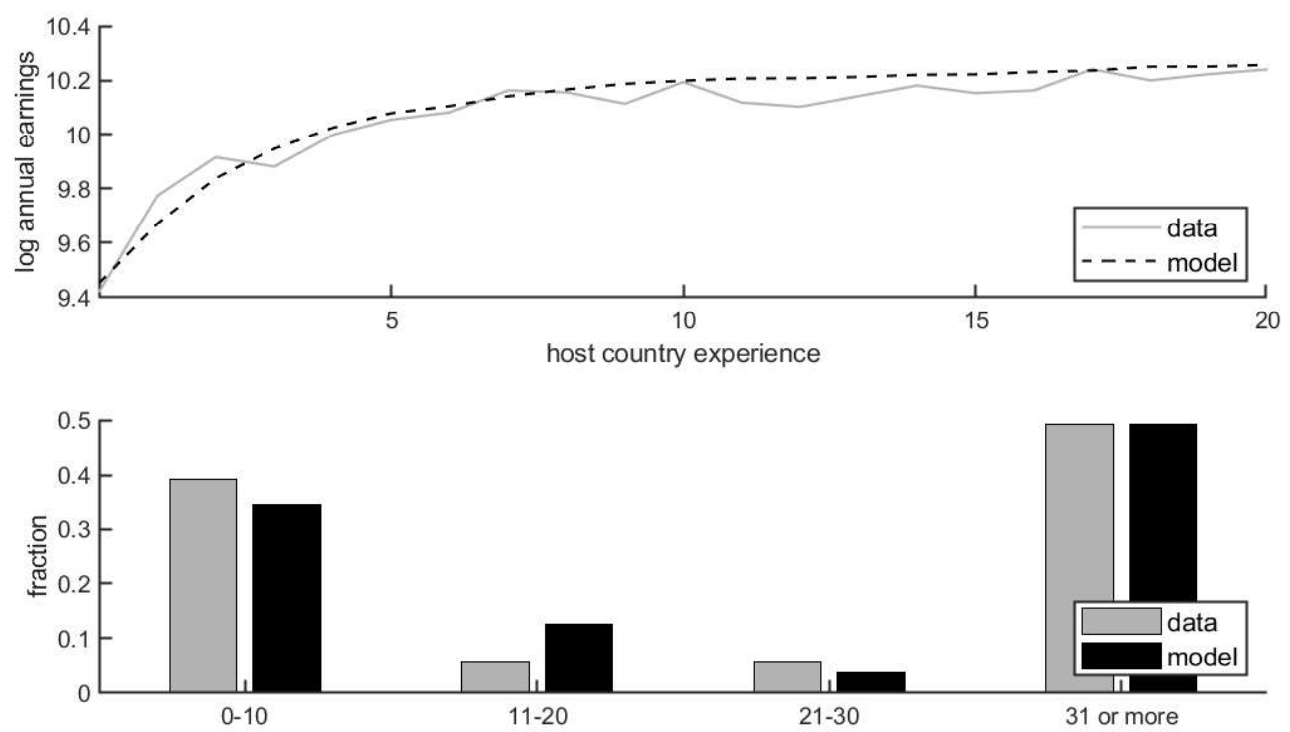

Intended length of stay (until age 65) among new immigrants (less than 10 years in Germany)

Note: Simulated profiles are based on a simulation of 40,000 individuals. Data profiles based on SOEP 19842011. Earnings are denoted in 2005 Euros. For immigrants planning to stay permanently, intended length of stay is computed as time until age 65 .

Figure 5: Model fit - Integration outcomes
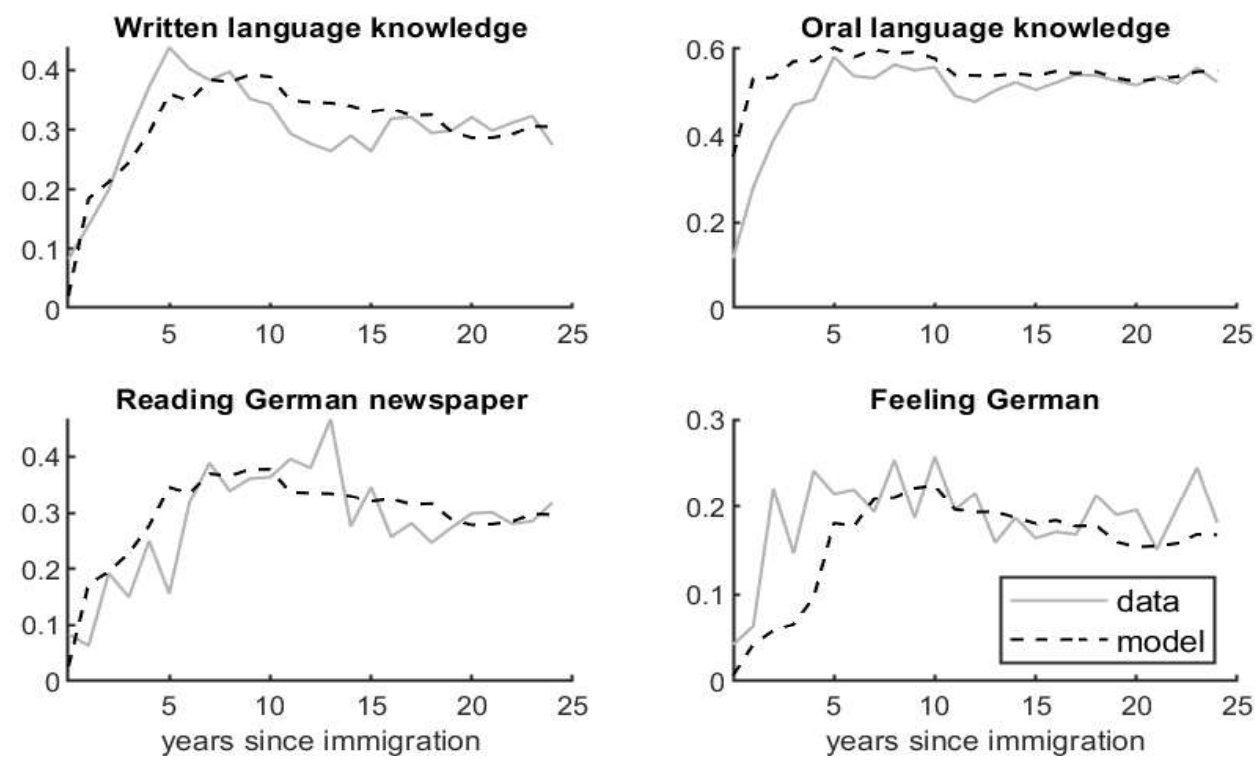

Note: Simulated profiles are based on a simulation of 40,000 individuals. Data profiles based on SOEP 19842011. Integration measures are on a scale from zero to one. 
Figure 6: Survival rates by type

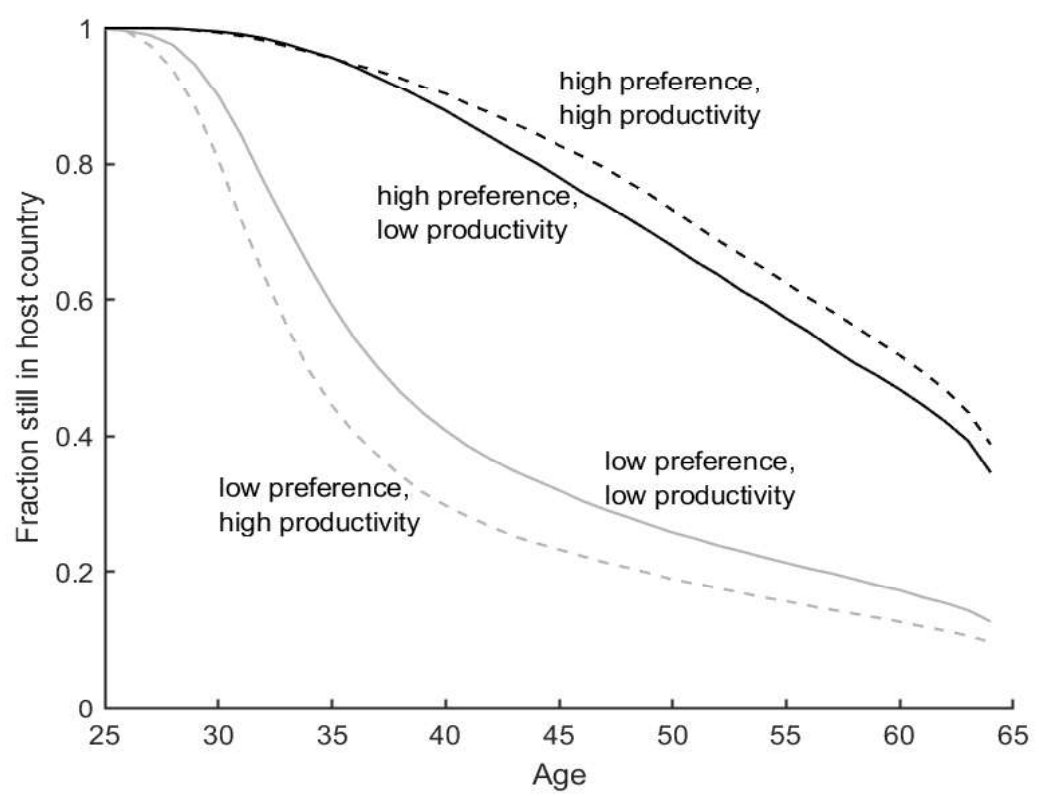

Note: Simulation of 40,000 immigrants who all arrive at age 25 in 1990. The figure displays the fraction of the initial immigrant cohort left in the host country by age and unobserved type. "Low preference" and "high preference" refers to initial preference for the receiving country. "Low productivity" and "high productivity" refers to the time constant unobserved level in log earnings.

\section{Figure 7: Selective return migration}

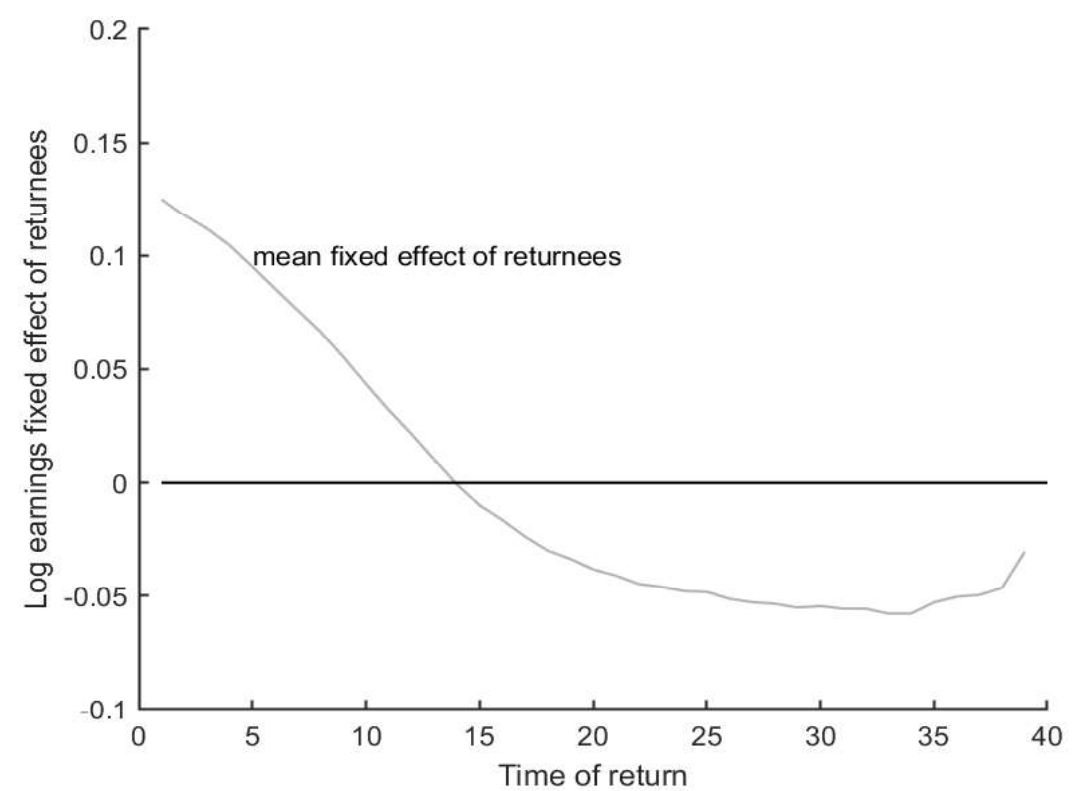

Note: Simulation of 40,000 immigrants who all arrive at age 25 in 1990. The figure shows the average log earnings fixed effect of migrants that return at different points in time. 
Figure 8: Effective wages of temporary migrants

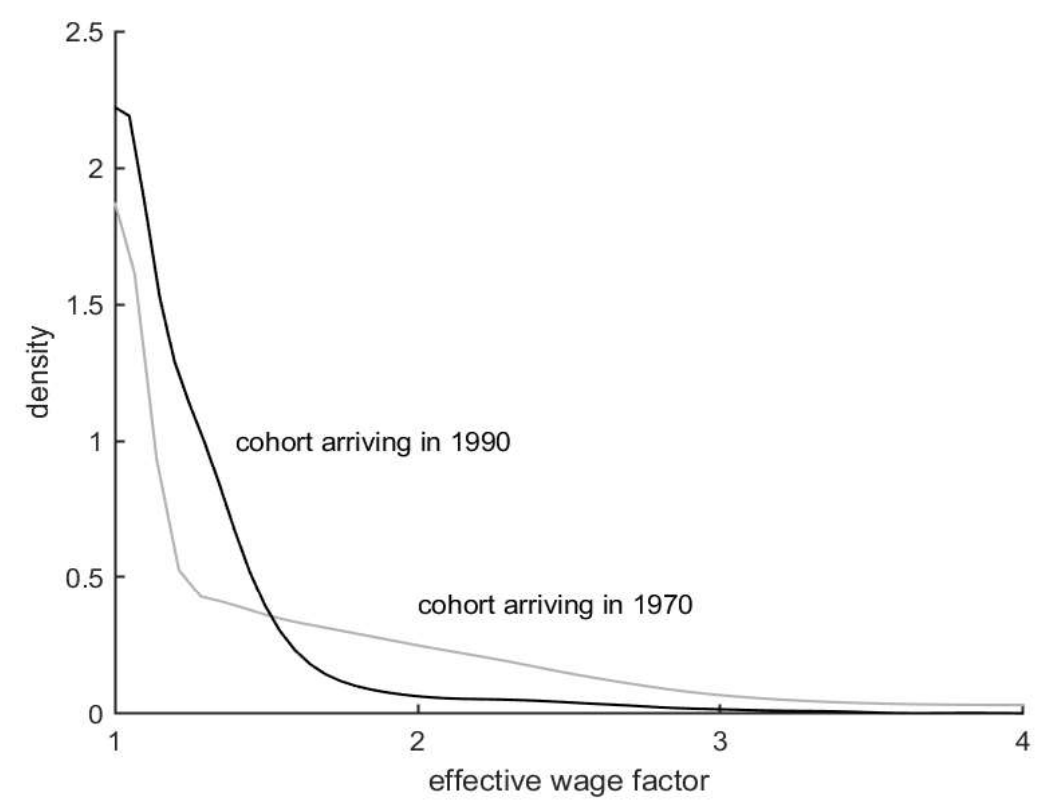

Note: Simulation of 40,000 immigrants who all arrive at age 25 in 1990. The figure shows, for different arrival cohorts, the density of the factor by which effective wages exceed wages paid in the host country if some migrants expect to consume part of their earnings in the country of origin. The difference results from a higher purchasing power of the host country currency in the country of origin. 
Table 1a: Summary Statistics - Socioeconomic Panel

\begin{tabular}{|c|c|c|c|}
\hline Variable & $\begin{array}{c}\text { Stay } \\
(38.95 \%)\end{array}$ & $\begin{array}{c}\text { Return } \\
(61.05 \%)\end{array}$ & $\begin{array}{c}\text { Total } \\
(100 \%) \\
\end{array}$ \\
\hline age & $\begin{array}{c}44.33 \\
(0.297)\end{array}$ & $\begin{array}{c}45.26 \\
(0.210)\end{array}$ & $\begin{array}{c}44.90 \\
(0.173)\end{array}$ \\
\hline years since immigration & $\begin{array}{l}20.33 \\
(0.244)\end{array}$ & $\begin{array}{c}18.46 \\
(0.152)\end{array}$ & $\begin{array}{l}19.17 \\
(0.13)\end{array}$ \\
\hline age at immigration & $\begin{array}{c}24.85 \\
(0.147)\end{array}$ & $\begin{array}{c}27.06 \\
(0.127)\end{array}$ & $\begin{array}{c}26.23 \\
(0.098)\end{array}$ \\
\hline work & $\begin{array}{l}67.1 \% \\
(0.012)\end{array}$ & $\begin{array}{c}76.2 \% \\
(0.009)\end{array}$ & $\begin{array}{l}72.7 \% \\
(0.007)\end{array}$ \\
\hline not working-to-working transition rate & $\begin{array}{c}9.8 \% \\
(0.014)\end{array}$ & $\begin{array}{c}15.4 \% \\
(0.016)\end{array}$ & $\begin{array}{c}12.7 \% \\
(0.011)\end{array}$ \\
\hline working-to-not working transition rate & $\begin{array}{l}7.2 \% \\
(0.008)\end{array}$ & $\begin{array}{c}7.3 \% \\
(0.006)\end{array}$ & $\begin{array}{c}7.3 \% \\
(0.005)\end{array}$ \\
\hline work experience in Turkey & $\begin{array}{c}6.10 \\
(0.145)\end{array}$ & $\begin{array}{c}8.01 \\
(0.132)\end{array}$ & $\begin{array}{c}7.27 \\
(0.010)\end{array}$ \\
\hline work experience in Germany & $\begin{array}{c}17.10 \\
(0.226)\end{array}$ & $\begin{array}{c}16.49 \\
(0.153)\end{array}$ & $\begin{array}{c}16.73 \\
(0.129)\end{array}$ \\
\hline real annual gross earnings & $\begin{array}{c}29,730.08 \\
(438.51)\end{array}$ & $\begin{array}{c}27,501.97 \\
(218.84)\end{array}$ & $\begin{array}{c}28,310.87 \\
(212.53)\end{array}$ \\
\hline annual savings & $\begin{array}{c}1,115.25 \\
(73.90)\end{array}$ & $\begin{array}{l}1,975.69 \\
(134.05)\end{array}$ & $\begin{array}{c}1,532.52 \\
(75.90)\end{array}$ \\
\hline $\begin{array}{l}\text { Oral language knowledge of German, scale from } 0 \text { (none) } \\
\text { to } 1 \text { (very good) }\end{array}$ & $\begin{array}{c}0.57 \\
(0.007)\end{array}$ & $\begin{array}{c}0.51 \\
(0.005)\end{array}$ & $\begin{array}{c}0.53 \\
(0.004)\end{array}$ \\
\hline $\begin{array}{l}\text { Written language knowledge of German, scale from } 0 \\
\text { (none) to } 1 \text { (very good) }\end{array}$ & $\begin{array}{c}0.38 \\
(0.010)\end{array}$ & $\begin{array}{c}0.30 \\
(0.006)\end{array}$ & $\begin{array}{c}0.33 \\
(0.005)\end{array}$ \\
\hline $\begin{array}{l}\text { Reads German newspapers, scale from } 0 \text { (only origin } \\
\text { country newspapers) to } 1 \text { (only German newspapers) }\end{array}$ & $\begin{array}{c}0.37 \\
(0.010)\end{array}$ & $\begin{array}{c}0.26 \\
(0.008)\end{array}$ & $\begin{array}{c}0.31 \\
(0.007)\end{array}$ \\
\hline feels German, scale from 0 (not at all) to 1 (completely) & $\begin{array}{c}0.34 \\
(0.010)\end{array}$ & $\begin{array}{c}0.14 \\
(0.005)\end{array}$ & $\begin{array}{c}0.21 \\
(0.005)\end{array}$ \\
\hline intended length of stay & - & $\begin{array}{c}6.93 \\
(0.117)\end{array}$ & $\begin{array}{c}6.93 \\
(0.117)\end{array}$ \\
\hline fraction who in the following period plan to stay & $\begin{array}{l}74.87 \% \\
(0.012)\end{array}$ & $\begin{array}{l}18.22 \% \\
(0.008)\end{array}$ & $\begin{array}{l}40.44 \% \\
(0.008)\end{array}$ \\
\hline
\end{tabular}

Source: SOEP 1984-2011.

Note: Means of variables by planned migration duration in a given year, with standard errors in parentheses. The sample includes males aged 18-64 without tertiary education and born in Turkey who arrived in Germany after 1961 at the age of 16 or older. Column 1 lists means for observations where individuals report an intention to stay until at least age 65; column 2 for intentions to return earlier. Employment transition rates are the fractions observed to switch working status; earnings and savings are measured in Euros, deflated to 2005; intended length of stay is measured in years. 
Table 1b: Summary Statistics - Micro Census

\begin{tabular}{lccc}
\hline \multicolumn{1}{c}{ Variable } & Mean & Std. Dev. & Obs. \\
age & 42.56 & 9.31 & 48,908 \\
age at arrival & 26.24 & 6.33 & 48,908 \\
years since immigration & 16.32 & 9.54 & 48,908 \\
post 1973 arrival & $43.30 \%$ & 0.50 & 48,908 \\
in work & $72.41 \%$ & 0.45 & 48,908 \\
log(real annual net earnings) & 9.87 & 0.35 & 34,511 \\
\hline Source: Micro Census 1976-2007 & & &
\end{tabular}

Source: Micro Census 1976-2007.

Note: Means of and standard deviations of variables used. The sample includes males aged 18-64 without tertiary education and born in Turkey who arrived in Germany after 1961 at the age of 16 or older. Earnings are calculated based on mid-points of monthly income brackets scaled to annual earnings, deflated to 2005 Euros.

Table 2: Persistence in migration plans

\begin{tabular}{llcc}
\hline Parameter & & \multicolumn{2}{c}{ Estimate } \\
\hline persistent shock stdev & $\left(\sigma_{v}\right)$ & 2.674 & 2.582 \\
& & $(0.530)$ & $(0.540)$ \\
transitory shock stdev & $\left(\sigma_{q}\right)$ & 4.333 & 4.386 \\
& & $(0.328)$ & $(0.322)$ \\
intentions net of year effects & & $\mathrm{X}$ \\
\hline
\end{tabular}

Note: Decomposition of intended length of stay into transitory and persistent shocks, allowing for an individual fixed effect and an age trend. Variance estimates are obtained by GMM, based on moments from the Socio-Economic Panel 19842011. The data sample is restricted to non-tertiary educated male immigrants from Turkey who arrive to Germany after 1961 at the age of at least 16 years. 
Table 3: Estimates - Earnings equation

\begin{tabular}{lccc}
\hline Parameter & & Estimate & Std. err. \\
\hline marginal effect of host country human capital & $\left(\alpha_{H}\right)$ & 0.095 & $(0.009)$ \\
marginal effect of host country experience: & $\left(f_{y}(X)\right)$ & & \\
at up to 2 years $(x 100)$ & & 21.057 & $(1.505)$ \\
at 3-5 years (x100) & & 6.728 & $(0.660)$ \\
at 6-10 years (x100) & & 2.161 & $(0.092)$ \\
at 11-20 years (x100) & & 0.533 & $(0.085)$ \\
at more than 20 years (x100) & $(\xi)$ & 0.045 & $(0.109)$ \\
effectiveness of home country experience & $\left(\alpha_{0}\right)$ & 0.315 & $(0.015)$ \\
intercept & $\left(\alpha_{H}-\alpha_{L}\right)$ & 0.769 & $(0.035)$ \\
difference between high and low productivity & $\left(\sigma_{\epsilon}\right)$ & 0.184 & $(0.060)$ \\
standard deviation of earnings shock & & $0.033)$ \\
\hline
\end{tabular}

Note: Estimates are obtained by indirect inference, based on 40,000 simulations and empirical moments from the Socio-Economic Panel 1984-2011 and the German Microcensus 1976-2007. The data sample is restricted to non-tertiary educated male immigrants from Turkey who arrive to Germany after 1961 at the age of at least 16 years. We weight moment differences by their standard deviation. Host country human capital is measured in standard deviations.

Table 4: Estimates -Employment transitions

\begin{tabular}{lcc}
\hline Parameter & Estimate & Std. err. \\
\hline $\begin{array}{l}\text { Job offer function } \lambda(\Omega) \\
\text { host country human capital }(x 100)\end{array}$ & 4.068 & $(1.427)$ \\
$\begin{array}{l}\text { marginal effect of age: } \\
\text { at age } 20(x 100)\end{array}$ & 0.364 & $(0.149)$ \\
at age $40(x 100)$ & -0.571 & $(0.197)$ \\
at age 60 (x100) & -0.088 & $(1.306)$ \\
annual job offer rate at mean values of state variables $(x 100)$ & 29.989 & $(45.626)$ \\
& & \\
Job loss function $\quad \delta(\Omega)$ & & \\
host country human captial capital (x100) & -1.303 & $(0.010)$ \\
marginal effect of age: & & \\
at age 20 (x100) & 0.061 & $(0.001)$ \\
at age 40 (x100) & 0.087 & $(0.001)$ \\
at age 60 (x100) & 1.941 & $(0.010)$ \\
annual job loss rate at mean values of state variables $(x 100)$ & 3.739 & $(0.022)$ \\
\hline
\end{tabular}

Note: The table shows marginal effects. Estimates are obtained by indirect inference, based on 40,000 simulations and empirical moments from the Socio-Economic Panel 1984-2011 and the German Microcensus 1976-2007. The data sample is restricted to non-tertiary educated male immigrants from Turkey who arrive to Germany after 1961 at the age of at least 16 years. We weight moment differences by their standard deviation. Marginal effects are computed at mean values of all variables. Host country human capital is measured in standard deviations. 
Table 5: Estimates - Utility function

\begin{tabular}{|c|c|c|c|}
\hline \multicolumn{2}{|l|}{ Parameter } & \multirow{2}{*}{$\frac{\text { Estimate }}{0.257}$} & \multirow{2}{*}{$\frac{\text { Std. err. }}{(0.040)}$} \\
\hline consumption exponent & $\left(\phi_{c}\right)$ & & \\
\hline cost of working & $(1-h)$ & 0.836 & $(0.021)$ \\
\hline host country human capital exponent & $\left(\phi_{H}\right)$ & 0.475 & $(0.033)$ \\
\hline relative preference for destination: & $\left(\Psi_{i t}\right)$ & & \\
\hline low preference & & 0.446 & $(0.000)$ \\
\hline high preference & & 9.870 & $(0.177)$ \\
\hline increase in probability of initially high preference by 1990 coh & 00) & 0.865 & $(0.000)$ \\
\hline correlation of preference with productivity & & -0.718 & $(0.000)$ \\
\hline persistence in annual transitions & $\left(\pi_{k k}\right)$ & 0.954 & $(0.001)$ \\
\hline investment effort cost, constant & $\left(e_{0}\right)$ & 1.202 & $(0.000)$ \\
\hline investment effort cost, effect of age & $\left(e_{1}\right)$ & 3.608 & $(0.000)$ \\
\hline increase in host country human capital if investing & $\left(d_{H}\right)$ & 1.071 & $(0.090)$ \\
\hline increase in initial host country human capital by 1990 cohort & $\left(H_{i 0}^{1990}\right)$ & 0.696 & $(0.076)$ \\
\hline
\end{tabular}

Note: Estimates are obtained by indirect inference, based on 40,000 simulations and empirical moments from the Socio-Economic Panel 1984-2011 and the German Microcensus 1976-2007. The data sample is restricted to nontertiary educated male immigrants from Turkey who arrive to Germany after 1961 at the age of at least 16 years. We weight moment differences by their standard deviation. 


\begin{tabular}{|c|c|c|c|c|}
\hline Panel (a) & & \multicolumn{3}{|c|}{ Policy } \\
\hline \multirow[b]{2}{*}{ Outcome } & \multirow[b]{2}{*}{$\begin{array}{l}\text { baseline without } \\
\text { restrictions }\end{array}$} & Scheme I & Scheme II & Scheme III \\
\hline & & $\begin{array}{c}\text { Permit if in work } \\
\text { and earning } \\
\text { above } € 20,000\end{array}$ & $\begin{array}{l}\text { Permit if above } \\
\text { 30th percentile } \\
\text { of host country } \\
\text { human capital }\end{array}$ & $\begin{array}{l}\text { Permission } \\
\text { declined at } \\
\text { random with } \\
30 \% \text { probability }\end{array}$ \\
\hline $\begin{array}{l}\text { Average annual gross earnings during } \\
\text { years spent in the host country }\end{array}$ & $25,142.16$ & $+1,963.99$ & $+2,072.20$ & $-1,940.95$ \\
\hline $\begin{array}{l}\text { Average annual taxes paid by those in } \\
\text { the host country }\end{array}$ & $3,973.86$ & +642.41 & +788.52 & -632.83 \\
\hline earnings tax & $2,106.58$ & +515.02 & +590.75 & -434.54 \\
\hline consumption tax & $1,867.28$ & +127.39 & +197.77 & -198.29 \\
\hline $\begin{array}{l}\text { Change in tax paid per capita among } \\
\text { entire initial arrival cohort (thus } \\
\text { accounting for taxes lost from migrants } \\
\text { leaving) }\end{array}$ & & $-1,460.22$ & -651.11 & $-1,921.16$ \\
\hline $\begin{array}{l}\text { Average annual consumption during } \\
\text { years spent in host country }\end{array}$ & $16,975.29$ & $+1,158.10$ & $+1,797.92$ & $-1,802.64$ \\
\hline \multicolumn{2}{|l|}{ Panel (b) } & \multicolumn{3}{|c|}{ Policy } \\
\hline Outcome & no restrictions & Scheme I & Scheme II & Scheme III \\
\hline Reduction in immigration & - & $-25.29 \%$ & $-3.34 \%$ & $-26.61 \%$ \\
\hline Voluntarily return in first five years & $9.29 \%$ & $21.42 \%$ & $34.35 \%$ & $20.88 \%$ \\
\hline Enforced return in year five & - & $22.64 \%$ & $17.00 \%$ & $24.70 \%$ \\
\hline \multicolumn{5}{|c|}{ Decrease in gain from migration for individuals with: } \\
\hline low preference, low productivity & & $-20.21 \%$ & $-27.10 \%$ & $-10.92 \%$ \\
\hline low preference, high productivity & & $-15.00 \%$ & $-22.02 \%$ & $-8.99 \%$ \\
\hline high preference, low productivity & & $-32.07 \%$ & $-2.72 \%$ & $-24.27 \%$ \\
\hline high preference, high productivity & & $-20.50 \%$ & $-1.55 \%$ & $-26.13 \%$ \\
\hline \multicolumn{5}{|c|}{$\begin{array}{l}\text { Note: Simulations based on } 40,000 \text { individuals per policy regime, who at age } 25 \text { in } 1970 \text { decide to migrate from } \\
\text { Turkey to Germany. The reference is a regime of free duration choice. The table shows the effects of schemes } \\
\text { under which residence permits beyond five years are granted (I) to immigrants surpasing the } 30 \text { th earnings } \\
\text { percentile; (II) to immigrants who at least achieve the } 30 \text { th percentile of host country human capital; and (III) at } \\
\text { random with } 30 \% \text { probability. Taxes include both earnings and consumption taxes. All monetary units are deflated } \\
\text { to } 2005 \text {. Welfare changes are computed for the time of arrival. }\end{array}$} \\
\hline
\end{tabular}




\section{Appendix Figures and Tables}

Figure A1: Evolution of integration measures

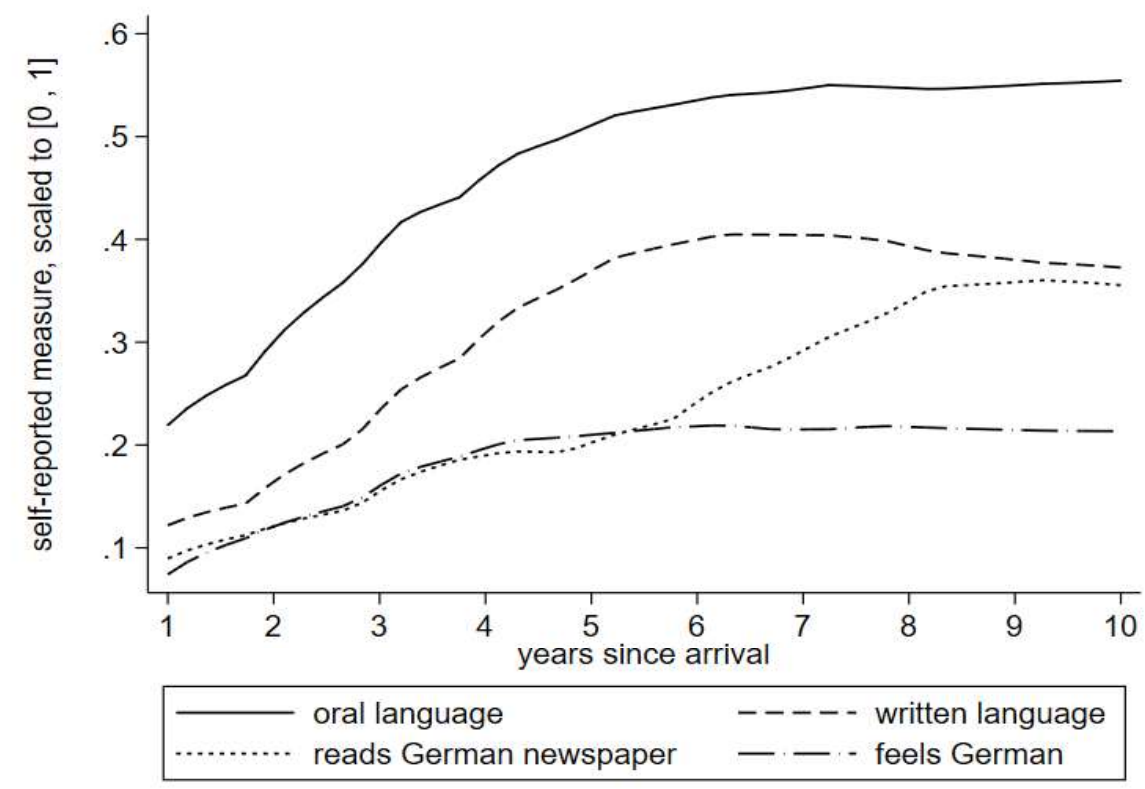

Source: Socio-Economic Panel 1984-2011. The sample is restricted to non-tertiary educated male immigrants from Turkey who arrive to Germany after 1961 at the age of at least 16 years. Integration outcomes are self-reported measured on a scale from 0 to 1 . 


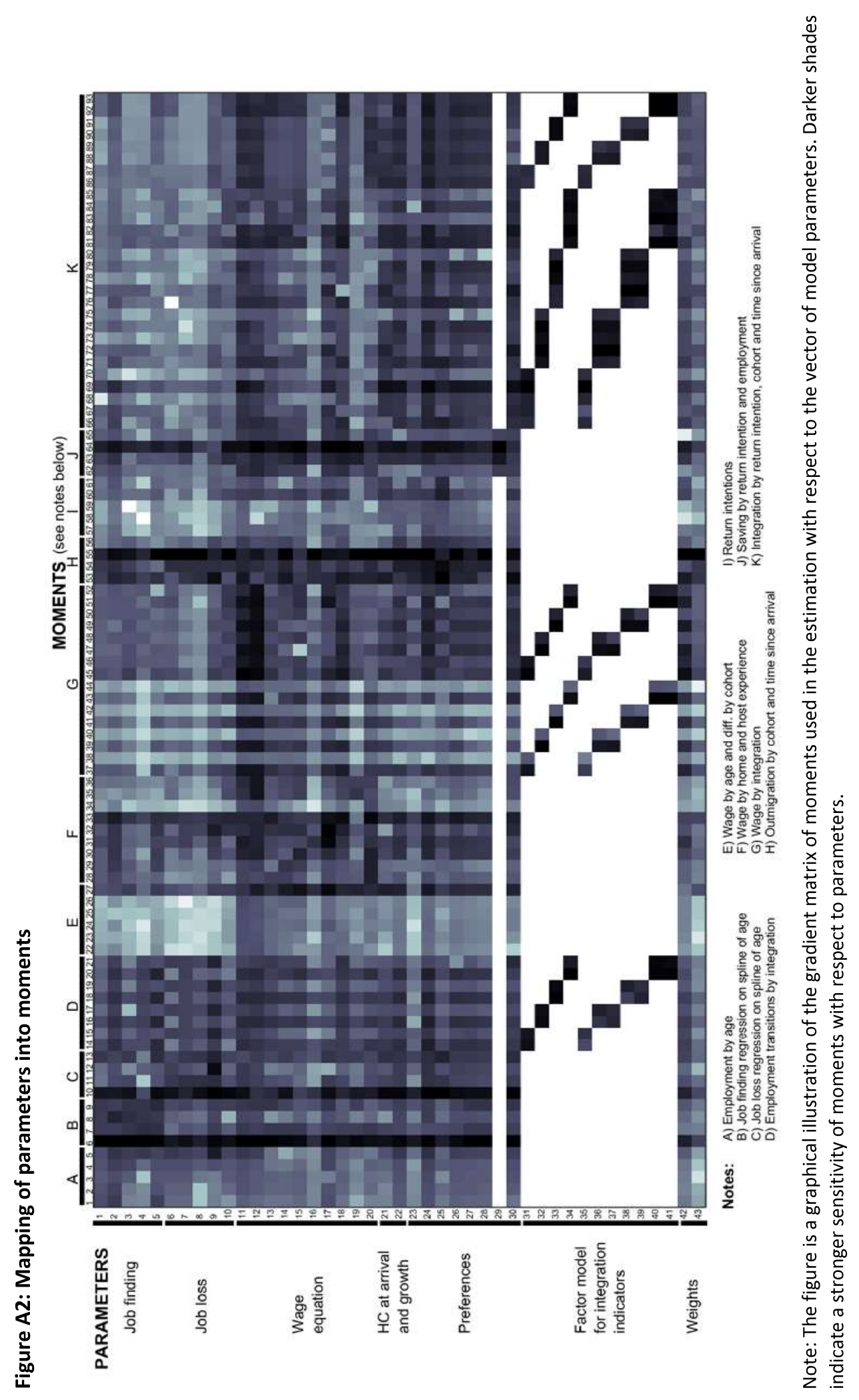


Figure A3: Overall model fit

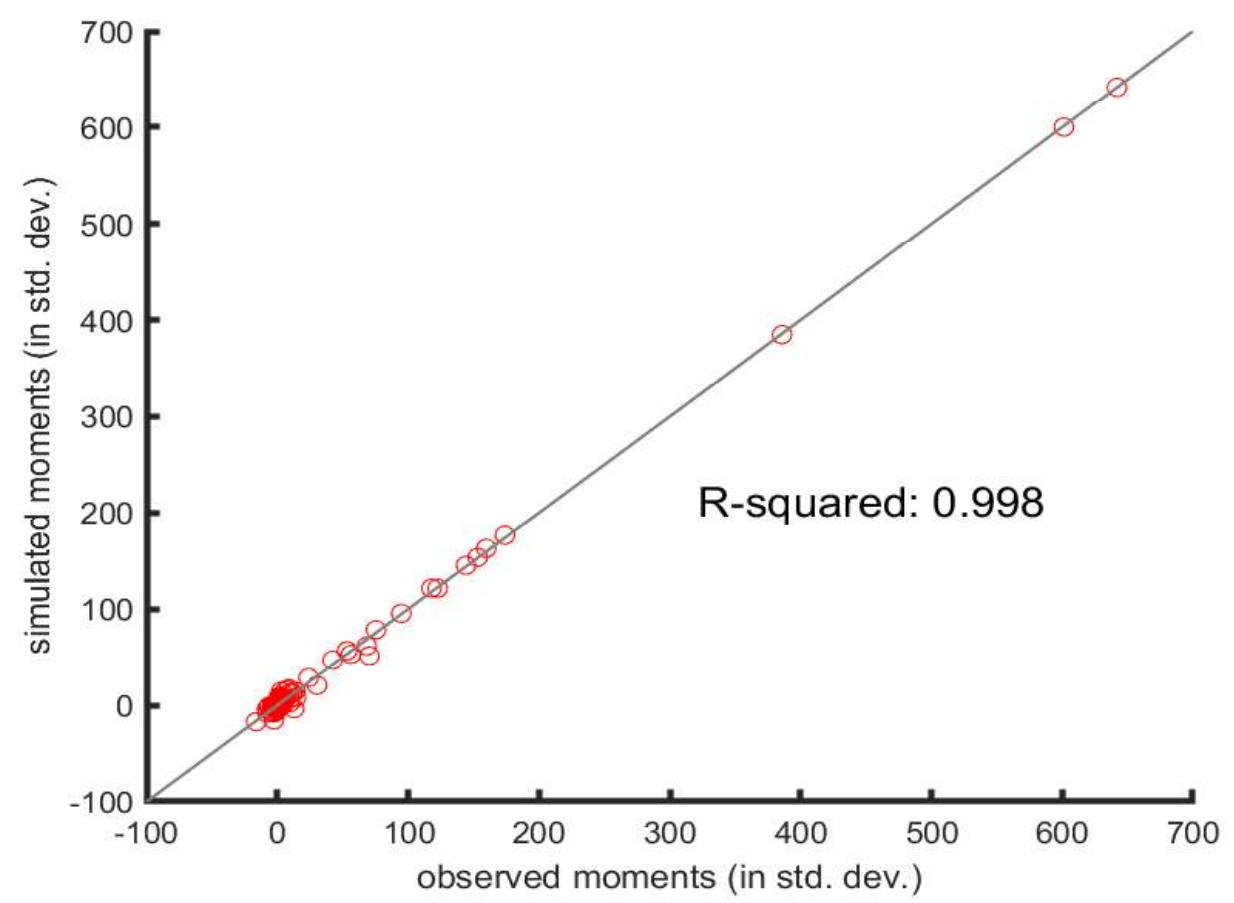

Note: The figure plots moments simulated from the model against their observed empirical counterparts together with the 45 degree line. All moments are measured in their standard deviations. 
Figure A4: Model fit - Working transition profiles
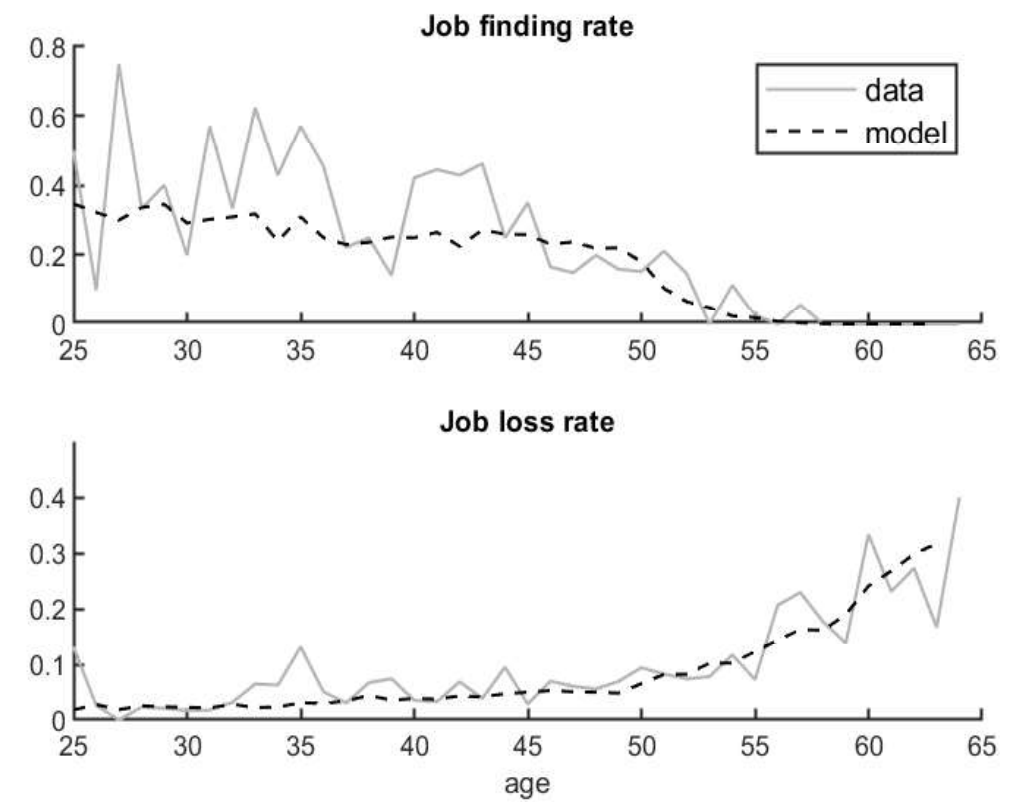

Note: Simulated profiles are based on a simulation of 40,000 immigrants. Data profiles based on SOEP 1984-2011. Job finding and job loss rate refer to transitions in and out of employment.

Figure A5: Model fit - Outmigration

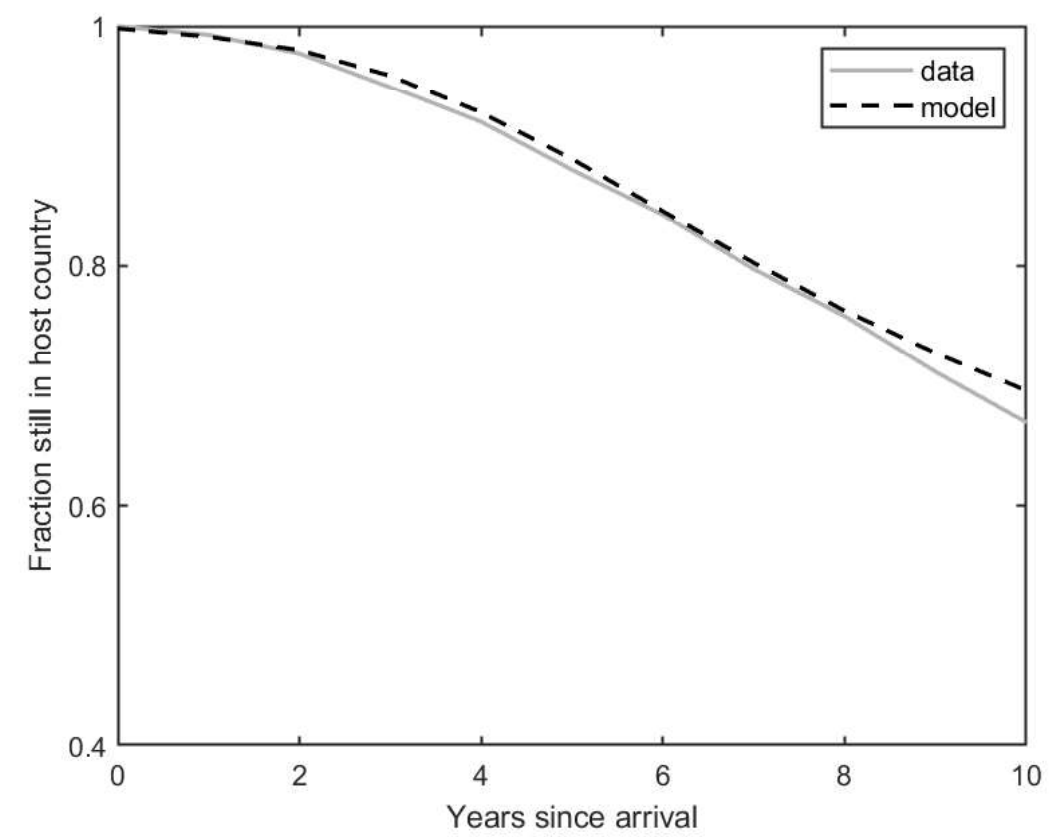

Note: Simulated profiles are based on a simulation of 40,000 immigrants . Data profiles based on synthetic cohorts constructed exploiting the representativeness of the micro-census samples and information on the year of arrival. 
Figure A6: Model fit - Emigration rates

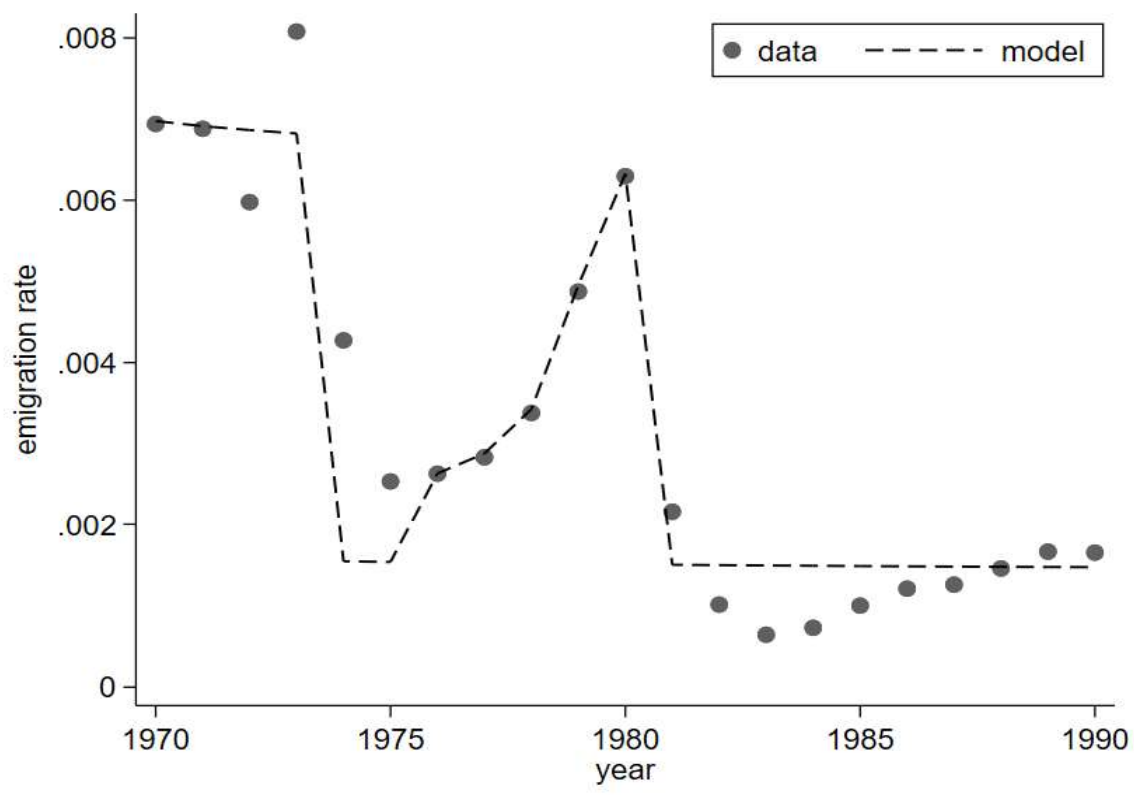

Note: Simulated profiles are based on a simulation of 40,000 individuals. Data points show annual migration rates of Turks to Germany, computed from German National Statistical Offices immigration flow data for Turkish males, and the male population in Turkey from Eurostat.

Figure A7: Model fit - Macroeconomic determinants of emigration

(a) Emigration rate by relative earnings level

(b) Emigration rate by relative price level
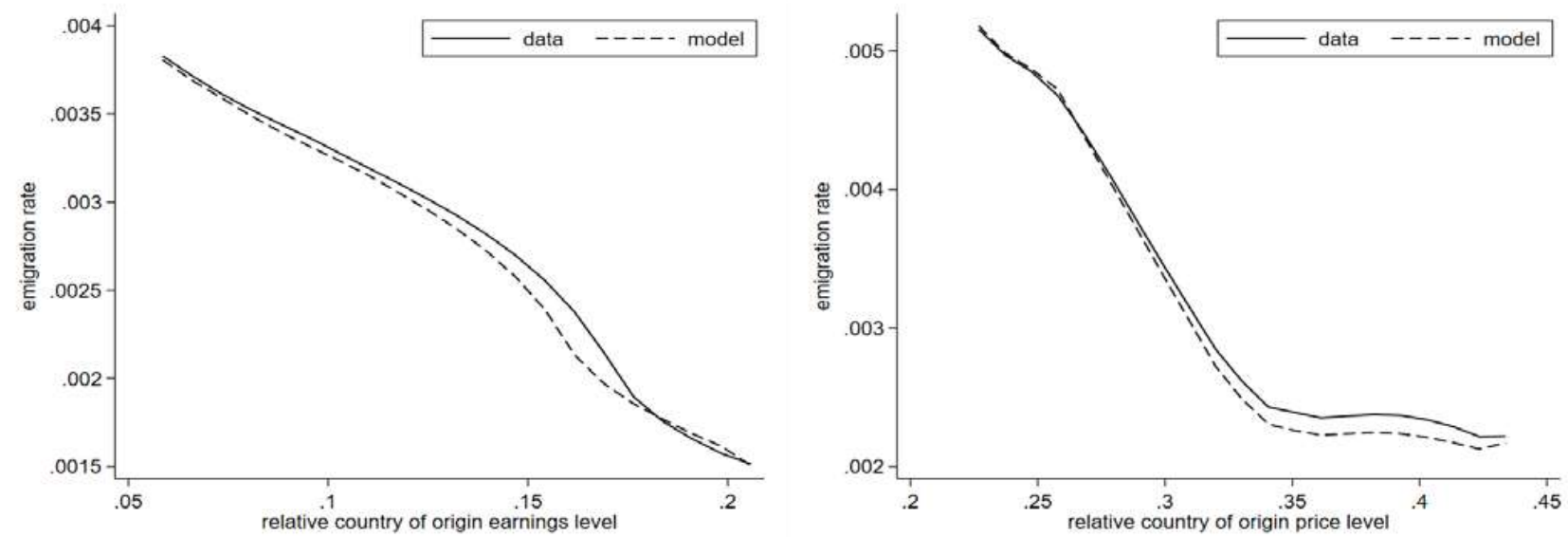

Note: Simulated profiles are based on a simulation of 40,000 individuals. Data points show annual migration rates of Turks to Germany, computed from German National Statistical Offices immigration flow data for Turkish males, and the male population in Turkey from Eurostat. Emigration rates plotted against predicted relative country of origin (a) earnings and (b) price levels as explained in Appendix B. 
Figure A8: Log wage profiles by unobserved type

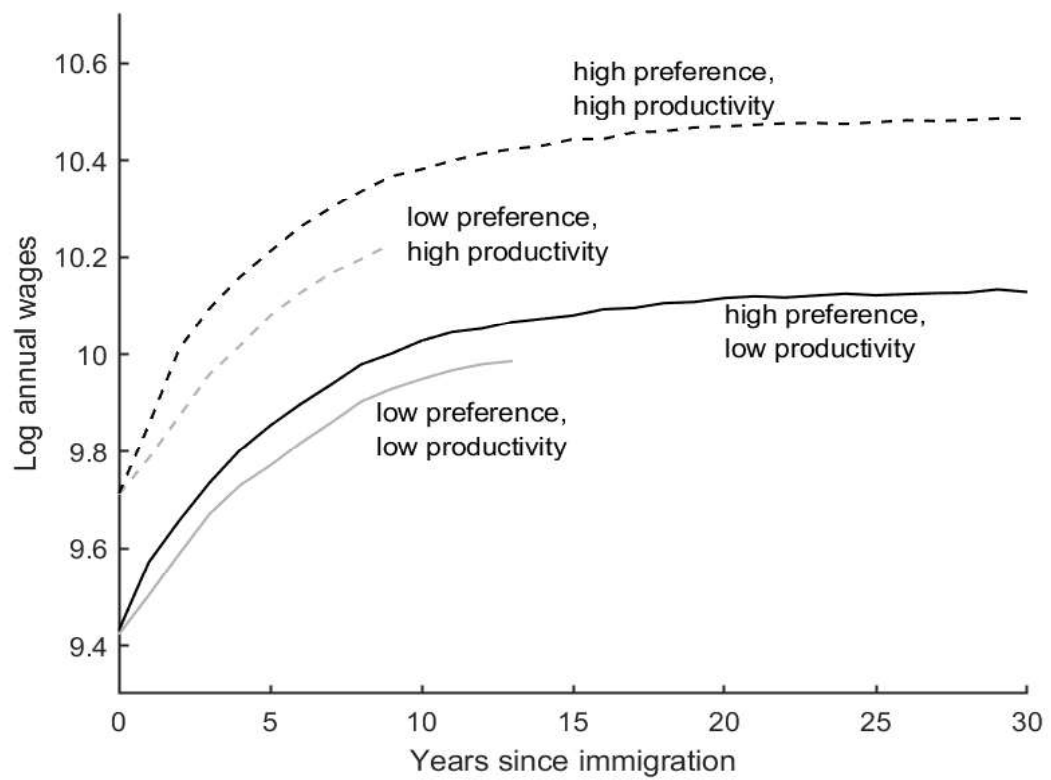

Note: Simulation of 40,000 immigrants who all arrive at age 25 in 1990. The figure shows the log annual earnings profiles by years since arrival for each of the unobserved types in the model. To capture differences in migration durations, we plot profiles until the median time of return within each type. "Low preference" and "high preference" refers to relative preference for the receiving country. "Low productivity" and "high productivity" refers to the time constant unobserved level in log earnings. 

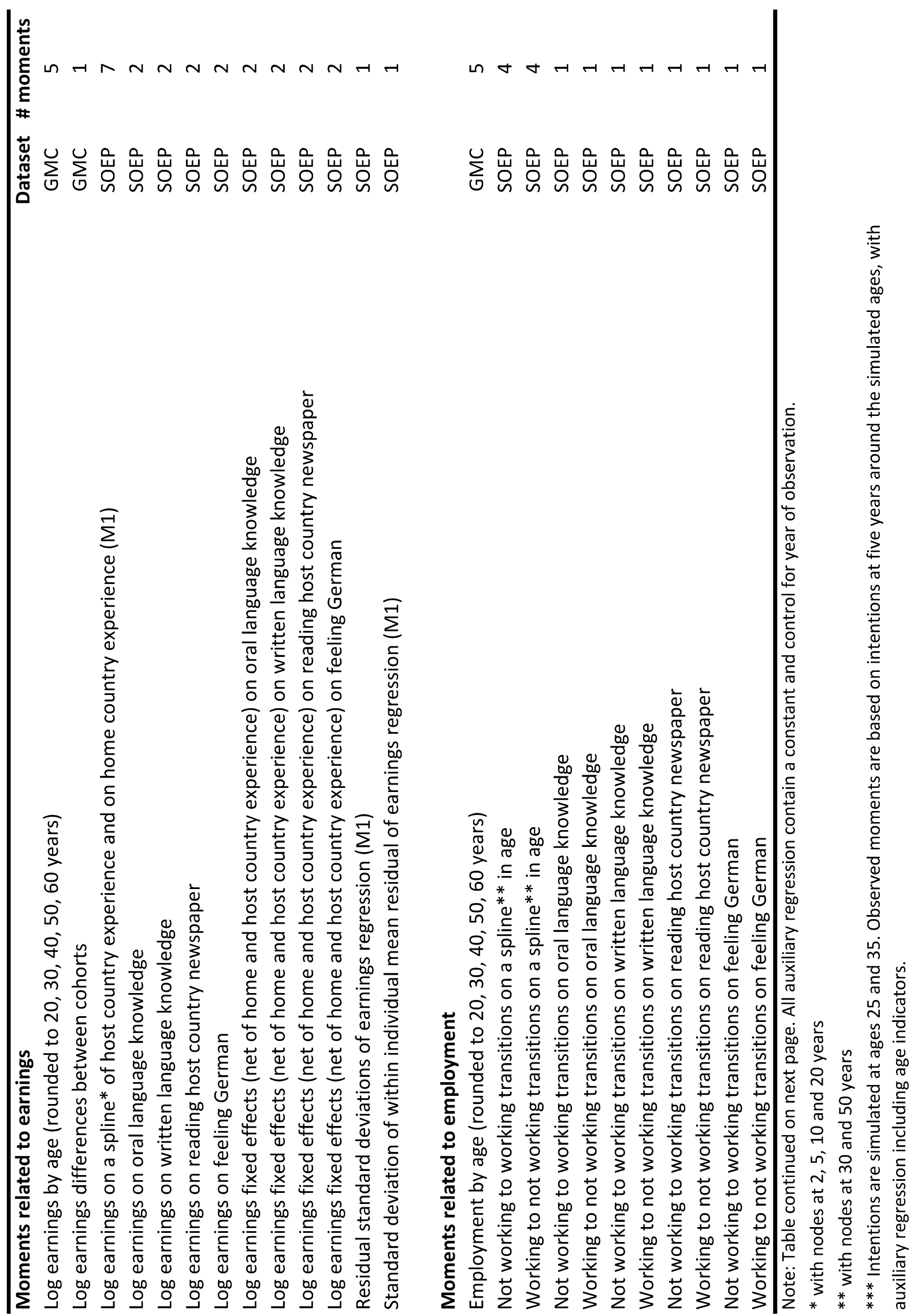


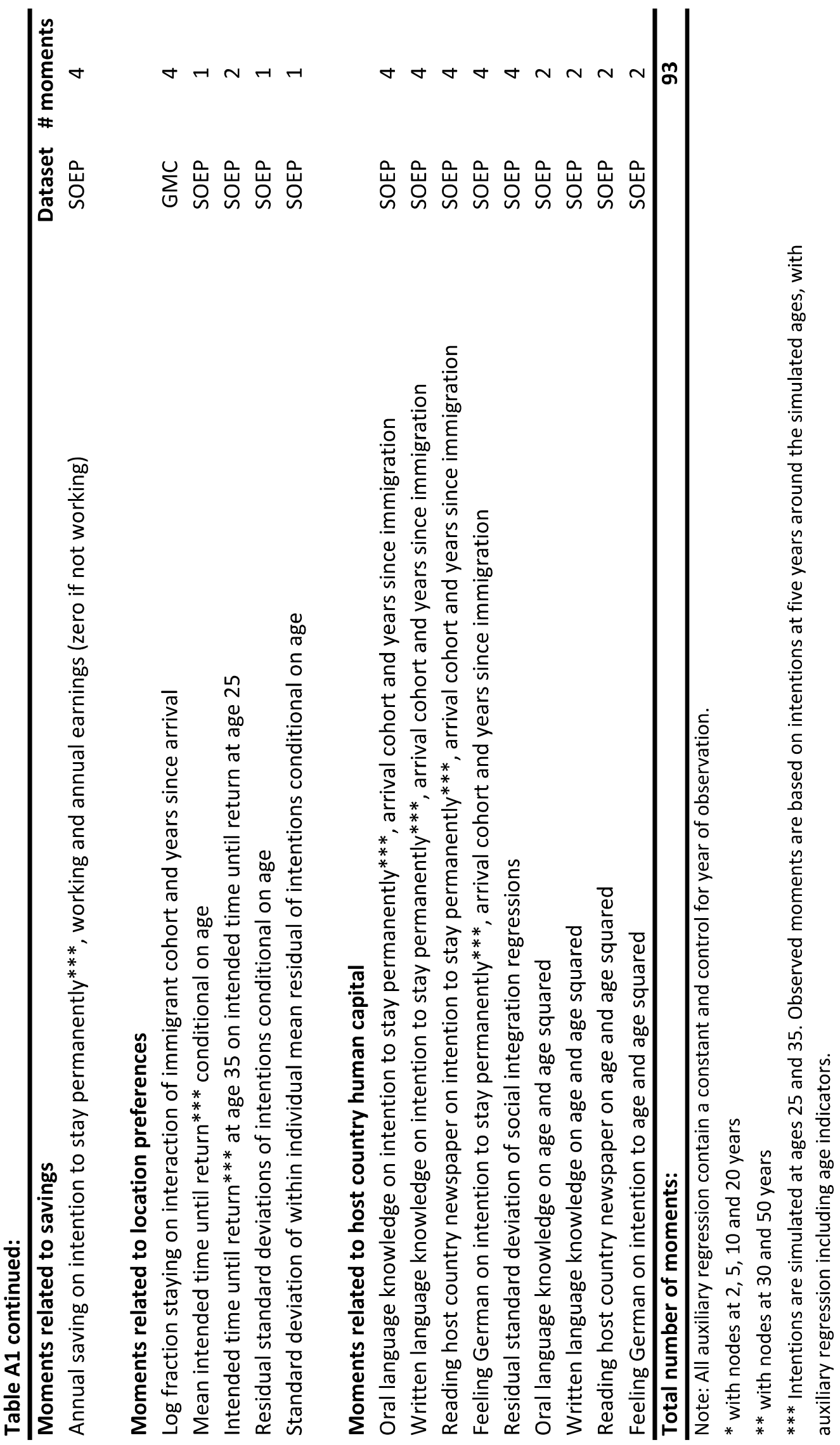


Table A2: Goodness of fit: Log annual earnings regression on experience

\begin{tabular}{lccc}
\hline & Data & Std. err. & Model \\
\hline Intercept & 9.531 & $(0.078)$ & 9.451 \\
Host country experience 0-2 years & 0.201 & $(0.049)$ & 0.205 \\
Host country experience 3-5 years & 0.062 & $(0.020)$ & 0.083 \\
Host country experience 6-10 years & 0.015 & $(0.008)$ & 0.019 \\
Host country experience 11-20 years & 0.013 & $(0.003)$ & 0.006 \\
Host country experience 21+ years & 0.000 & $(0.003)$ & 0.005 \\
Origin country experience & -0.008 & $(0.001)$ & -0.002 \\
Residual standard deviation & 0.396 & $(0.013)$ & 0.270 \\
Within-individual mean residual standard deviation & 0.327 & $(0.033)$ & 0.228 \\
\hline
\end{tabular}

Note: Model moments are based on 40,000 simulations. Empirical moments are obtained from the Socio-Economic Panel 1984-2011. The data sample is restricted to non-tertiary educated male immigrants from Turkey who arrive to Germany after 1961 at the age of at least 16 years. Host and origin country experience refer to years of actual work experience accumulated after and prior to immigration, respectively. The regression controls for the year of observation. 
Table A3: Goodness of fit: Integration age profiles

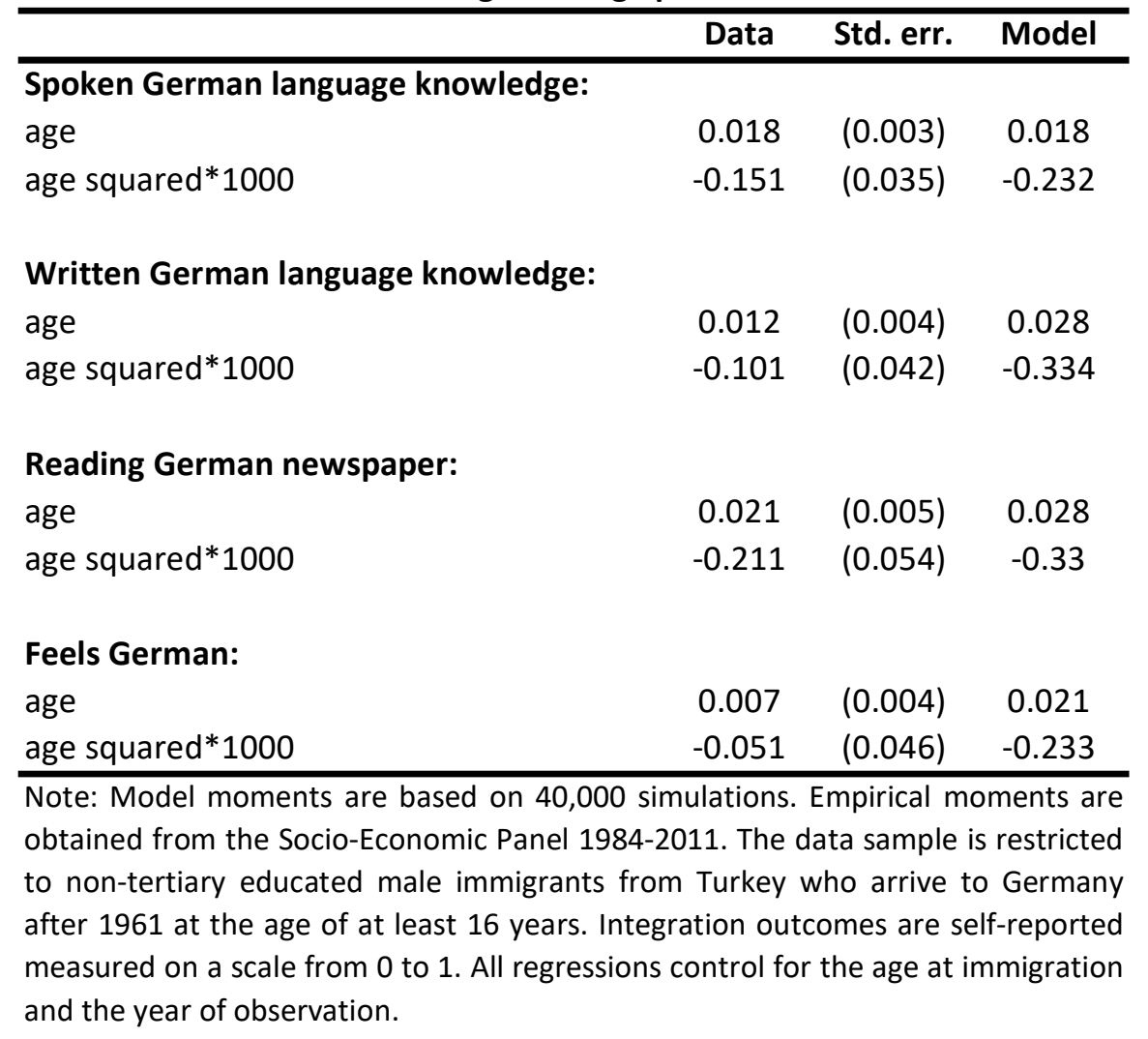


Table A4: Goodness of fit: Integration regressions

Data Std. err. Model

Feels German:

Intends to stay permanently

$\begin{array}{lll}0.144 & (0.030) & 0.131\end{array}$

Arrived after 1973

$\begin{array}{lll}0.057 & (0.048) & 0.098\end{array}$

Years since immigration

$0.013 \quad(0.004) \quad 0.061$

Constant

$-0.004(0.082) \quad-0.444$

Residual standard deviation

$\begin{array}{lll}0.214 & (0.004) & 0.228\end{array}$

Reading German newspaper:

Intends to stay permanently

$\begin{array}{lll}0.067 & (0.033) & 0.171\end{array}$

Arrived after 1973

$\begin{array}{lll}0.195 & (0.068) & 0.111\end{array}$

Years since immigration

$\begin{array}{lll}0.032 & (0.005) & 0.076\end{array}$

Constant

$\begin{array}{lll}-0.222 & (0.130) & -0.438\end{array}$

Residual standard deviation

$\begin{array}{lll}0.308 & (0.006) & 0.289\end{array}$

Spoken German language knowledge:

Intends to stay permanently

$\begin{array}{lll}0.016 & (0.024) & 0.124\end{array}$

Arrived after 1973

$\begin{array}{lll}0.139 & (0.038) & 0.135\end{array}$

Years since immigration

$\begin{array}{lll}0.034 & (0.004) & 0.046\end{array}$

Constant

$\begin{array}{lll}0.080 & (0.052) & -0.065\end{array}$

Residual standard deviation

$\begin{array}{lll}0.283 & (0.004) & 0.207\end{array}$

Written German language knowledge:

Intends to stay permanently

$\begin{array}{ccc}0.054 & (0.030) & 0.174 \\ 0.221 & (0.047) & 0.123 \\ 0.039 & (0.004) & 0.076 \\ -0.221 & (0.064) & -0.437 \\ 0.331 & (0.005) & 0.298\end{array}$

Arrived after 1973

$\begin{array}{lll}0.221 & (0.047) & 0.123\end{array}$

Years since immigration

$\begin{array}{lll}-0.221 & (0.064) & -0.437\end{array}$

Constant

Note: Model moments are based on 40,000 simulations. Empirical moments are obtained from the Socio-Economic Panel 1984-2011. The data sample is restricted to non-tertiary educated male immigrants from Turkey who arrive to Germany after 1961 at the age of at least 16 years. Integration outcomes are self-reported measured on a scale from 0 to 1. Intention to stay permanently takes value 0 if an intention to return prior to age 65 is reported, and value 1 if either an intention to stay permanently or to return after the age of 65 is stated. All regressions control for the year of observation. 
Table A5: Goodness of fit: Log earnings regressions on integration outcomes

Data Std. err. Model

Regression on spoken German language knowledge:

Spoken language

$0.123 \quad(0.043) \quad 0.230$

Constant

$10.066(0.026) \quad 10.038$

Regression on written German language knowledge:

Written language

$\begin{array}{lll}0.049 & (0.034) & 0.231\end{array}$

Constant

$10.115(0.017) \quad 10.092$

Regression on reading German language newspaper:

Newspaper

$0.215 \quad(0.053) \quad 0.237$

Constant

$10.057(0.066) \quad 10.092$

Regression on feeling German:

$\begin{array}{lccc}\text { Feeling German } & 0.049 & (0.037) & 0.322 \\ \text { Constant } & 10.113 & (0.016) & 10.113\end{array}$

Note: Model moments are based on 40,000 simulations. Empirical moments are obtained from the Socio-Economic Panel 1984-2011. The data sample is restricted to non-tertiary educated male immigrants from Turkey who arrive to Germany after 1961 at the age of at least 16 years. Integration outcomes are self-reported measured on a scale from 0 to 1 . All regressions control for year of observation. 
Table A6: Goodness of fit: Regressions of log earning fixed effects on integration outcomes

Data Std. err. Model

Regression on spoken German language knowledge:

Spoken language

$0.189 \quad(0.128) \quad 0.042$

Constant

$-0.157(0.071) \quad-0.082$

Regression on written German language knowledge:

Written language

$\begin{array}{lll}0.329 & (0.099) & 0.089\end{array}$

Constant

$\begin{array}{lll}-0.164 & (0.039) & -0.084\end{array}$

Regression on reading German language newspaper:

Newspaper

$0.400 \quad(0.124) \quad 0.090$

Constant

$\begin{array}{lll}-0.147 & (0.045) & -0.084\end{array}$

Regression on feeling German:

Feeling German

$\begin{array}{lll}0.306 & (0.128) & 0.131\end{array}$

Constant

$\begin{array}{lll}-0.120 & (0.035) & -0.078\end{array}$

Note: Model moments are based on 40,000 simulations. Empirical moments are obtained from the SocioEconomic Panel 1984-2011. The data sample is restricted to non-tertiary educated male immigrants from Turkey who arrive to Germany after 1961 at the age of at least 16 years. Log earnings fixed effects are obtained from a regression on home and host country experience (as in Table A2). Integration outcomes are self-reported measured on a scale from 0 to 1 . All regressions control for year of observation. 


\begin{tabular}{lccc}
\hline & Data & Std. err. & Model \\
\hline Intended length of stay regression on age: & & & \\
Mean intended length of stay & 23.662 & $(0.559)$ & 26.241 \\
Residual standard deviation net of age and year & 12.496 & $(0.165)$ & 12.995 \\
Within-individual mean residual standard deviation & 10.773 & $(0.450)$ & 12.900 \\
& & & \\
Intended length of stay auto-regression: & & & \\
Intended length of stay (t-10) & 0.145 & $(0.060)$ & 0.260 \\
Constant & 24.701 & $(4.926)$ & 17.045 \\
\hline
\end{tabular}

Note: Model moments are based on 40,000 simulations. Empirical moments are obtained from the Socio-Economic Panel 1984-2011. The data sample is restricted to non-tertiary educated male immigrants from Turkey who arrive to Germany after 1961 at the age of at least 16 years. Intended length of stay refers to the number of years until age 65 if either an intention to stay permanently or to return after the age of 65 is stated. Regressions control for age and the year of observation. 
Table A8: Goodness of fit: Regressions of employment transitions on age

Data Std. err. Model

Not working-to-working transitions:

Age $18-30$ years

$\begin{array}{lll}0.028 & (0.008) & -0.001\end{array}$

Age 31-50 years

$\begin{array}{lll}-0.019 & (0.002) & -0.009\end{array}$

Age $50+$ years

$\begin{array}{lll}-0.012 & (0.003) & -0.017\end{array}$

Constant

$\begin{array}{lll}-0.338 & (0.203) \quad 0.360\end{array}$

Working-to-not working transitions:

Age 18-30 years

$\begin{array}{lll}-0.002 & (0.004) & 0.000\end{array}$

Age 31-50 years

$\begin{array}{lll}0.002 & (0.001) & 0.002\end{array}$

Age $50+$ years

$\begin{array}{lll}0.013 & (0.002) & 0.016\end{array}$

Constant

$\begin{array}{lll}0.105 & (0.099) & 0.021\end{array}$

Note: Model moments are based on 40,000 simulations. Empirical moments are obtained from the Socio-Economic Panel 1984-2011. The data sample is restricted to non-tertiary educated male immigrants from Turkey who arrive to Germany after 1961 at the age of at least 16 years. Employmet transitions are year-to-year transitions into and out of working. Regressions control for the year of observation. 


\begin{tabular}{|c|c|c|c|}
\hline & Data & Std. err. & Model \\
\hline \multicolumn{4}{|l|}{ Log annual earnings } \\
\hline age 20 & 9.734 & $(0.103)$ & 9.810 \\
\hline age 30 & 9.840 & $(0.068)$ & 9.910 \\
\hline age 40 & 9.849 & $(0.057)$ & 9.999 \\
\hline age 50 & 9.768 & $(0.061)$ & 9.972 \\
\hline age 60 & 9.662 & $(0.082)$ & 9.972 \\
\hline \multicolumn{4}{|l|}{ Fraction working } \\
\hline age 20 & 0.659 & $(0.103)$ & 0.810 \\
\hline age 30 & 0.804 & $(0.071)$ & 0.845 \\
\hline age 40 & 0.823 & $(0.060)$ & 0.874 \\
\hline age 50 & 0.733 & $(0.063)$ & 0.798 \\
\hline age 60 & 0.399 & $(0.076)$ & 0.338 \\
\hline \multicolumn{4}{|l|}{ Wage gap by arrival cohort } \\
\hline Arrived after 1973 (conditional on age an years since arrival) & 0.090 & $(0.006)$ & 0.051 \\
\hline \multicolumn{4}{|l|}{ Log fraction staying: } \\
\hline years since arrival & -0.014 & $(0.001)$ & -0.015 \\
\hline post 1973 arrival & 0.071 & $(0.025)$ & 0.003 \\
\hline post 1973 arrival*years since arrival & -0.004 & $(0.001)$ & -0.001 \\
\hline intercept & 0.283 & $(0.022)$ & -0.077 \\
\hline
\end{tabular}

Note: Model moments are based on 40,000 simulations. Empirical moments are obtained from the German Microcensus 1976-2007. The data sample is restricted to non-tertiary educated male immigrants from Turkey who arrive to Germany after 1961 at the age of at least 16 years. Earnings and savings are denoted in Euros, deflated to 2005. The fraction staying is calculated based on synthetic cohorts. 
Table A10: External validity: Savings and relative price levels

\begin{tabular}{lccc}
\hline & Data & Std. err. & Model \\
\hline Savings ratio: & & & \\
Relative price level in Turkey & $-4,658.0$ & $(618.3)$ & $-5,043.6$ \\
t-ratio for relative price level: & -7.53 & & \\
\hline
\end{tabular}

Note: Model moments are based on 40,000 simulations. Empirical moments are obtained from the Socio-Economic Panel 1984-2011, merged to exchange rates and price indices from the OECD. The data sample is restricted to non-tertiary educated male immigrants from Turkey who arrive to Germany after 1961 at the age of at least 16 years. Annual savings and earnings are denoted in Euros, deflated to 2005. The regression controls for a full set of age indicators. 
Table A11: Estimates - Integration measures

\begin{tabular}{lccc}
\hline Parameter & & Estimate & Std. err. \\
\hline Spoken German, intercept & $\left(\gamma_{0}^{S}\right)$ & -2.078 & $(0.194)$ \\
Spoken German, effect of social capital & $\left(\gamma_{1}^{S}\right)$ & 1 & (normalization) \\
Spoken German, error stdev. & $\left(\sigma_{S}\right)$ & 0.088 & $(0.025)$ \\
& & & \\
Written German, intercept & $\left(\gamma_{0}^{W}\right)$ & -4.852 & $(0.737)$ \\
Written German, effect of social capital & $\left(\gamma_{1}^{W}\right)$ & 1.656 & $(0.324)$ \\
Written German, error stdev. & $\left(\sigma_{W}\right)$ & 0.172 & $(0.082)$ \\
& & & \\
Reads German Newspaper, intercept & $\left(\gamma_{0}^{N}\right)$ & -4.525 & $(0.313)$ \\
Reads German Newspaper, effect of social capital & $\left(\gamma_{1}^{N}\right)$ & 1.500 & $(0.315)$ \\
Reads German Newspaper, error stdev. & $\left(\sigma_{N}\right)$ & 0.175 & $(0.136)$ \\
& & & \\
Feel German, intercept & $\left(\gamma_{0}^{F}\right)$ & -4.236 & $(0.304)$ \\
Feel German, effect of social capital & $\left(\gamma_{1}^{F}\right)$ & 1.036 & $(0.121)$ \\
Feel German, error stdev. & $\left(\sigma_{F}\right)$ & 0.040 & $(0.018)$ \\
\hline
\end{tabular}

Note: Estimates are obtained by indirect inference, based on 40,000 simulations and empirical moments from the Socio-Economic Panel 1984-2011 and the German Microcensus 1976-2007. The data sample is restricted to non-tertiary educated male immigrants from Turkey who arrive to Germany after 1961 at the age of at least 16 years. We weight moment differences by their standard deviation. 
Table A12: Calibrated parameters for initial immigration choice

\begin{tabular}{lcc}
\hline Parameter & Value \\
\hline Utility cost of migration $\left(C_{t}\right)$ during guest-worker program (until 1973) & 291.05 \\
Utility cost of migration $\left(C_{t}\right)$ post guest-worker program & 370.32 \\
Utility cost of migration $\left(C_{t}\right)$ during years of unrest in Turkey & 1976 & 342.88 \\
& 1977 & 338.17 \\
& 1978 & 329.17 \\
& 1979 & 310.32 \\
Value of migrating to rest of the world ( $\left.V^{R O W}\right)$ & 1980 & 297.69 \\
Spread parameter of extreme value distribution $(\tau)$ & 61.16 \\
\hline
\end{tabular}

Note: Calibration based on 40,000 simulations; identification through annual emigration rates based on immigration flow data from the German National Statistical Office for Turkish males, and the male population in Turkey from Eurostat. The value of migrating to rest of the world is identified through the observed number of Turkish emigrants in all OECD countries (except Germany), taken from Docquier, Lowell and Marfouk (2009). 
OLS FD OLS FD

\begin{tabular}{lcccc}
\hline $\begin{array}{l}\text { Bias in average returns to experience } \\
\text { during first } 10 \text { years }\end{array}$ & $-10.2 \%$ & $+14.2 \%$ & $-16.1 \%$ & $+10.1 \%$ \\
$\begin{array}{l}\text { Bias in average returns to experience } \\
\text { during first 20 years }\end{array}$ & $-30.2 \%$ & $+14.2 \%$ & $-29.9 \%$ & $+10.0 \%$ \\
$\begin{array}{l}\text { host country human capital } \\
\text { individual fixed effects }\end{array}$ & $\mathrm{X}$ & $\mathrm{X}$ & $\mathrm{X}$ & $\mathrm{X}$ \\
restriction to same age (25) at arrival & & & $X$ & $\mathrm{X}$ \\
\hline
\end{tabular}

Note: Estimates based on a sample of 200,000 individuals simulated from the model. We compare regression coefficients to the predicted returns to experience in a model that accounts both for log wage fixed effects and host country specific human capital. The first and third columns show the downward bias from selection on productivity. The second and forth columns show the upward bias from behavioral selection. The simulated sample is restricted to continuously employed individuals. OLS regressions condition on year of immigration. Standard errors can be made arbitrarily small for large simulation sizes and are thus not reported. 